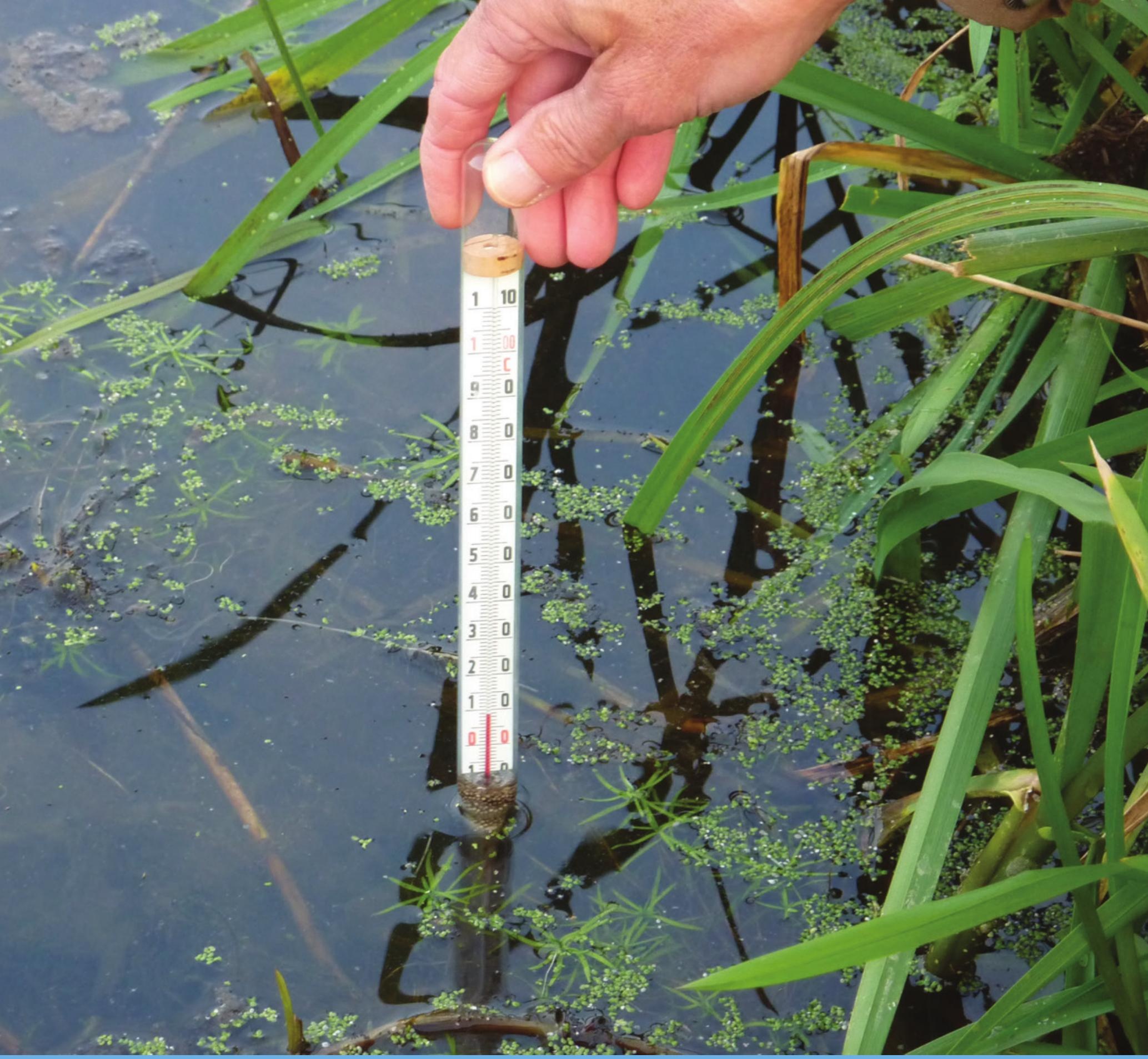

\title{
Temperature in water and sediment in the pesticide model TOXSWA
}

Implementation report

W.H.J. Beltman, P.I. Adriaanse, C.M.J. Jacobs and H.M. Mulder

WAGENINGEN

UNIVERSITY \& RESEARCH 



\section{Temperature in water and sediment in the pesticide model TOXSWA}

Implementation report

W.H.J. Beltman, P.I. Adriaanse, C.M.J. Jacobs and H.M. Mulder

This research was funded by the Dutch Ministry of Economic Affairs (project number BO-20-002-002).

Wageningen Environmental Research

Wageningen, March 2017

Report 2794

ISSN 1566-7197 
Beltman, W.H.J., P.I. Adriaanse, C.M.J. Jacobs and H.M. Mulder, 2017. Temperature in water and sediment in the pesticide model TOXSWA; Implementation report. Wageningen, Wageningen Environmental Research, Report 2794. 68 pp.; 17 fig.; 6 tab.; 21 ref.

Keywords: TOXSWA, water temperature, pesticide, waterbody

The pdf file is free of charge and can be downloaded at http://dx.doi.org/10.18174/409564 or via the website www.wur.nl/environmental-research (scroll down to Publications - Wageningen Environmental Research reports). Wageningen Environmental Research does not deliver printed versions of the Wageningen Environmental Research reports.

(9) 2017 Wageningen Environmental Research (an institute under the auspices of the Stichting Wageningen Research), P.O. Box 47, 6700 AA Wageningen, The Netherlands,

T +31 (0)317 4807 00, E info.alterra@wur.nl, www.wur.nl/environmental-research. Wageningen Environmental Research is part of Wageningen University \& Research.

- Acquisition, duplication and transmission of this publication is permitted with clear acknowledgement of the source.

- Acquisition, duplication and transmission is not permitted for commercial purposes and/or monetary gain.

- Acquisition, duplication and transmission is not permitted of any parts of this publication for which the copyrights clearly rest with other parties and/or are reserved.

Wageningen Environmental Research assumes no liability for any losses resulting from the use of the research results or recommendations in this report.

Wageningen Environmental Research Report 2794 | ISSN 1566-7197

Photo cover: Paulien Adriaanse 


\section{Contents}

$\begin{array}{ll}\text { Preface } & 5\end{array}$

$\begin{array}{ll}\text { Summary } & 7\end{array}$

$\begin{array}{ll}\text { Samenvatting } & 9\end{array}$

$\begin{array}{ll}\text { The water temperature module } & 12\end{array}$

2.1 The TOXSWA model 12

2.2 Energy balance of small water bodies 13

2.2.1 Overview of processes determining the water temperature 13

2.2.2 Absorption of shortwave (solar) radiation 15

2.2.3 Exchange of longwave (terrestrial) radiation 16

2.2.4 Turbulent transport of energy at the surface 16

2.2.5 Heat exchange due to precipitation 16

2.2.6 Exchange of heat with the sediment and the surrounding soil $\begin{array}{ll}\text { environment } & 16\end{array}$

2.2.7 Supply and extraction of energy through external mechanisms $\quad 17$

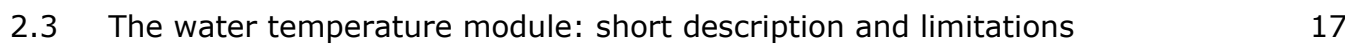

2.4 The water temperature module: detailed description of the modelled energy budget terms 19

2.4.1 Balance equation $\quad 19$

2.4.2 Incoming shortwave radiation $\left(K_{d}\right)$, shortwave radiation absorbed by sediment $\left(K_{\mathrm{b}}\right)$ and reflected shortwave radiation at the water surface $\left(K_{\mathrm{u}}\right) 20$

2.4.3 Incoming longwave radiation $\left(L_{d}\right)$ and outgoing longwave radiation $\left(L_{u}\right) \quad 23$

2.4.4 Turbulent fluxes: sensible heat flux $(H)$ and latent heat flux $(\lambda E) \quad 24$

2.4.5 Heat flux through precipitation $\left(Q_{\mathrm{pr}}\right) \quad 26$

2.4.6 Sensible heat flux between water and sediment $\left(G_{\mathrm{s}}\right) \quad 26$

2.4.7 Other heat sources and sinks $(\Sigma S) \quad 26$

2.4.8 Water temperatures below $4^{\circ} \mathrm{C} \quad 29$

$\begin{array}{ll}2.4 .9 \text { Numerical implementation } & 29\end{array}$

$3 \quad$ Input, output and example calculation $\quad 31$

$\begin{array}{lll}3.1 & \text { Introduction } & 31\end{array}$

3.2 Description of input 31

3.2.1 TOXSWA input file $\quad 31$

3.2.2 Meteo input file $\quad 33$

3.3 Description of output $\quad 34$

3.3.1 The intermediate temperature file $\quad 34$

3.4 Example calculation 36

4.2 Test 1: Comparison of water temperature calculated by TOXSWA and through SIM3 simulation of Jacobs et al. $\quad 37$

4.2.1 Setup of the test

4.2.2 Results and discussion $\quad 37$

4.3 Test 2: Robustness of the TOXSWA model for high water temperatures $\quad 38$

$\begin{array}{ll}\text { 4.3.1 Setup of the test } & 38\end{array}$

$\begin{array}{ll}\text { 4.3.2 Results and discussion } & 38\end{array}$ 
4.4 Test 3: Contribution of external energy from drainage 39

4.4.1 Setup of the test $\quad 39$

4.4.2 Results and discussion $\quad 40$

$\begin{array}{lll}4.5 & \text { Conclusions } & 40\end{array}$

5 Impact of improvement on calculated exposure concentrations

$\begin{array}{lll}5.1 & \text { Introduction } & 41\end{array}$

$\begin{array}{lll}5.2 & \text { Transformation in water } & 41\end{array}$

5.2.1 Setup of the test $\quad 41$

5.2.2 Results and discussion $\quad 42$

$\begin{array}{lll}5.3 & \text { Volatilization from the water layer } & 43\end{array}$

5.3.1 Setup of the test $\quad 43$

5.3.2 Results and discussion $\quad 43$

5.4 Diffusion between water and sediment $\quad 44$

5.4.1 Setup of the test $\quad 44$

5.4.2 Results and discussion $\quad 44$

$\begin{array}{lll}5.5 & \text { Conclusions } & 46\end{array}$

$6 \quad$ Conclusions and recommendations $\quad 47$

$\begin{array}{ll}\text { References } & 48\end{array}$

Annex 1 Description of parameters in the temperature module $\quad 50$

Annex 2 Relation between diffusion coefficient in water and temperature 52

$\begin{array}{lll}\text { Annex } 3 & \text { Radiation at the air-water interface } & 56\end{array}$

Annex 4 Calculation of shortwave radiation from solar elevation, atmospheric turbidity and cloud cover $\quad 57$

Annex $5 \quad$ Upward shortwave radiation at the water-air interface 58

$\begin{array}{lll}\text { Annex } 6 & \text { Parameters with fixed values in TOXSWA } & 60\end{array}$

Annex 7 Description of the PEARL *.e2t output file extended with $\begin{array}{ll}\text { temperatures of drain fluxes } & 61\end{array}$

$\begin{array}{lll}\text { Annex } 8 & \text { TOXSWA input file for example simulation } & 63\end{array}$

Annex 9 Meteorological file used for robustness test of TOXSWA for high water temperatures

Annex 10 Sections of *.txw file used for calculations assessing impact of calculated hourly water temperatures on exposure concentrations 


\section{Preface}

Since 1999 TOXSWA v1.2 has been applied in the Dutch registration procedure for plant protection products to calculated exposure concentrations for an edge-of-field ditch with constant flow rates. Since 2003 FOCUS_TOXSWA (versions 1.1.1, 2.2.1 and 3.3.1) has been applied in the EU registration procedure to calculate exposure concentrations in ponds, ditches and streams with transient flow conditions. FOCUS_TOXSWA v.4.4.3 calculates also exposure concentrations for metabolites formed in water and in sediment. This version was released in 2015. The TOXSWA kernel (=v. 3.3) used in FOCUS_TOXSWA v.4.4.3 is now extended with the option to simulate temperature of the waterbody on the basis of hourly meteorological data, in addition to using monthly averaged air temperatures. This report describes the implemented concept for temperature of the waterbody calculated from hourly meteorological data in the new TOXSWA kernel version 3.4. 


\section{Summary}

TOXSWA simulates the fate of substances in water bodies to calculate exposure concentrations for aquatic or sediment-dwelling organisms as part of the risk assessment of plant protection products (PPP). The TOXSWA model contains a description of processes that affect exposure concentrations, such as transformation in water and in sediment, volatilization from the water layer and transport in the water layer and in sediment by advection, dispersion and diffusion. Several processes describing the fate of the active ingredient depend on the temperature. Until now the change of temperature was described in a simple way by using monthly averaged temperatures. The temperature of the sediment equated the temperature of the water layer. This description of the temperature does not consider the daily change of the temperature in the water layer, and neither the change in daily average during the month. The concepts for describing the temperature in the water layer and in the sediment were improved, enabling enhanced incorporation of the effect of temperature on exposure concentrations.

The improved description of the temperature in the water layer is based on quantification of contributions of all relevant terms of the energy budget of the water system. These terms are incoming and outgoing shortwave and longwave radiation, sensible and latent heat exchange between air and water, precipitation, potential heat exchange between water and sediment and external sources, such as incoming drainage water. In this improved temperature concept it is assumed that the water layer is perfectly mixed, hence the temperature is constant for each time horizontally and vertically in the entire water layer. The temperature of sediment is assumed equal to the water temperature. The improved temperature model then comprises a $1 \mathrm{D}$ bulk model.

The improved concept for temperature in TOXSWA was tested using an existing model implementation of the 1D bulk model. De temperatures calculated by TOXSWA agreed well with temperatures determined with the 1D bulk model.

The effect of use of the improved temperature module was evaluated by executing calculations of the TOXSWA model using the two options, i.e. the option of the 1-D bulk model as well as the option of the monthly averaged temperatures. Notable differences were calculated for the impact on transformation and volatilization. Depending on the change of temperature in the month using the improved concept of temperature can result in higher or lower exposure concentrations.

The improved description of the effect of temperature on diffusion not only considered the improved description of the temperature as a function of time, but also the introduction of dependency of the diffusion coefficient on temperature. Test calculations showed that introduction of temperature dependency of the diffusion coefficient had a larger impact on exposure concentrations in the water layer than the improvement of description of change of temperature in time.

As with transformation and volatilization also for diffusion the change of temperature during the month calculated with the improved temperature concept can lead to higher or lower exposure concentrations in the water layer.

When the option for monthly averaged temperatures is used, it is important to use the best procedure to calculate these averages. The monthly averaged temperatures should preferable be calculated using the hourly values of air temperatures instead of the average of the minimum and maximum air temperature of each day. Using the first method accounts for the variation of the temperature during the day. 


\section{Samenvatting}

TOXSWA simuleert het gedrag van stoffen in oppervlaktewater om blootstellingsconcentraties te berekenen voor organismen die in water of sediment leven, als onderdeel van de aquatische risicobeoordeling van gewasbeschermingsmiddelen (GBM). Het TOXSWA model bevat een beschrijving van processen die invloed hebben op het verloop in de tijd en plaats van de blootstellingsconcentratie, zoals omzetting van de actieve stof in de waterlaag en het sediment, vervluchtiging vanuit de waterlaag en transport in de waterlaag en in het sediment door advectie, dispersie en diffusie. Meerdere processen in de beschrijving van het gedrag van de actieve stof zijn afhankelijk van de temperatuur. Tot nog toe werd het verloop van de temperatuur in de tijd op een simpele manier beschreven, nl. door gebruik te maken van maandelijkse gemiddelde temperaturen. Verder werd de temperatuur in het sediment gelijkgesteld aan de temperatuur in de waterlaag. Deze beschrijving van de temperatuur in de waterlaag houdt geen rekening met het dagelijks verloop van de temperatuur in de waterlaag noch met het verloop van de daggemiddelde temperatuur gedurende de maand. De concepten voor de beschrijving van de temperatuur in de waterlaag en in het sediment werden verbeterd zodat met het effect van de temperatuur op de blootstellingsconcentraties beter rekening kan worden gehouden.

De vernieuwde beschrijving van de temperatuur in de waterlaag is gebaseerd op de kwantificering van de bijdragen van alle relevante termen in de warmtebalans van het watersysteem. Deze termen betreffen de inkomende en uitgaande straling, de voelbare en latente warmteflux tussen atmosfeer en water, de warmteflux tussen water en sediment, alsmede de warmteflux als gevolg van regenval en instromend drainagewater. In dit vernieuwde temperatuur concept wordt aangenomen dat de waterlaag perfect gemengd is, zodat de waterlaag op elk tijdstip een constante temperatuur heeft, d.w.z. de temperatuur hangt niet af van de plaats en diepte in de waterlaag. De temperatuur van het sediment wordt verondersteld gelijk te zijn aan de temperatuur van de waterlaag. Dit nieuwe temperatuur model betreft dus een 1D bulk model.

Het vernieuwde concept voor de beschrijving van de temperatuur in het TOXSWA model werd getest aan de hand van een bestaande implementatie van het 1D bulk model. De berekende temperaturen van TOXSWA kwamen goed overeen met die van het bestaande 1D bulk model.

De invloed van de verbeterde temperatuur module werd onderzocht door berekeningen met het TOXSWA model uit te voeren voor zowel de optie van het 1D bulkmodel als voor de optie voor het gebruik van maandgemiddelde temperaturen. Substantiële verschillen werden berekend voor de mate van omzetting en vervluchtiging. Afhankelijk van het verloop van de temperatuur binnen de maand kan de verbeterde beschrijving van de temperatuur leiden tot hogere of lagere blootstellingsconcentraties in de waterlaag.

De verbeterde beschrijving van het effect van de temperatuur op de diffusie betrof niet alleen de verbeterde beschrijving van de temperatuur als functie van de tijd, maar ook de introductie van een temperatuurafhankelijkheid van de diffusiecoëfficiënt. Uit test berekeningen bleek dat het effect van de introductie van deze temperatuurafhankelijkheid een grotere invloed heeft op de blootstellingsconcentraties in de waterlaag dan een verbetering van de beschrijving van het verloop van de temperatuur in de tijd.

Net als bij omzetting en vervluchtiging geldt ook voor diffusie, dat afhankelijk van het verloop van de temperatuur binnen de maand, de verbeterde beschrijving van de temperatuur kan leiden tot hogere of lagere blootstellingsconcentraties in de waterlaag.

Bij gebruik van de optie van maandgemiddelde water temperaturen is het van belang om de beste procedure te volgen om deze gemiddelden uit te rekenen. De maandgemiddelde temperaturen kunnen het best berekend worden op basis van uurlijkse luchttemperaturen in plaats van het gemiddelde van de minimum en -maximum luchttemperaturen voor elke dag. Met de eerste methode wordt rekening gehouden met de variatie van de temperatuur gedurende de dag. 


\section{Introduction}

The TOXSWA model simulates the fate of substances in water bodies to calculate exposure concentrations for aquatic organisms or sediment-dwelling organisms as part of the risk assessment of plant protection products (PPP). TOXSWA simulates the fate processes: convective and dispersive transport in water and sediment, diffusive transport in sediment, transformation, volatilization and sorption to suspended solids, macrophytes and sediment.

Dissipation processes, such as transformation or volatilization affect exposure concentrations in surface water and in sediment. Especially for water bodies with stagnant water or low water flow velocities, repeated applications in combination with low dissipation may lead to accumulation of PPP. As a result, PPP concentrations will be higher, leading to increased acute and chronic risks for aquatic organisms (Westein et al., 1998).

In the TOXSWA model the dissipation processes of transformation in water and in sediment and volatilization from water to air are a function of the ambient temperature. In the current version of TOXSWA (kernel 3.3) the water temperature is estimated in a simplified way: it is approximated by monthly averages of the air temperature. However, the temperature in small water bodies is strongly influenced by weather conditions that vary at time scales down to less than one hour. Therefore, to provide a proper description of the response of water temperature to the weather conditions, TOXSWA was improved with a new module, describing the water temperature with the aid of a physically-based balance for energy exchange between the atmosphere and a water body (Jacobs et al., 2010). With this new water temperature module the simulation of dissipation of PPP via transformation, volatilization and diffusion is improved, resulting in more realistic exposure concentrations.

This report describes the implementation of the new algorithm for calculation of the temperature of the water body in TOXSWA.

TOXSWA version 3.3 is the kernel of FOCUS_TOXSWA 4.4.3. (which also includes a user interface and a database). This report concerns the new kernel version 3.4 and further updates. Hence, where in this report TOXSWA is mentioned, this refers to kernel 3.4, unless indicated otherwise.

Chapter 2 describes the theory of air-water interaction that drives temperature changes in a water body and implementation of this theory in TOXSWA. In Chapter 3 the input and output relevant for the implemented temperature module are described. Also, an example simulation is given. Tests to check whether the concept has been implemented correctly in the source code are described in Chapter 4. Calculation examples to determine the effect of the improvement on calculated exposure concentrations are described in Chapter 5. In Chapter 6 some conclusions and recommendations are given. 


\section{The water temperature module}

\subsection{The TOXSWA model}

The TOXSWA model describes the behaviour of substances in a water body at the edge-of-field scale, i.e. a ditch, pond or stream adjacent to a single, treated field (Adriaanse, 1996; Adriaanse et al., 2015; Beltman et al., 2014). TOXSWA calculates concentrations of parent substances and their metabolites in water and in sediment. The modelled system consists of two types of subsystem: (1) the water layer containing suspended solids and macrophytes and (2) the sediment. The properties of the sediment. i.e. porosity, organic matter content and bulk density, may vary with depth. In the water layer concentrations may vary in the horizontal direction, whereas in the sediment concentrations may vary in the horizontal and the vertical direction.

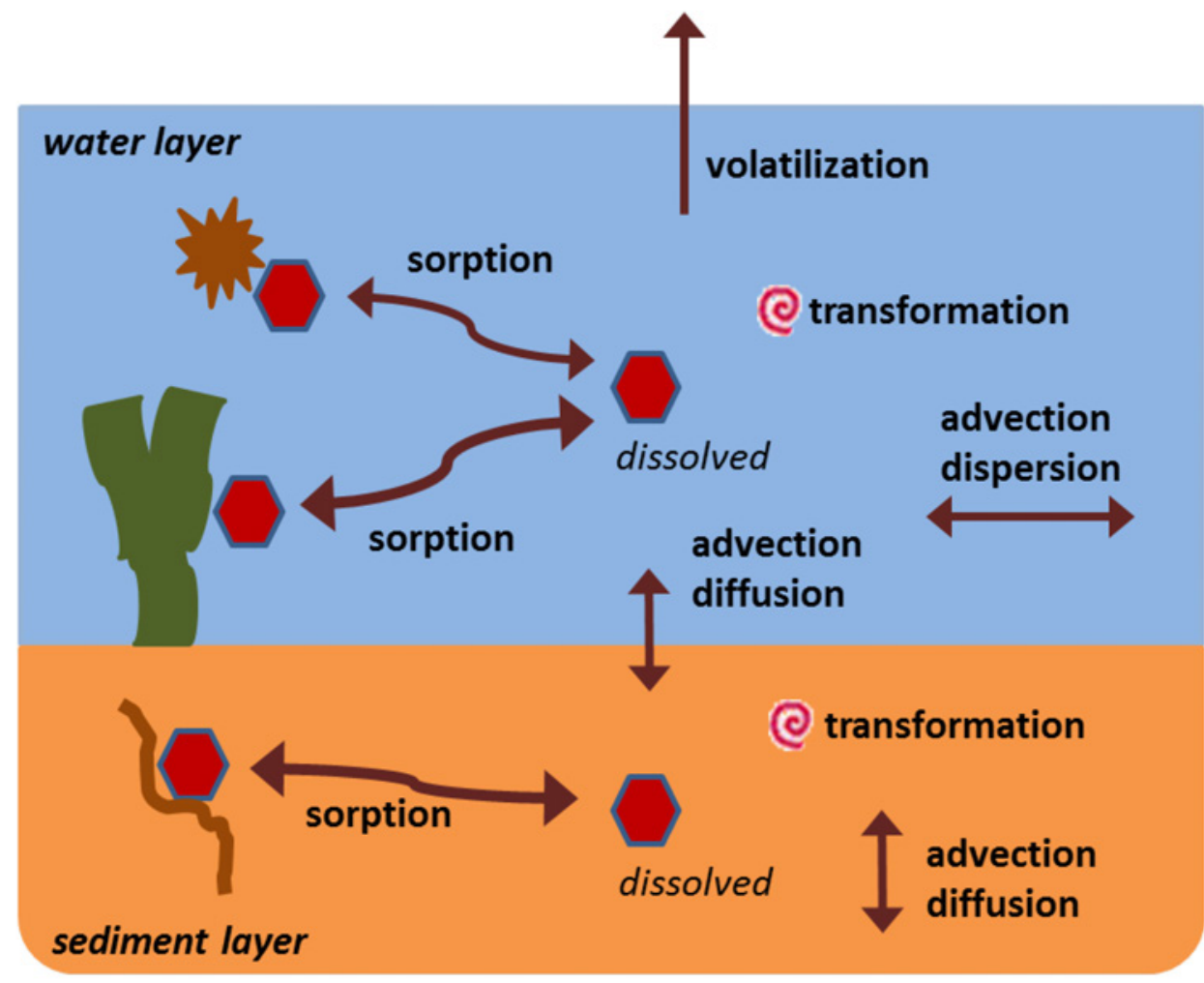

suspended solids

macrophytes

5

sediment solid phase

Figure 1 Processes in TOXSWA.

TOXSWA considers four processes for the parent substance and its metabolites: (i) transport, (ii) transformation, (iii) sorption and (iv) volatilization (see Figure 1). In the water layer substances are transported by advection and dispersion, both dissolved in the water phase or sorbed to suspended solids. In the sediment substances are transported by advection, dispersion and by diffusion. Exchange across the water-sediment interface is due to by advection (upward or downward seepage) and by diffusion. Transformation is simulated in the water layer as well as in the sediment. 
The transformation rate covers biodegradation, hydrolysis and in the water layer also photolysis. Sorption to suspended solids and to sediment is described by the Freundlich isotherm. Sorption to macrophytes is described by a linear sorption isotherm.

The model solves two mass conservation equations to simulate the substance behaviour; one for the water layer and one for the sediment.

Processes influenced by temperature

In the TOXSWA model the dissipation processes of transformation in water and in sediment, volatilization from water to air and molecular diffusion between water and sediment as well as within sediment are a function of the ambient temperature.

The transformation rates are temperature dependent. The Arrhenius equation is used to describe this dependency. The volatilization rate is temperature dependent because two parameters determining the volatilization rate coefficient, the vapour pressure and the solubility of a substance, are temperature dependent, via their molar activation energies (see Beltman et al., 2006).

Diffusion of the substance in water is also temperature dependent. Diffusion is important for the transfer between water and the sediment and for transport in the sediment (it is not considered in the water layer). The effect of temperature on the diffusion coefficient had not yet been implemented in version 3.3 of TOXSWA, but now has been implemented in version 3.4 of TOXSWA. The implementation is described in 2 .

\subsection{Energy balance of small water bodies}

\subsubsection{Overview of processes determining the water temperature}

Here an overview of the processes determining the water temperature in edge-of-field water bodies is presented. The description of the water temperature is limited to the water layer of the water bodies, so, the thermal behaviour of the sediment has not been included in TOXSWA 3.4.

The water temperature in outdoor small water bodies is determined by a number of processes, that have been described below. The terms in bold were implemented in TOXSWA. Section 2.4 describes the processes that were implemented into detail. The processes are presented schematically in Figure 2 by showing the different terms in the water layer, at the air-water, and at the watersediment and water-soil interfaces. These constitute the energy balance of the water layer.

a. Absorption of shortwave (solar) radiation, which is the energetic difference between total incoming shortwave radiation and total reflected shortwave radiation, also taking into account reflection of shortwave radiation by the sediment.

Absorption of shortwave radiation (see Annex 3 for a definition) in the water column is one of the major controls of the water temperature variations, in particular on sunny summer days. Part of the incoming shortwave radiation is reflected directly at the water surface, but usually most of it will penetrate into the water column. Therefore, the absorption of shortwave radiation is not only related to the weather conditions, but the turbidity of the water and water depth may be important as well. Part of the incoming shortwave radiation reaches the sediment and may be reflected there. The portion of the reflected part not absorbed by the water on its way back to the surface is added to the portion of the shortwave radiation that is directly reflected at the surface. Usually, the amount of shortwave radiation absorbed by the sediment is small, but it may sometimes be significant in the case of clear and shallow water bodies (see Annex 3 as well). 
b. Exchange of longwave (terrestrial) radiation, which is the energetic difference between incoming longwave (terrestrial) radiation and outgoing longwave (terrestrial) radiation.

Longwave radiation exchange (see Annex 3 for a definition) at the surface usually is the major cause of cooling of the water during the night and may become the major cause of water temperature variations, particular during clear winter nights.

c. Turbulent transport of energy at the surface, consisting of turbulent exchange of sensible heat and turbulent exchange of latent heat (i.e. heat transported by water vapour via evaporation and condensation)

d. Heat exchange due to precipitation. (Note that the energy transfer between precipitation and the water layer has now been included in TOXSWA 3.4, but the increase in water volume of the water layer by precipitation has not yet been implemented in the TOXSWA model.)

All of the processes mentioned under a-d are directly related to the weather conditions and to the conditions of the water body, including the temperature at the air-water interface.

e. Exchange of heat with the sediment and the surrounding soil environment, which is

(i) exchange of sensible heat at water-sediment interface.

(ii) exchange of sensible heat at the sediment-soil and water-soil interface

The exchange of heat with surrounding soil is usually small, but in some cases wall effects may have to be considered.

f. Supply and extraction of energy through external mechanisms, which are other (bulk) sink and source terms.

This category concerns natural processes like surface runoff as well as more or less artificial processes like supply of drainage water.

g. Heat mixing by mixing of water.

Finally the water temperature can be influenced by the mixing of heat or energy by mixing of water. Water can be mixed by density effects related to heat exchange, absorption of radiation, and momentum transfer between the water and the air or the sediment and walls. For the TOXSWA model this term is not relevant as the TOXSWA model assumes instantaneous and complete mixing of water (and thus also energy) over the cross sectional area of the watercourse.

In Section 2.2.2 to 2.2.7 a short summary of the processes is given per category. For a more extensive description of the processes the reader is referred to Jacobs et al. (2010). 


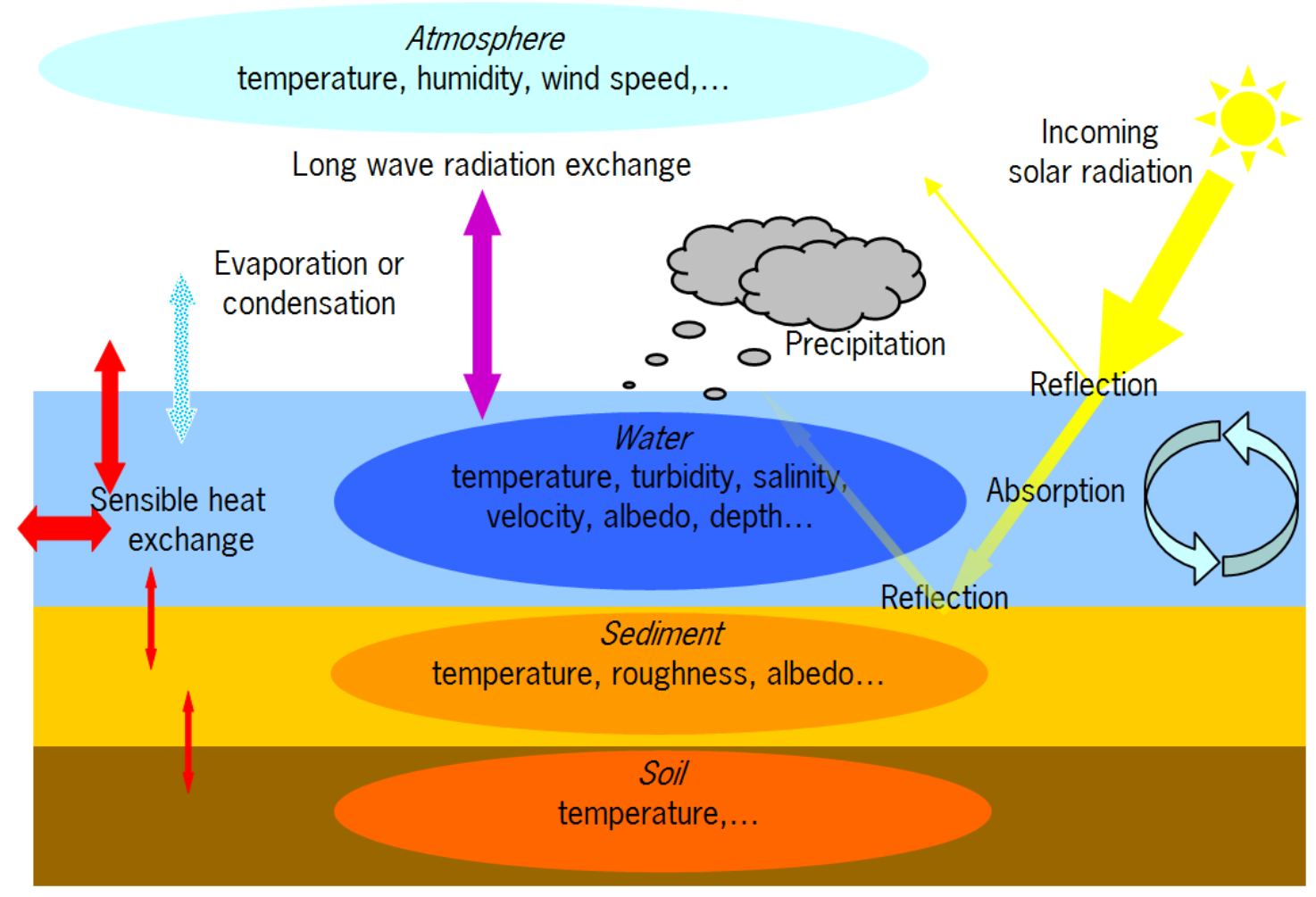

Figure 2 Schematic display of processes that determine the temperature of a water body. The ovals represent the four compartments of which information needs to be available to be able to calculate the energy balance. The straight arrows and the clouds represent energy flows and the curved arrows represent mixing. (source: Jacobs et al., 2010). Note that the water-soil interface at the water body walls is not represented in this figure.

\subsubsection{Absorption of shortwave (solar) radiation}

Shortwave radiation represents the radiation in the visible and near-infrared portions of the electromagnetic spectrum (wavelength $400-4000 \mathrm{~nm}$ ). At the Earth's surface, this radiation usually is of solar origin (see Annex 2 for more details). The energy allotted to downward, incoming radiation

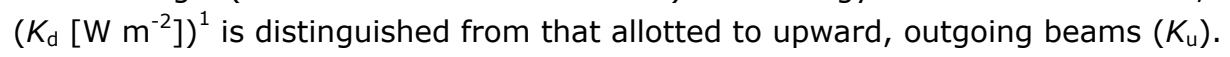

The fraction of $K_{d}$ not reflected directly at the water surface enters the water layer and will be absorbed in the water layer to a large extent, depending on the turbidity of the water and the depth of the water layer. Of the radiation that reaches the bottom of the water layer a fraction equal to the albedo of the sediment, $\alpha_{b}[-]$, will be reflected, and the remainder absorbed by the sediment. Part of the radiation reflected by the sediment will also be absorbed in the water layer. The remainder of the radiation reflected by the sediment will leave the water again as sediment-bottom-reflected radiation, but this is usually a small to negligible fraction of the original incoming shortwave radiation.

The portion of shortwave radiation absorbed in the water layer depends on the wavelength and is determined by the amount of floating particles, algae and macrophytes (higher water plants). Two important wavelength bands are distinguished in the shortwave radiation spectrum: PAR

('Photosynthetic Active Radiation', 400-700 nm, used by plants for photosynthesis), and NIR ('nearby infrared, 700-4000 nm). See Annex 2 as well. Near the Earth's surface, the energy of the downwelling shortwave radiation is approximately equally divided between PAR and NIR (Monteith and Unsworth, 1990). Most of the energy in the NIR band is absorbed almost immediately, just beneath the water surface (in the first millimetre); the energy in the PAR band penetrates much further (order of meters, e.g., De Lange, 2000) and decreases exponentially with increasing distance from the surface (Paulson and Simpson, 1977; Scheffer, 2004). The absorption within the PAR band depends on the

\footnotetext{
1 All symbols in this report with their descriptions are given in Annex 1.
} 
characteristics of the absorbing parts of the water such as algae, waste products or floating sediment particles (De Lange, 2000), but such effects are ignored in the present version of the model.

\subsubsection{Exchange of longwave (terrestrial) radiation}

Longwave radiation refers to the portion of electromagnetic radiation contained in wavelengths longer than $4000 \mathrm{~nm}$. In the atmosphere this radiation usually is of terrestrial origin (see Annex 2). All objects near the earth's surface that can "view" each other exchange longwave energy. This includes the atmosphere and water surfaces. The net exchange of longwave radiation between objects depends on the temperature differences between objects and on their emissivity (efficiency of radiation expressed on a scale from 0 to 1), along with the (relative) size of the exchanging surfaces ("view factors"). The emission of longwave radiation is proportional to the absolute temperature to the fourth power, so minor temperature differences could lead to major radiation differences. At the water surface, upward or outgoing longwave radiation emitted by the water surface $\left(L_{u}\right)$ will be distinguished from downward or incoming longwave radiation, emitted by the atmosphere $\left(L_{d}\right)$. Longwave radiation emitted by obstacles like trees and houses is ignored.

\subsubsection{Turbulent transport of energy at the surface}

\section{Turbulent exchange of sensible heat}

The transfer of sensible heat is driven by temperature differences between the water and the atmosphere and is facilitated by turbulence. The sensible heat flux can be directed upward or downward across the air-water interface. If directed upward the water will cool down, if directed downward the water will heat up. A strong wind will stimulate the energy transfer because it creates a strong turbulence in the atmosphere which will ease mixing and transport of heat. Positive water-air vertical temperature differences will also stimulate turbulence and thus enhance sensible heat transport, while negative temperature differences will inhibit turbulence and therefore sensible heat transport.

\section{Turbulent exchange of latent heat}

Transport of latent heat is heat transport by water vapour via evaporation and condensation. The energy needed for evaporation will be extracted from the water, causing the water to cool down. In a reverse process condensation at the water surface will release energy which will slightly heat up the water. The transport of water vapour is driven by difference in the atmospheric water vapour concentration immediately at the surface and at a reference level further away. A positive difference (more water vapour at the air-water interface than in the air) results in evaporation and a negative one in condensation. Like in the case of sensible heat, strong winds and positive vertical temperature differences will stimulate turbulent transport of latent heat, but negative temperature differences will inhibit turbulent transport.

\subsubsection{Heat exchange due to precipitation}

Precipitation on the water surface can heat or cool the water, depending on the temperature difference between the precipitation and the surface water and on the intensity of the precipitation. In practice, the contribution of precipitation to temperature changes in a water body is small (Jacobs et al., 2009). Intense precipitation on a very shallow water body might have noticeable effects within a limited period of time.

\subsubsection{Exchange of heat with the sediment and the surrounding soil environment}

The heat exchange between water and sediment, between sediment and soil below, and between water and surrounding soil are sensible heat fluxes. They depend on the temperature differences between the water body and its surroundings. These fluxes are considered small according to Jacobs et al. (2010), who however mention the option that in the case of a relatively narrow deep ditch the lateral heat exchange could significantly influence in the energy budget of those ditches. In TOXSWA version 3.4 only the sensible heat exchange between water and sediment has been modelled. This exchange is considered to be the most important component of heat exchange between a ditch and its 
surrounding sediments and soils, but however contributes little to the energy budget of waterbodies that are commonly modelled with TOXSWA.

\subsubsection{Supply and extraction of energy through external mechanisms}

In addition to the energy budget terms mentioned above, other sources and sinks of energy exist, that may affect the water temperature. Examples of such energy sinks and sources are runoff water, drainage water, water inflow across the upstream boundary of the water body, or outflow across the downstream boundary. The magnitude of these sources or sinks is given by the difference in the heat content of water volume under consideration and the water volume that is being supplied, taking into account the rate of the water supply. The heat content per unit volume is given by the specific heat capacity, the density and the absolute temperature of the water. Under the assumption of perfect mixing the source or sink strength can then be expressed as a heat flux per unit horizontal surface area, similar to all other energy fluxes. In TOXSWA version 3.4 inflow of energy via water inflow across the upstream boundary of the water body, runoff or drainage water has been included, as well as outflow of energy by water outflow across the downstream boundary of the water body. Exchange of energy via subsurface water flow has not yet been operationalised in the TOXSWA model. Heat mixing by mixing of water. Mixing of fresh water is enhanced by (1) cooling of water at the surface and warming at the bottom, and by (2) air-water momentum exchange and momentum transport in the water layer, due to wind, breaking waves, and from vertical velocity differences (shear), notably at the surface or at the bottom of the water layer. The mechanical impact of intense precipitation falling on the water surface may also be considered as a mechanism of air-water momentum exchange. Mixing can also be reduced because of warming of water at the surface and cooling at the bottom.

Temperature variations arise by the processes described in the previous sections. Depending mainly on cooling or heating directly at the water surface, turbulence is stimulated or is suppressed respectively. The air-water momentum exchange and momentum transport in the water layer stimulate turbulence of the water layer. Turbulence results in vertical mixing of the water layer and therefore reduces vertical temperature differences. If turbulence is suppressed, the reduced vertical mixing may cause significant temperature differences.

Cooling of the water surface is caused by emission of longwave radiation, evaporation, sensible heat transport towards the atmosphere and relatively cold precipitation. The density of water generally increases with decreasing temperature. The cooler water sinks, causing a downward motion of the water, leading to turbulence. Heating of the water surface is caused by absorption of shortwave radiation, supply of sensible heat, condensation and relatively warm precipitation. The hotter water does not sink because its density is decreased, suppressing turbulence. Note that freshwater reaches a maximum density at about $4^{\circ} \mathrm{C}$ so that the aforementioned effects of heating and cooling are reversed for water temperatures between $0^{\circ} \mathrm{C}$ and $4^{\circ} \mathrm{C}$ degrees. For a more detailed description of the mixing processes the reader is referred to Jacobs et al. $(2009,2010)$.

Conditions with thermal stratification in shallow ponds are relatively rare (Scheffer, 2004; Jacobs et al. 2009), which justifies the assumption of well-mixed conditions in TOXSWA in the present stage of the development. However, it is noted that especially in summer during conditions of clear, calm weather, the sequence of heating and cooling of the water surface can result in a diurnal cycle of stratification and mixing conditions.

\subsection{The water temperature module: short description and limitations}

A one-dimensional (1D) energy budget model with the assumption of a well-mixed water layer as proposed by Jacobs et al. (2010) is implemented in TOXSWA. Because the water is assumed to be perfectly mixed there are by definition no vertical temperature gradients. No layers inside the water column need to be distinguished. Therefore, this approach is referred to as a '1D-bulk' approach. 
The 1-D bulk model described in this report thus refers to the one-dimensional description of the thermal behaviour of perfectly mixed water bodies, that is, a description of the vertical energy exchange processes. The 'bulk' approach implies that the energy in the control volumes of the water layer is assumed to be entirely mixed in vertical direction. Also, addition or extraction of heat will be mixed through immediately, that is, within each time step considered. Note that, in the TOXSWA model, the control volumes are assumed to be horizontally homogeneous, i.e. well-mixed in horizontal directions. So, the 1-D bulk model is here used in a modular sense, and assumes well-mixed control volumes of uniform depth. The model focuses on the thermal behaviour of the water layer only, and so, the sediment has not been modelled as a separate system.

Under this assumption of well-mixed control volumes in the water layer, the parameterizations described by Jacobs et al. (2010) are used for each of the categories described in Section 2.2. This approach is considered to be sufficiently accurate in the context of TOXSWA. The most important components of the energy budget are modelled with reasonable accuracy, in particular the absorption of shortwave radiation in the water layer and the various fluxes (radiative, turbulent) at the air-water interface. Errors in the energy budget arising from the fact that temperature gradients near the surface or at the water-sediment interface are neglected, are considered acceptable for most applications. The equations from Jacobs et al. (2010) that have been coded in TOXSWA are given in Section 2.4 .

The TOXSWA model is a quasi 2-D model with water and pesticide flow simulated in horizontal direction and pesticide penetration in the sediment in vertical direction. The numerical solution of the mass balance for the water layer results in segments, where mass is exchanged between the water layer and the sediment (Fig 1.2 of Jacobs et al., 2010). There is no interaction between the underlying segments in the direction of flow. The segments in TOXSWA's water layer are assumed to be ideally mixed. For the vertical direction this corresponds well to our 1-D bulk description of the thermal behaviour of the waterbody. For the horizontal direction we simplified the description of the thermal behaviour into the assumption that the temperature is uniform over the entire length of the modelled watercourse. This implies that temperature differences due to differences in water depth are neglected. Such differences might occur in watercourses where the water depth strongly increases or decreases in the direction of flow while, e.g., incoming radiation is high and flow rates are low. However, the approach matches the concept implemented in the current previous of TOXSWA, in which the pesticide mass balance has been solved for the evaluated stretch of the watercourse assuming a constant water depth. Energy inputs by precipitation, drainage or runoff water from adjacent fields or upward or downward seepage via the sediment have been described as source or sink terms and are assumed to be equally distributed along the entire length of the watercourse; thus this also corresponds to the assumption that the temperature is uniform over the entire length of the evaluated watercourse.

Summarising: a 1-D bulk model for simulation of the thermal behaviour of edge-of-field surface water bodies was used, as this matches the modelled water flow in TOXSWA based upon well-mixed control volumes. This 1-D bulk approach is a convenient framework as it does not require a detailed description of turbulence and density effects on stratification, and the data requirement is limited (see Jacobs et al., 2010).

The energy model implemented in TOXSWA has the following main limitations:

(i) the light absorption model will not necessarily be valid for systems where macrophytes dominate light absorption,

(ii) the possible influence of walls horizontal exchange of energy and on radiation exchange is not taken into account,

(iii) contribution of sensible heat from soil below the sediment is not taken into account,

(iv) situations where horizontal exchange is exceptionally large in comparison with the vertical exchange, may not be adequately described,

(v) thermal stratification cannot be handled,

(vi) freezing of water and melting of ice are not modelled. 
In the present version the contribution of sensible heat from the sediment, and from soil and groundwater below the sediment is not taken into account. Paaijmans et al. (2008) measured and modelled the daily energy gains and losses of small ponds with water shallow water depths. They found that on a daily timescale the contribution of sensible heat from sediment to waterbodies with a water depth of $16 \mathrm{~cm}$ or more is in the order of $1 \%$ at most Although at the timescale of an hour, the absorption of short wave radiation by the sediment may lead to an increase of the sediment temperature of up to several degrees Celsius, notably in the summer period around noon, the net contribution from the sediment heat flux remains relatively small compared to the other energy fluxes under such conditions, even at such small timescales. Furthermore, the warming may be largely compensated by cooling within that day (Paaijmans et al., 2008).

The temperature of the sediment is assumed to be equal to the water temperature. This is a reasonable assumption for the top millimetres of the sediment which are in direct contact with the water layer and often have a high porosity (Adriaanse et al., 2015). As plant protection products entering waterbodies reside predominantly in the top $\mathrm{cm}$ of the sediment the effect of temperature on transformation and on diffusion is considered to be described in a defensible manner in the TOXSWA model.

\subsection{The water temperature module: detailed description of the modelled energy budget terms}

This section describes in detail the energy budget and its separate terms as implemented in the TOXSWA kernel 3.4. The equations and descriptions are taken from Jacobs et al. (2010). They based the proposed set of equations on previously published theory and modelling work; for references to the original literature the reader is referred to their report.

\subsubsection{Balance equation}

The energy budget of a horizontally and vertically homogeneous, well-mixed water layer in contact with the atmosphere and with water depth $h$ is given by:

$$
\rho_{w} c_{w} h \frac{\Delta T_{w}}{\Delta t}=K_{d}-K_{b}-K_{u}+L_{d}-L_{u}-H-\lambda E+Q_{p r}+G_{s}+\sum S_{\text {ext }}
$$

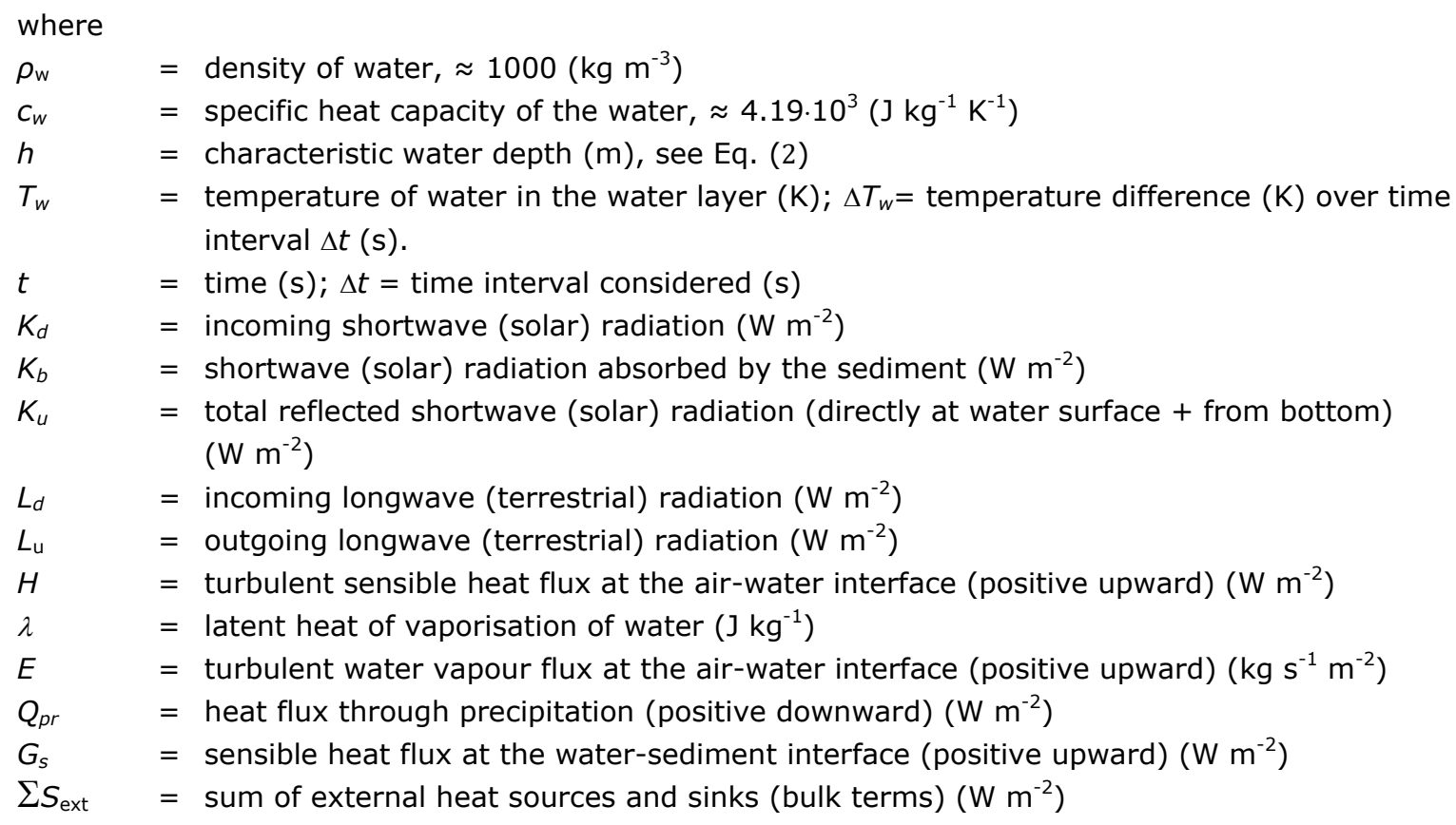

The energy budget is expressed per $\mathrm{m}^{2}$ (horizontal) of surface area of the water layer. An overview of all parameters used in this report is given in Annex 1. 
The depth $h$ in Eq. (1) is the effective or characteristic water depth, defined as follows:

$h=\frac{V}{O_{x}}$

where

$V \quad=$ volume of water layer $\left(\mathrm{m}^{3}\right)$

$O_{\mathrm{x}} \quad=$ horizontal surface area of the water layer $\left(\mathrm{m}^{2}\right), L * w$ in Fig. 3.

Calculation of the terms in Eq. (1) is further detailed in the next sections.

\subsubsection{Incoming shortwave radiation $\left(K_{\mathrm{d}}\right)$, shortwave radiation absorbed by sediment $\left(K_{\mathrm{b}}\right)$ and reflected shortwave radiation at the water surface $\left(K_{\mathrm{u}}\right)$}

The energy terms in Eq. (1) related to shortwave radiation are the incoming shortwave radiation received by the water surface $\left(K_{\mathrm{d}}\right)$, shortwave radiation absorbed by the sediment $\left(K_{\mathrm{b}}\right)$, and the shortwave radiation directly reflected at the water surface plus the portion of the radiation that leaves the water again after reflection at the sediment surface $\left(K_{\mathrm{u}}\right)$. See Annex 3 for a definition of "shortwave radiation." For our purpose, it is considered sufficiently accurate to treat the radiative fluxes in terms of two separate beams: a downward and an upward one.

The incoming shortwave radiation, $K_{\mathrm{d}}$, is, by default, taken from observations made at a meteorological station (also see Annex 3):

$K_{d}=K_{d, o b s}$

where

$K_{d, o b s}=$ observed incoming shortwave radiation $\left(\mathrm{W} \mathrm{m}^{-2}\right)$

Gaps in the observed shortwave radiation are filled by computing the incoming shortwave radiation $\left(K_{d}\right)$ using Eqs (56) to (58) given in Annex 4.

The shortwave radiation absorbed by the sediment, $K_{\mathrm{b}}$, is the portion of the shortwave radiation that reaches the sediment but is not reflected by the sediment surface, given as

$K_{b}=\left(1-\alpha_{b}\right) K_{b o t}$

where

$K_{\mathrm{b}}=$ downward shortwave radiation absorbed by the sediment $\left(\mathrm{W} \mathrm{m}^{-2}\right)$

$\alpha_{b} \quad=$ albedo of the sediment (-)

$K_{\text {bot }}=$ downward shortwave radiation reaching the sediment $\left(\mathrm{W} \mathrm{m}^{-2}\right)$

Note that this term needs to be considered for each wavelength band considered (e.g., PAR verus NIR). It was not explicitly included in the energy budget in Jacobs et al. (2010). In deep water the downward radiation reaching the sediment usually is small, so the radiation absorbed by the sediment can be ignored. However, for shallow water bodies (e.g. $0.3 \mathrm{~m}$ ) this term cannot be neglected anymore when calculating the water temperature, in particular under weather conditions representative of sunny summer days.

The fraction of $K_{d}$ reflected directly at the surface is given by the albedo $\alpha_{\mathrm{t}}$ of the water surface. The albedo is calculated using

$\alpha_{t}=f \alpha_{d i r}+(1-f) \alpha_{d i f}$ 
where

$\alpha_{\mathrm{t}} \quad=$ albedo of the water surface $(-)$

$f \quad=$ the fraction of direct radiation in the incoming shortwave radiation (-)

$\alpha_{\text {dir }} \quad=$ albedo component related to reflection of direct shortwave radiation (-)

$\alpha_{\text {dif }} \quad=$ albedo component related to reflection of diffuse shortwave radiation (-)

See Annex 3 for a definition of direct and diffuse shortwave radiation. The albedo component $\alpha_{\text {dif }}$ is approximately constant with a typical value of 0.06 (see references in Jacobs et al., 2010). The albedo component $\alpha_{\text {dir }}$ is given by the Fresnel albedo which depends on the solar zenith angle $Z$ :

$Z=\frac{\pi}{2}-\varphi$

where

$Z \quad=$ solar zenith angle (radians)

$\varphi \quad=$ solar elevation (radians)

and on refraction angle $r(-)$, given by

$r=\sin ^{-1}\left[\frac{\sin (Z)}{1.33}\right]$

For solar elevation $\varphi>0$ :

$\alpha_{d i r}=0.5\left[\frac{\sin ^{2}(Z-r)}{\sin ^{2}(Z+r)}+\frac{\tan ^{2}(Z-r)}{\tan ^{2}(Z+r)}\right]$

Solar elevation $\varphi$ is obtained via

$\sin \varphi=\sin \delta \sin \Phi-\cos t_{h} \cos \delta \cos \Phi$

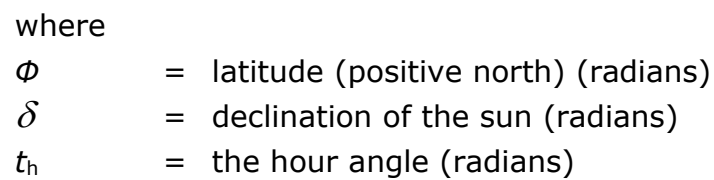

The declination of the sun, $\delta$, is calculated as

$\delta=0.409 \cos \left[\frac{2 \pi\left(D-d_{s}\right)}{365.25}\right]$

where

$D=$ day of year $(-)$

$d_{\mathrm{s}} \quad=$ day of the summer solstice, $=172^{2}(-)$

The hour angle $t_{\mathrm{h}}$ is approximated by

$t_{h}=\frac{\pi t_{d}}{12-\Lambda-\pi}$

where

$t_{\mathrm{d}} \quad=$ time of day in UTC (h)

$\Lambda=$ longitude (positive west) (radians)

2 Jacobs et al. (2010) use a value of 171. TOXSWA uses a value of 172 for non-leap years and 173 for leap years. Since the start of summer is commonly set on June 21st, we use this date as the day of summer solstice, which results in values of $d_{s}$ of 172 for non-leap years and 173 for leap years. 
The fraction $f$ in Eq. (5) is determined from the atmospheric transmissivity $\tau_{\text {a }}$ using the following parameterisation:

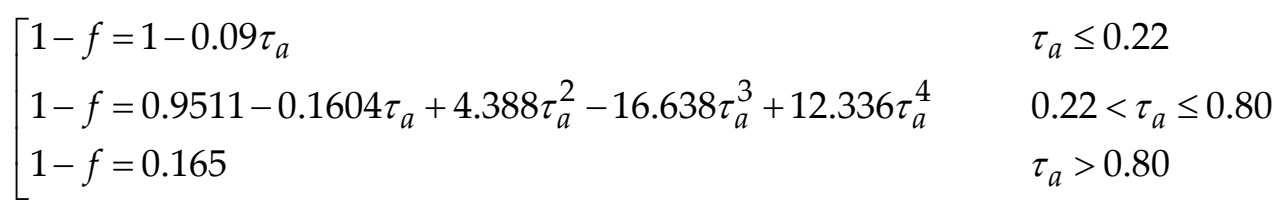

where the atmospheric transmissivity $\tau_{a}$ is approximated using:

$$
\tau_{a}=\frac{K_{d}}{1367 \sin \varphi}
$$

Thus, the fraction of direct radiation is large in case of sunny weather, which comes with high atmospheric transmissivity (e.g., not hindered by clouds or fog). Inversely, the fraction of diffuse radiation, i.e., 1-f, is large in case of low transmissivity, e.g., in cloudy conditions. The portion of the incoming shortwave radiation not reflected at the water surface travels downward in the water layer. Part of this portion may be reflected at the sediment surface and next, the reflected part travels back in upward direction towards the water surface. Both during downward and upward travelling in the water layer the shortwave radiation is attenuated. We first calculate the fraction of the downward radiation that reaches the sediment. Next, the amount of shortwave radiation that reaches the surface again upon reflection at the sediment is computed.

The downward radiation reaching the depth of the sediment $K_{\text {bot }}$ is calculated with

$$
\sum_{j=1}^{n} K_{b o t, j}=K^{\downarrow}(h)=\left(1-\alpha_{t}\right) K_{d} \sum_{j=1}^{n} \xi_{j} \exp \left(-\mu_{j} h\right)
$$

(also see Annex 5) where

$$
\begin{array}{ll}
K_{\text {bot,j }} & =\text { downward shortwave radiation in wavelength band } j \text { that reaches the sediment }\left(\mathrm{W} \mathrm{m} \mathrm{m}^{-2}\right) \\
\alpha_{t} & =\text { albedo of the water surface }(-) \\
K^{\downarrow}(h) & =\text { energy in the downward beam at the bottom of the water layer or the distance } h \text { from } \\
& \text { the water surface, i.e., at the characteristic water depth } h(\mathrm{~m})\left(\mathrm{W} \mathrm{m} \mathrm{m}^{-2}\right) \\
\xi_{j} & =\text { energy fraction of } K_{\mathrm{d}} \text { contained in wavelength band } j(-) \\
\mu_{j} & =\text { extinction or attenuation coefficient in water for wavelength band } j\left(\mathrm{~m}^{-1}\right)
\end{array}
$$

In the present version of TOXSWA, two wavelength bands are distinguished for the solution of Eq. (14), the NIR and the PAR band. Hence $n=2$. The energy fraction $\xi$ and the attenuation coefficient $\mu$ are given in Table 1 for two cases: clear water and turbid water. Since NIR is absorbed almost completely in the first millimetre of the water column there is only a difference in PAR absorption for the two cases. In TOXSWA the default values for clear water are used.

Table 1 Energy fraction $\xi$ and attenuation coefficient $\mu$. Two sets of values are given for the attenuation coefficient $\mu: 1$ ) from a fit to the light attenuation; 2) values derived from measurements in a $32 \mathrm{~cm}$ deep pond with high turbidity due to abundant presence of algae. (from Jacobs et al., 2010).

\begin{tabular}{cccc} 
Wavelength Band & $\begin{array}{c}\text { Anergy fraction } \\
\xi(-)\end{array}$ & Default & $\mu\left(\mathrm{m}^{-1}\right)$ \\
& & & Turbid \\
\hline 1. NIR & 0.45 & 1000 & 1000 \\
\hline 2. PAR & 0.55 & 2.52 & 4.25 \\
\hline
\end{tabular}


A fraction of the downward beam that reaches the sediment, $K_{\text {bot, }}$ is reflected at the sediment with albedo $\alpha_{\mathrm{b}}$. The reflected part is attenuated while travelling back in upward direction in the same way as the downward beam was attenuated. At the surface, we then have:

$$
K^{\uparrow}(h)=\alpha_{b} \sum_{j=1}^{n} K_{b o t, j} \exp \left(-\mu_{j} h\right)
$$

Where $K^{\uparrow}(h)$ is the energy contained in the upward shortwave radiation beam that reaches the surface upon reflection at the bottom (see Annex 4 as well). In conclusion, the reflected shortwave radiation, $K_{\mathrm{u}}$, is the sum of two terms; the energy directly reflected by the water surface and the energy reaching the water surface after reflection by the sediment. It is given by

$$
K_{u}=\alpha_{t} K_{d}+\alpha_{b} \sum_{j=1}^{n} K_{b o t, j} \exp \left(-\mu_{j} h\right)
$$

Note that in TOXSWA only the PAR component of the two wavelength bands will have an upward component because the NIR component is almost completely absorbed in the first millimetre of the water layer (see also Annex 5). Also note that in the present development the albedo is assumed to be independent of the wavelength, both at the water surface and at the sediment.

\subsubsection{Incoming longwave radiation $\left(L_{d}\right)$ and outgoing longwave radiation $\left(L_{u}\right)$}

The incoming longwave radiation, $L_{d}$, is estimated using

$L_{d}=\varepsilon_{r} \sigma T_{r}^{4}+c_{2} N$

where

$\varepsilon_{r} \quad=$ apparent emissivity of the atmosphere $(-)$

$\sigma=$ Stefan-Boltzmann constant $\left(\mathrm{W} \mathrm{m}^{-2} \mathrm{~K}\right)\left[=5.67 \cdot 10^{-8} \mathrm{~W} \mathrm{~m}^{-2} \mathrm{~K}\right]$

$T_{\mathrm{r}} \quad=$ air temperature at reference height $z_{r}$ (taken $2 \mathrm{~m}$ above the surface) $(\mathrm{K})$

$c_{2} \quad=$ empirical coefficient, cloud contribution factor $\left(\mathrm{W} \mathrm{m}^{-2}\right)\left[c_{2}=70 \mathrm{~W} \mathrm{~m}^{-2}\right]$

$N \quad=$ total cloud cover, i.e., the fraction of the sky covered with clouds of any kind (-)

See Annex 3 for a definition of "Iongwave radiation." In the case of small water bodies where the water surface is well below the surrounding land surface, $L_{d}$ may have to be corrected for interactions between the walls and the water surface, and the reduced fraction of the sky "seen" at a point on the water surface, but for the time being we ignore these effects.

The apparent emissivity of the atmosphere, $\varepsilon_{\mathrm{r}}$, is estimated by

$\varepsilon_{r}=1.2\left(\frac{0.01 e_{s}\left(T_{r}\right) H_{r}}{T_{r}}\right)^{1 / 7}$

where

$H_{\mathrm{r}} \quad=$ relative humidity at the reference level (-)

$e_{\mathrm{s}}\left(T_{\mathrm{r}}\right)=$ saturation vapour pressure at the air temperature (Pa) [(see Eq. (24)]

$0.01=$ factor for unit scaling, from $[\mathrm{Pa}]$ to $[\mathrm{hPa}]$

The outgoing longwave radiation is given by:

$$
L_{u}=\varepsilon_{w} \sigma T_{w}^{4}+\left(1-\varepsilon_{w}\right) L_{d}
$$

where

$\varepsilon_{\mathrm{W}} \quad=$ emissivity of the water (-) 
A good estimate of the emissivity of water is $\varepsilon_{W}=0.97$. For specific cases, the emissivity can be estimated from radiation measurements. Since perfect mixing is assumed, the surface temperature of the water simply equals the computed temperature of the water layer. This temperature is taken to be the water temperature at the end of the previous timestep.

\subsubsection{Turbulent fluxes: sensible heat flux $(H)$ and latent heat flux $(\lambda E)$}

Two turbulent heat fluxes occur at the air-water interface: the sensible heat flux, $H\left(\mathrm{~W} \mathrm{~m}^{-2}\right)$, and the latent heat flux, $\lambda E\left(\mathrm{~W} \mathrm{~m}^{-2}\right)$, connected to water vapour exchange, i.e., evaporation and condensation. For both turbulent fluxes the so-called bulk transfer approach is applied. In that approach the efficiency of turbulent transport in the atmospheric layer between the surface and a reference level is described by means of the so-called bulk transfer coefficient for heat and water vapour transport, respectively. In this case, the term "bulk" refers to the fact that only one layer of air is distinguished between the surface and the reference level. The efficiency of turbulence in this entire layer is characterized by a single coefficient multiplied by the wind speed at the reference level. The gradients that drive the transport are also given by the "bulk" or "overall" difference between the conditions at the surface and the reference level, without further description of the strength of the gradients as a function of height within that layer. The gradients determine the sign of the transport. According to micrometeorological convention, the turbulent fluxes are taken positive upward, which is the case when the temperature or water vapour content at the surface is larger than at the reference level. Thus, a positive flux represents an energy loss for the water body.

Within this concept, $H$ at the air-water surface is given by :

$$
H=\rho_{a} C_{a} C_{H} u_{r}\left(T_{w}-T_{r}\right)
$$

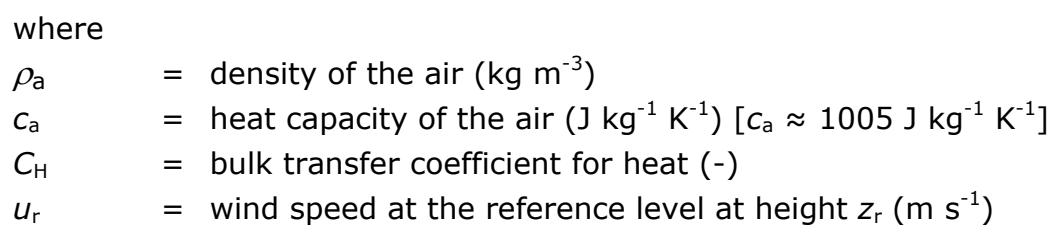

with

$\rho_{a}=\frac{p_{a}}{R T_{r}}$

where

$p_{\mathrm{a}} \quad=$ atmospheric pressure at the surface $(\mathrm{Pa})$

$R=$ specific gas constant for dry air $\left(\mathrm{J} \mathrm{kg}^{-1} \mathrm{~K}^{-1}\right)\left[R=287 \mathrm{~J} \mathrm{~kg}^{-1} \mathrm{~K}^{-1}\right]$

Furthermore, $\lambda E$ is given by:

$\lambda E=\rho_{a} \lambda C_{E} u_{r}\left(q_{s}\left(T_{w}\right)-H_{r} q_{s}\left(T_{r}\right)\right)$

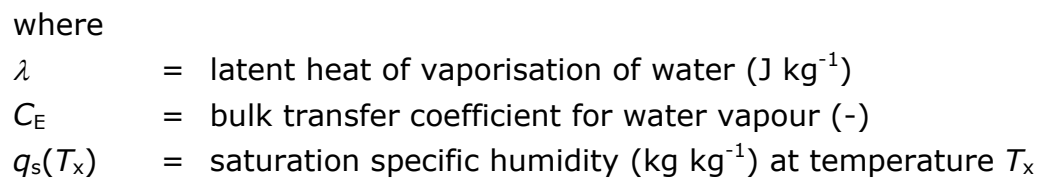

Note that $\lambda E / \lambda=E$ is a mass flux in $\mathrm{kg} \mathrm{m}^{-2} \mathrm{~s}^{-1}$, which also corresponds to a mass flux in $\mathrm{mm} \mathrm{m}^{-2} \mathrm{~s}^{-1}$. Thus $E$ can directly be used in water budget calculations. 
Saturation specific humidity $q_{\mathrm{s}}(T)$ in Eq. (22) is estimated using:

$q_{s}(T)=\varepsilon \frac{e_{s}(T)}{p_{a}}$

with

$e_{S}(T)=611 \cdot \exp \left[17.27 \cdot \frac{T-273}{T-36}\right]$

where

$e_{\mathrm{s}} \quad=$ saturation vapour pressure $(\mathrm{Pa})$

$T=$ absolute temperature (water or air in Eq. (22)) $(\mathrm{K}$ )

$\varepsilon \quad=$ ratio of molecular mass of water vapour to air $(-)[\varepsilon=0.622]$

Jacobs et al. (2010) used a single value for $\lambda$ in their assessment, but in this implementation we take into account the effect of temperature on $\lambda$ :

$\lambda\left(T_{w}\right)=1000 *\left(2500.82-2.358 T_{w}\right)$

from a linear fit for $\lambda\left(T_{\mathrm{w}}\right)$ between 0 and $35^{\circ} \mathrm{C}$ by Drake (1972) where $T_{\mathrm{w}}$ is expressed in ${ }^{\circ} \mathrm{C}$. Eq. (25) is consistent with reference values for saturated vapour pressure given in the Smithsonian Meteorological Tables (List, 1966), according to Henderson-Sellers (1984).

For small water bodies the turbulent characteristics over the water layer are completely governed by the surrounding land surface characteristics, so that the bulk transfer coefficients for heat, $C_{H}$ and for moisture, $C_{\mathrm{E}}$, may be somewhat larger. In general, for neutral conditions $C_{\mathrm{H}}$ (in Eq. (20)) and $C_{\mathrm{E}}$ (in Eq. (22)) over land between the surface and height $z_{r}$ is given by:

$$
C_{H} \approx C_{E}=\frac{\kappa^{2}}{\ln \left(z_{r} / z_{0}\right) \ln \left(z_{r} / z_{h}\right)}
$$

where

$z_{r} \quad=$ reference height $(\mathrm{m})$

$z_{0} \quad=$ aerodynamic roughness $(\mathrm{m})$

$z_{\mathrm{h}} \quad=$ roughness length for heat $(\mathrm{m})\left[z_{\mathrm{h}} \approx 0.1 z_{0}\right]$

$\kappa=$ Von Kármán constant $(-)[\kappa \approx 0.4]$

For the aerodynamic roughness $z_{0}$ in Eq. (26) a default value of $0.03 \mathrm{~m}$ is used, representing the roughness of a typical grassland area. Paaijmans et al. (2008) found good results with $C_{\mathrm{H}}=C_{\mathrm{E}}=$ 0.003 , for a tropical water pool. The latter value was derived for a small water surface surrounded by short grass.

The wind speed $u_{\mathrm{r}}$ at reference height in Eq. (20) is estimated from the observed wind speed $u_{\mathrm{obs}}$ at observation height $z_{\text {obs }}$ using the so-called logarithmic wind profile:

$u_{r}=u_{o b s}\left[1-\ln \left(z_{o b s} / z_{r}\right) / \ln \left(z_{o b s} / z_{0}\right)\right]$

where

$u_{\text {obs }} \quad=$ observed wind speed at observation height $z_{\mathrm{obs}}\left(\mathrm{m} \mathrm{s}^{-1}\right)$

$z_{\text {obs }}=$ observation height $(\mathrm{m})$ 
The aerodynamic roughness in Eq. (27) applies at the site of the wind speed observations, usually a grassland. Since the default roughness represents such a surface in the surroundings of the modelled water body the form of Eq. (27) is generally appropriate.

\subsubsection{Heat flux through precipitation $\left(Q_{\mathrm{pr}}\right)$}

The impact of precipitation on the energy budget, represented by heat flux $Q_{\mathrm{pr}}$, is calculated assuming that the temperature of the raindrops approaches the wet bulb temperature near the Earth's surface:

$Q_{p r}=\rho_{w} c_{w} P_{I}\left(T_{p}-T_{w}\right)$

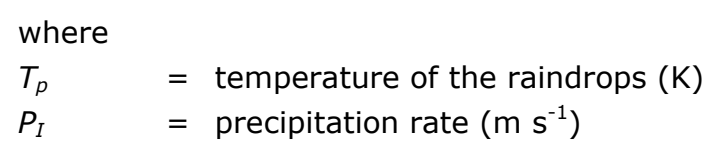

The temperature of the raindrops, $T_{\mathrm{p}}$, assumed equal to the wet bulb temperature at the reference level, is calculated from the temperature $\left(T_{\mathrm{r}}\right)$ and the humidity $\left(H_{\mathrm{r}}\right)$ at the reference level using

$$
T_{p} \approx T_{r}-\frac{\left(1-H_{r}\right) e_{s}\left(T_{r}\right)}{66+s\left(T_{r}\right)}
$$

where

$s\left(T_{\mathrm{r}}\right) \quad=$ rate of increase of the saturation vapour pressure with temperature evaluated at $T_{\mathrm{r}}\left(\mathrm{Pa} \mathrm{K}^{-1}\right)$

which is computed as

$s\left(T_{r}\right)=\frac{\lambda e_{s}\left(T_{r}\right)}{462 T_{r}^{2}}$

Note that while the energy transfer between precipitation and the water layer has now been included in TOXSWA 3.4, the increase of the water volume by precipitation has not yet been implemented in the TOXSWA model.

\subsubsection{Sensible heat flux between water and sediment $\left(G_{s}\right)$}

The sensible heat flux between the water and the sediment $\left(G_{s}\right)$ is modelled as:

$$
G_{s}=\frac{k_{s e d}\left(T_{s e d}-T_{w}\right)}{0.5 D_{s e d}}
$$

where

$T_{\text {sed }}=$ temperature of the sediment $(\mathrm{K})$

$k_{\text {sed }}=$ heat conduction coefficient of the sediment $\left(\mathrm{W} \mathrm{m}^{-1} \mathrm{~K}^{-1}\right)$

$D_{\text {sed }} \quad=$ thickness of the sediment $(\mathrm{m})$

Here, it is assumed that $T_{\text {sed }}=T_{\mathrm{w}}$. Thus, the sensible heat flux between the water layer and the sediment becomes zero. Like discussed in Section 2.3 this is considered a reasonable approximation in the context of the present implementation.

\subsubsection{Other heat sources and sinks $(\Sigma S)$}

For the description of the source and sink terms two dimensions play a role: for the 1-D water temperature module the vertical axis is the main axis, while for the TOXSWA water flow the horizontal axis, the direction of flow, is the main axis. To account for the energy transport in water flows all water flows are expressed on the basis of the horizontal water surface area. In this report external source and sink terms in general are referred to as external terms $\left(S_{\text {ext }}\right)$. 
Based on Section 3.2.6 of Jacobs et al. (2010), other heat source and sink terms of the energy budget, are described by

$\sum S_{\text {ext }}=S_{u p s}+S_{r o}+S_{d r}+S_{s u b}-S_{d o w n}$

with

$S_{\text {ups }} \quad=$ energy source or sink via water entering via the upstream boundary of the water body $\left(\mathrm{W} \mathrm{m} \mathrm{m}^{-2}\right)$

$S_{\text {ro }} \quad=$ energy source or sink via runoff water $\left(\mathrm{W} \mathrm{m}^{-2}\right)$

$S_{\mathrm{dr}} \quad=$ energy source or sink via drainage water $\left(\mathrm{W} \mathrm{m}^{-2}\right)$

$S_{\text {sub }} \quad=$ energy source or sink via subsurface flow water from or to an adjacent field $\left(\mathrm{W} \mathrm{m}^{-2}\right)$ [positive if water is flowing in, negative if water is flowing out]

$S_{\text {down }} \quad=$ energy source or sink via water leaving via the downstream boundary of the water body $\left(\mathrm{W} \mathrm{m} \mathrm{m}^{-2}\right)$

Inflow and outflow across upstream and downstream boundaries of waterbody

The heat inflow due to entry of water via the upstream boundary of the water body and heat outflow due to outflow of water leaving the water body, is described by

$S_{u p s}=\rho_{w} c_{w} F_{u p s}\left(T_{u p s}-T_{w}\right)$

$S_{\text {down }}=\rho_{w} c_{w} F_{\text {down }}\left(T_{w}-T_{\text {down }}\right)$

with

$F_{\text {ups }} \quad=$ areic volume flux of water entering the water body divided by surface area of the water layer $\left(\mathrm{m}^{3} \mathrm{~m}^{-2} \mathrm{~s}^{-1}\right)$

$T_{\text {ups }} \quad=$ temperature of water entering the water body $(\mathrm{K})$

$F_{\text {down }} \quad=$ areic volume flux of water leaving the water body divided by surface area of the water layer $\left(\mathrm{m}^{3} \mathrm{~m}^{-2} \mathrm{~s}^{-1}\right)$

$T_{\text {down }} \quad=$ temperature of water across the downstream boundary of the watercourse $(\mathrm{K})$

The aeric volume fluxes (calculated for the surface area of the waterbody $w \cdot L$ ), are described by

$F_{u p s}=\frac{Q_{x=0}}{w L}$

$F_{\text {down }}=\frac{Q_{x=L}}{w L}$

with

$Q_{\mathrm{x}=\mathrm{x}} \quad=$ discharge or volumic rate of water at the boundary of the watercourse (upstream $x=0$, downstream $x=L)\left(\mathrm{m}^{3} \mathrm{~s}^{-1}\right)$

$w \quad=$ width of the water surface $(\mathrm{m})$

$L \quad=$ length of the waterbody $(\mathrm{m})$

The temperature of water upstream and downstream of the water body is assumed to be equal to the water temperature in the waterbody, hence

$T_{\text {ups }}=T_{w}$

$T_{\text {down }}=T_{w}$ 
Note that by using Eqs (37) and (38) the terms $S_{\text {ups }}$ and $S_{\text {down }}$ in Eqs (33) and (34) have become zero.

Inflow and outflow across lateral boundary of waterbody

The heat inflow due to input of water via runoff $\left(S_{\text {ro }}\right)$, drainage $\left(S_{d r}\right)$ or heat inflow or outflow via the subsurface water flows $\left(S_{\text {sub }}\right)$ are described by:

$$
\begin{aligned}
& S_{r o}=\rho_{w} c_{w} F_{r o}\left(T_{r o}-T_{w}\right) \\
& S_{d r}=\rho_{w} c_{w} F_{d r}\left(T_{d r}-T_{w}\right) \\
& S_{s u b}=\rho_{w} c_{w} F_{s u b}\left(T_{s u b}-T_{w}\right)
\end{aligned}
$$

where

$F_{\text {ro }} \quad=$ areic volume flux from runoff water ${ }^{3}$, i.e. volume of runoff divided by surface area of the water layer $\left(\mathrm{m}^{3} \mathrm{~m}^{-2} \mathrm{~s}^{-1}\right)$

$T_{\text {ro }} \quad=$ temperature of runoff water $(\mathrm{K})$

$F_{\mathrm{dr}} \quad=$ areic volume flux from drainage water, i.e. volume of drainage divided by surface area of the water layer $\left(\mathrm{m}^{3} \mathrm{~m}^{-2} \mathrm{~s}^{-1}\right)$

$T_{\mathrm{dr}} \quad=$ temperature of drainage water $(\mathrm{K})$

$F_{\text {sub }} \quad=$ areic volume flux from subsurface water flow, i.e. volume of subsurface flow divided by surface area of the water layer $\left(\mathrm{m}^{3} \mathrm{~m}^{-2} \mathrm{~s}^{-1}\right)$

$T_{\text {sub }} \quad=$ temperature of subsurface water flow $(\mathrm{K})$

The areic volume flux from runoff is illustrated in Figure 3. The runoff, drainage and subsurface water fluxes are given by

$$
\begin{aligned}
& F_{r o}=\frac{B q_{r o}}{w} \\
& F_{d r}=\frac{B q_{d r}}{w} \\
& F_{s u b}=\frac{B q_{s u b}}{w}
\end{aligned}
$$

where

$B \quad=$ width of the adjacent field (perpendicular to the watercourse) discharging its excess water into the watercourse $(\mathrm{m})$

$q_{\mathrm{ro}}=$ areic volume flux of runoff water of the adjacent field $\left(\mathrm{m}^{3} \mathrm{~m}^{2} \mathrm{~s}^{-1}\right)$

$q_{\mathrm{dr}} \quad=$ areic volume flux of drainage water of the adjacent field $\left(\mathrm{m}^{3} \mathrm{~m}^{2} \mathrm{~s}^{-1}\right)$

$q_{\text {sub }}=$ areic volume flux of subsurface water flow, based on the area of the adjacent field $\left(\mathrm{m}^{3} \mathrm{~m}^{2} \mathrm{~s}^{-1}\right)$ [see also p.22 in Adriaanse and Beltman, 2009]

\footnotetext{
${ }^{3}$ See p. 21 of Adriaanse and Beltman (2009) for definitions used.
} 


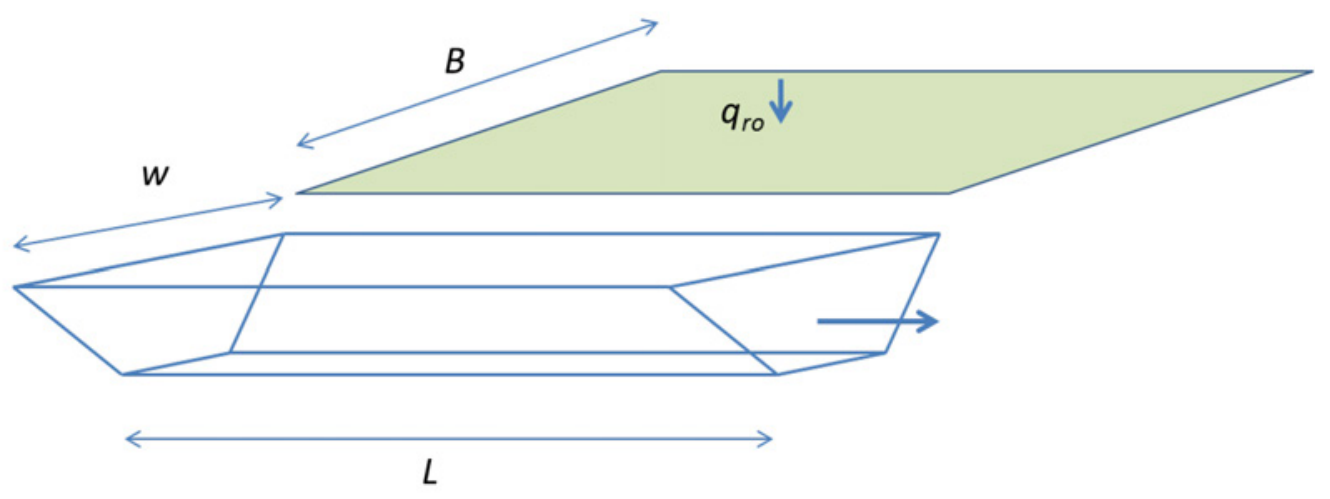

Figure 3 Watercourse with length $L$, width of the water surface $w$, and adjacent field width $B$, for which a runoff flux (per $\mathrm{m}^{2}$ of the field) enters the water body.

When water is leaving the water layer by subsurface flow, i.e. $q_{\text {sub }}<0$, the temperature in the subsurface water flow is assumed to be equal to the water temperature in the waterbody, hence

$T_{\text {sub }}=T_{w}$

Then the term $S_{\text {sub }}$ has become zero. Note that the energy transfer between the subsurface water flow and the water layer has not yet been included in TOXSWA 3.4.

\subsubsection{Water temperatures below $4^{\circ} \mathrm{C}$}

When the simulated water temperature in the TOXSWA model approaches $4{ }^{\circ} \mathrm{C}$ and continues to decrease, we assume that an ice layer is formed (that may grow downwards) and that the water below the ice remains $4^{\circ} \mathrm{C}$. So, the temperature of the water layer under the ice layer is modelled as:

if $T_{w}<277.15 \mathrm{~K}$ then $T_{w}=277.15 \mathrm{~K}$

This is based upon the following reasoning. For fresh water a maximum density is reached at $4{ }^{\circ} \mathrm{C}$ and decreases at lower temperatures down to the freezing point. Density differences related to temperature and effects of wind stimulate turbulence in the water and therefore mixing. When the water temperature reaches $4^{\circ} \mathrm{C}$ and upon further cooling the cooler and less dense water tends to stay on top of a layer of denser, warmer water at the bottom. When freezing conditions occur and sustain, ice is formed at the top and grows downwards (De Bruin and Wessels, 1988).

The followed approach is rather simplified, but because plant protection products are not applied in winter periods, and processes sensitive to temperature slow down at low temperatures, effects on the calculated concentrations are limited.

\subsubsection{Numerical implementation}

The temperature in water is calculated using the energy budget equation (1), implemented numerically as an explicit time stepping scheme:

$$
\begin{aligned}
T_{w}^{i}=T_{w}^{i-1}+ & \\
& \frac{\Delta t}{\rho_{w} c_{w} h^{i}}\left(K_{d}-K_{b}-K_{u}+L_{d}-L_{u}-H-\lambda E+Q_{p r}+G_{s}+\sum S_{\text {ext }}\right)
\end{aligned}
$$


where $i$ is the time step. To take into account freezing conditions the calculated new temperature is checked with:

$$
T_{w}^{i}=\max \left(T_{w}^{i}, 277.15\right)
$$

keeping the temperature in the watercourse at $4^{\circ} \mathrm{C}$.

The temperature of the sediment is assumed to be the same as the temperature of water. Hence

$T_{\text {sed }}^{i}=T_{w}^{i}$

The external heat sources due to runoff, drainage and subsurface flow in the $S$ term in Eq. (47) are calculated with

$$
S_{r o}^{i}=\rho_{w} c_{w} F_{r o}^{i}\left(T_{r o}^{i}-T_{w}^{i-1}\right)
$$

$S_{d r}^{i}=\rho_{w} c_{w} F_{d r}^{i}\left(T_{d r}^{i}-T_{w}^{i-1}\right)$

$q_{\text {sub }}^{i}>0: \quad S_{\text {sub }}^{i}=\rho_{w} c_{w} F_{\text {sub }}^{i}\left(T_{\text {sub }}^{i}-T_{w}^{i-1}\right) \quad$ or $\quad q_{\text {sub }}^{i} \leq 0: \quad S_{\text {sub }}^{i}=0$

The temperatures of runoff water $\left(T_{\mathrm{ro}}\right)$, drainage water $\left(T_{\mathrm{dr}}\right)$ and seepage water $\left(T_{\mathrm{sub}}{ }_{\mathrm{sub}}\right)$ entering the water body are to be delivered by other simulation models, e.g. soil runoff models, soil drainage models or a time series derived otherwise.

The external heat sources for runoff and for seepage entering the waterbody have not yet implemented in the source code of TOXSWA version 3.4. So, only the energy transfer by the drainage entry route is implemented in TOXSWA 3.4.

In the implementation for the GEM application of TOXSWA, where the discharged water volume enters the watercourse at the upstream boundary, Eq. (32) can be supplemented with a term for the greenhouse energy contribution to obtain the temperature of incoming water. Another option is to assume that the temperature of greenhouse water is equal to the temperature in the waterbody (which seems reasonable because water is stored in an outside basin). Then the TOXSWA 3.4 model does not need any changes.

An overview of all constants and parameters that have a fixed value in the TOXSWA code is shown in Annex 6, with their value implemented in TOXSWA. The input needed for a simulation with the module for temperature on hourly basis is described in in Chapter 3. 


\section{Input, output and example calculation}

\subsection{Introduction}

The current version of TOXSWA requires at least two input files: (1) a file with parameter values for the scenario, the substance and the entries of the substance (the txw file), and (2) a file with a time series of temperature or weather data. TOXSWA reports a summary of the results in the summary output file.

New parameters, input data and boundary conditions are required to simulate the temperature in water and in sediment. These have been added to existing files, i.e. the txw file and the e2t file. Several input parameters to calculate the terms of the energy budget and an initial value for the temperature have been added to the *.txw file. Furthermore, a file with hourly values of several weather data is needed, the *.meth file replacing the existing met file. The changes in the txw and meteo input files are described in Section 3.2.

Additional input files are needed when drainage or runoff entries occur (Beltman et al., 2014). Which additional file is needed depends on the model used to calculate these entries; *.e2t file for PEARL, *.m2t file for MACRO and *.p2t file for PRZM. Currently only the connection with PEARL (Van den Berg et al., 2016) is implemented, and described in this report.

The existing drainage entry file generated by PEARL was extended to obtain incoming energy fluxes from source or sink terms. When incoming energy fluxes from other models are to be modelled, equivalent changes need to be made.

TOXSWA writes an additional intermediate file, *.tem file, in which the results of the energy module are written: temperature and all terms of the energy balance of Eq (1). The file is described into detail in Section 3.3.

\subsection{Description of input}

In this section all changes in the *.txw file and in the *.meth file with meteorological data are described. An example of the drainage file made by PEARL, the *.e2t file, is shown and described in Annex 7.

\subsubsection{TOXSWA input file}

The *.txw file consists of 9 sections, of which the sections 5 'Meteo' and 6 'Temperature' were adapted to simulate the temperature on the basis of hourly meteorological data.

\section{Meteo section}

In the Meteo section data on the meteorological station, data needed to convert meteorological data i.e. coordinates, time zone and reference levels, as well as data required to calculate shortwave radiation when there are missing observations of this quantity need to be entered.

The name of the file (Meteostation) and the type of input data (OptMetInp) must be given in the file (see Figure 4). For the hourly option the meteo file must have the extension "meth" ("met" for the monthly option). If the option is "monthly" no further input is needed in the Meteo section.

When the option is "hourly", the location of the meteo station must be provided by specifying its latitude, $\Phi$, (LocLat) (positive north) and its longitude, $\Lambda$, (LocLong) (positive west) and also the time 
zone (Timzone) of the location. TOXSWA calculates the latitude and longitude in radians by multiplication with a factor $(\pi / 180)$.

To correct the meteorological data from their value at the observation level $z_{\mathrm{obs}}$ (MetLvlobs) to the reference level $z_{r}$, (MetLvlRef) used in TOXSWA, these levels must be specified.

When values for shortwave radiation are missing, TOXSWA fills the gaps by calculating the shortwave radiation at a location for an average atmospheric attenuation, given by $a_{1}, a_{2}$ (FacAtmWavLenShort1, FacAtmWavLenShort2) and for cloud contribution $b_{1}, b_{2}$ (FacCldB1, FacCldB2) (see also Annex 4). For the central Netherlands, default values for De Bilt are used: $a_{1}=1041 \mathrm{~W} \mathrm{~m}^{-2}$ and $a_{2}=-69 \mathrm{~W} \mathrm{~m}^{-2}$. Values for $b_{1}$ and $b_{2}$ derived from measurements in Western Europe are -0.75 and 3.4, respectively (Jacobs et al. 2010).

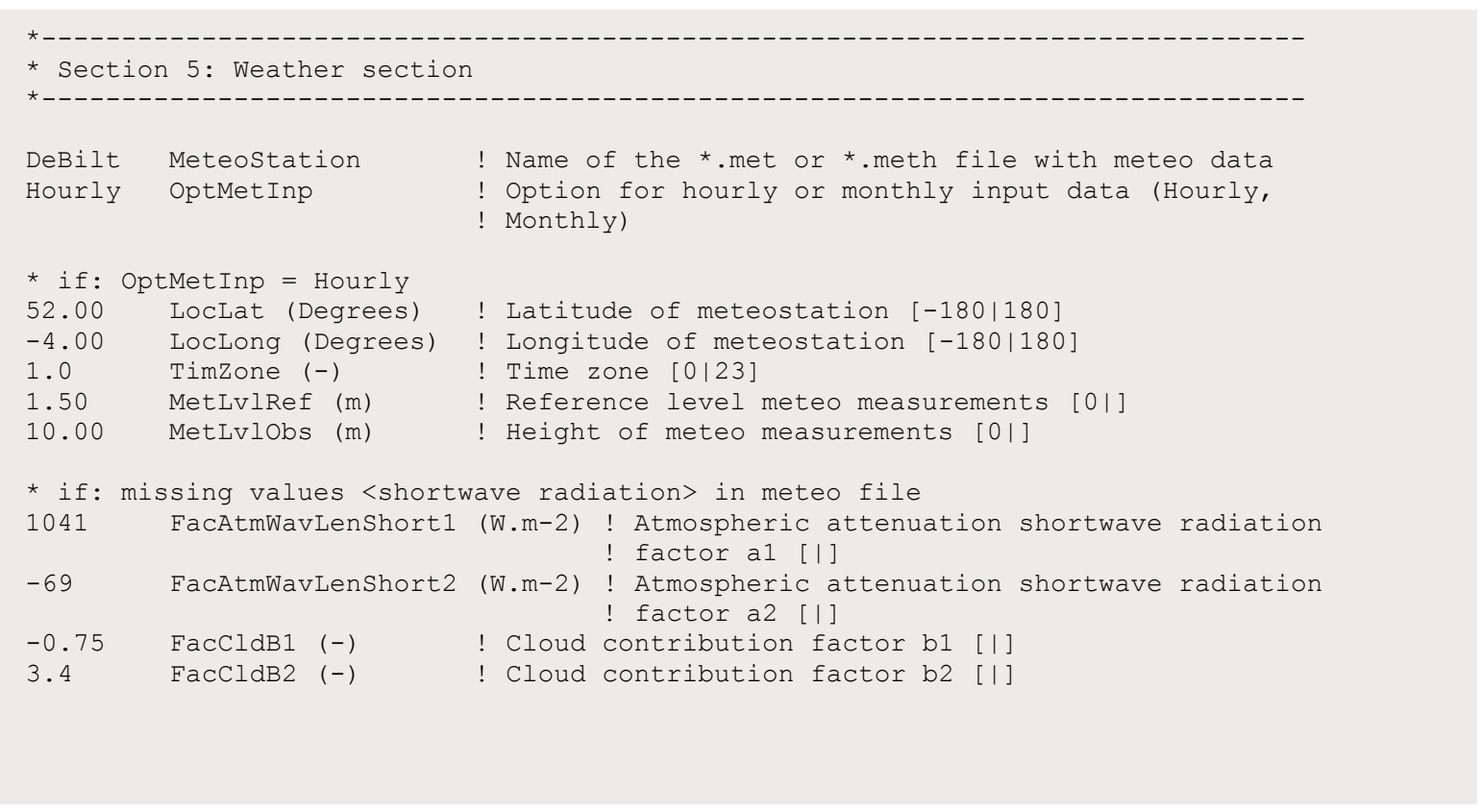

Figure 4 Excerpt from the TOXSWA input *.txw file, section with input for weather data.

\section{Temperature section}

In the main input file a temperature section was added (see Figure 5). The input of this section needs only be given when the type of input data (OptMetInp) is "hourly".

The initial temperature in the water layer (TemWatIni) must be entered along with the attenuation factors, $\mu_{j}$, for the PAR and NIR wavelength bands (CofSorPAR, CofSorNIR) to calculate the contribution of shortwave radiation to the energy budget of the water.

Attention should be paid to the time that is needed for the temperature simulation to become independent of the initial water temperature. There are no explicit rules to estimate the required spinup time. For the shallow waterbodies mostly simulated by TOXSWA, it is recommended to calibrate the intitial temperature via repetitive calculations. Do a first simulation with a best guess value of the initial temperature, hence $T_{\text {initial }}=T_{1}$. As a best guess value for the first simulation the air temperature can be used. Then repeat the simulation, and set the initial temperature to the previous initial temperature plus the difference between the temperature calculated at the end of Day 1 and the previous initial temperature (hence new $T_{\text {initial }}=T_{1}+\left(T_{\text {Day } 1}-T_{1}\right)$. Repeat these steps, until the temperature at the end of Day 1 does not change anymore. This calibrated temperature can be used as initial temperature in the simulation. 


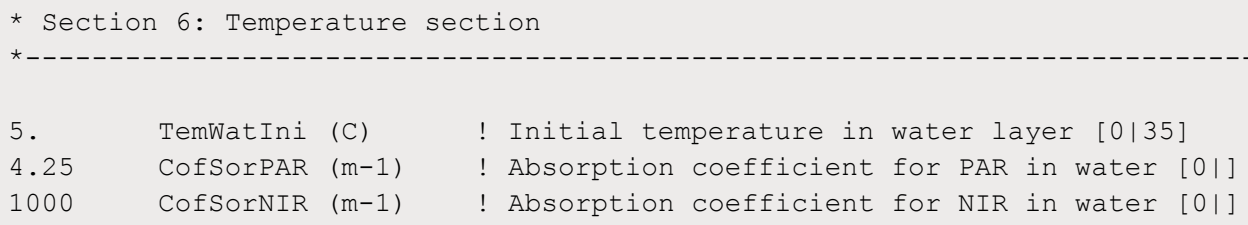

Figure 5 Excerpt from the TOXSWA input *.txw file, section with input for temperature data.

\subsubsection{Meteo input file}

There are two types of meteo files that can be used by TOXSWA, one of which is needed for a particular simulation. The two types are:

- monthly meteo file, providing the monthly temperature of the air, used with FOCUS surface water scenarios. This file type has extension "met".

- hourly meteo file, providing hourly meteorological data. This file type has extension "meth".

TOXSWA needs the hourly meteo file to simulate the temperature in water and in sediment from weather data. An example of the hourly meteo file for TOXSWA is given in Figure 6 . The times are given in UTC.

\begin{tabular}{|c|c|c|c|c|c|c|c|c|c|c|c|c|}
\hline * $\quad$ MSTAT & YYYY & MM & DD & $\mathrm{HH}$ & $\begin{array}{r}\text { RAD } \\
k J \cdot m-2\end{array}$ & $\begin{array}{l}\mathrm{T} \\
\mathrm{C}\end{array}$ & $\begin{array}{r}\text { HUM } \\
-\end{array}$ & $\begin{array}{r}\text { CLD } \\
-\end{array}$ & $\begin{array}{r}\text { WIND } \\
\mathrm{m} \cdot \mathrm{s}-1\end{array}$ & $\begin{array}{r}\mathrm{PA} \\
\mathrm{kPa}\end{array}$ & $\begin{array}{r}\text { RAIN } \\
\text { mm }\end{array}$ & $\begin{array}{r}\text { ETref } \\
\mathrm{mm}\end{array}$ \\
\hline \multicolumn{13}{|c|}{ 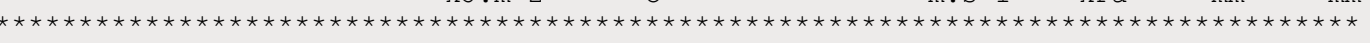 } \\
\hline 'DeBilt' & 1981 & 1 & 1 & 1 & 0 & 6.3 & 0.75 & 0.62 & 7.7 & 101.28 & 0.2 & -99.9 \\
\hline 'DeBilt' & 1981 & 1 & 1 & 2 & 0 & 5.7 & 0.77 & 0.38 & 7.7 & 101.26 & 0.0 & -99.9 \\
\hline 'DeBilt' & 1981 & 1 & 1 & 3 & 0 & 5.6 & 0.77 & 0.25 & 8.2 & 101.29 & 0.0 & -99.9 \\
\hline 'DeBilt' & 1981 & 1 & 1 & 4 & 0 & 4.8 & 0.72 & 0.38 & 7.7 & 101.36 & 0.0 & -99.9 \\
\hline 'DeBilt' & 1981 & 1 & 1 & 5 & 0 & 5.1 & 0.63 & 0.12 & 7.2 & 101.43 & 0.0 & -99.9 \\
\hline 'DeBilt' & 1981 & 1 & 1 & 6 & 0 & 3.5 & 0.83 & 0.75 & 7.7 & 101.47 & 0.0 & -99.9 \\
\hline 'DeBilt' & 1981 & 1 & 1 & 7 & 0 & 4.3 & 0.73 & 1.00 & 7.2 & 101.53 & 0.0 & -99.9 \\
\hline 'DeBilt' & 1981 & 1 & 1 & 8 & 0 & 0.7 & 0.98 & 1.00 & 8.7 & 101.65 & 3.0 & -99.9 \\
\hline 'DeBilt' & 1981 & 1 & 1 & 9 & 270 & 2.3 & 0.87 & 0.50 & 6.2 & 101.71 & 0.0 & -99.9 \\
\hline 'DeBilt' & 1981 & 1 & 1 & 10 & 520 & 5.2 & 0.66 & 0.50 & 7.2 & 101.73 & 0.0 & -99.9 \\
\hline 'DeBilt' & 1981 & 1 & 1 & 11 & 700 & 5.3 & 0.69 & 0.75 & 7.7 & 101.83 & 0.0 & -99.9 \\
\hline 'DeBilt' & 1981 & 1 & 1 & 12 & 500 & 5.2 & 0.71 & 0.75 & 8.7 & 101.87 & 0.0 & -99.9 \\
\hline 'DeBilt' & 1981 & 1 & 1 & 13 & 210 & 3.3 & 0.86 & 0.88 & 6.7 & 101.95 & 0.1 & -99.9 \\
\hline 'DeBilt' & 1981 & 1 & 1 & 14 & 90 & 3.2 & 0.81 & 0.50 & 5.1 & 102.00 & 1.1 & -99.9 \\
\hline 'DeBilt' & 1981 & 1 & 1 & 15 & 10 & 3.5 & 0.77 & 0.50 & 5.1 & 102.11 & 0.2 & -99.9 \\
\hline 'DeBilt' & 1981 & 1 & 1 & 16 & 0 & 3.2 & 0.80 & 0.38 & 5.7 & 102.16 & 0.0 & -99.9 \\
\hline 'DeBilt' & 1981 & 1 & 1 & 17 & 0 & 3.3 & 0.84 & 0.88 & 4.6 & 102.24 & 0.1 & -99.9 \\
\hline 'DeBilt' & 1981 & 1 & 1 & 18 & 0 & 2.9 & 0.86 & 1.00 & 2.6 & 102.24 & 0.4 & -99.9 \\
\hline 'DeBilt' & 1981 & 1 & 1 & 19 & 0 & 4.0 & 0.79 & 0.62 & 3.1 & 102.24 & 0.0 & -99.9 \\
\hline 'DeBilt' & 1981 & 1 & 1 & 20 & 0 & 4.5 & 0.79 & 0.88 & 4.6 & 102.24 & 0.1 & -99.9 \\
\hline 'DeBilt' & 1981 & 1 & 1 & 21 & 0 & 4.5 & 0.81 & 0.75 & 4.1 & 102.24 & 0.3 & -99.9 \\
\hline 'DeBilt' & 1981 & 1 & 1 & 22 & 0 & 5.0 & 0.78 & 0.88 & 5.1 & 102.24 & 0.0 & -99.9 \\
\hline 'DeBilt' & 1981 & 1 & 1 & 23 & 0 & 5.1 & 0.83 & 0.88 & 5.7 & 102.20 & 0.0 & -99.9 \\
\hline 'DeBilt' & 1981 & 1 & 1 & 24 & 0 & 4.6 & 0.87 & 0.88 & 5.1 & 102.16 & 0.7 & -99.9 \\
\hline 'DeBilt' & 1981 & 1 & 2 & 1 & 0 & 4.1 & 0.89 & 1.00 & 4.1 & 102.17 & 0.4 & -99.9 \\
\hline 'DeBilt' & 1981 & 1 & 2 & 2 & 0 & 3.6 & 0.95 & 1.00 & 4.1 & 102.11 & 1.2 & -99.9 \\
\hline 'DeBilt' & 1981 & 1 & 2 & 3 & 0 & 4.6 & 0.95 & 1.00 & 3.6 & 102.03 & 0.1 & -99.9 \\
\hline
\end{tabular}

Figure 6 Example of a meteo input file, DeBilt.meth, with hourly values of meteorological data.

The description of the headers of the columns in the "meth" file is given in Table 2. Also, the name of the parameter used in this report and the equation number in which it is applied is given. In TOXSWA the values are converted into S.I. units. Note that the shortwave radiation is therefore divided by the number of seconds in the hour and by 1000 , to obtain the unit of $\mathrm{W} / \mathrm{m}^{2}\left(\mathrm{~J} \mathrm{~m}^{-2} \mathrm{~s}^{-1}\right)$. Shortwave radiation read from the meteorological file is used in TOXSWA as input for global radiation (see Section 2.2.2). 
Table 2 Description of header of the meteo file, *.meth, with reference to the parameters and equations given in Chapter 2.

\begin{tabular}{|c|c|c|c|}
\hline $\begin{array}{l}\text { Parameter in } \\
\text { "meth" ffle }\end{array}$ & Unit & Description & $\begin{array}{c}\text { Parameter and } \\
\text { equation } \mathrm{nr}\end{array}$ \\
\hline MSTAT & - & name of meteo station & - \\
\hline MM & - & month & - \\
\hline DD & - & day & - \\
\hline $\mathrm{T}$ & ${ }^{\circ} \mathrm{C}$ & temperature at reference level & $T_{\mathrm{r}}(18)$ \\
\hline HUM & - & relative atmospheric humidity at reference level (relative to $1(=100 \%)$ ) & $H_{\mathrm{r}}(180 \mathrm{0})$ \\
\hline CLD & octants & cloud cover, (and 9=sky invisible) & $N(17)$ \\
\hline WIND & $\mathrm{m} / \mathrm{s}$ & hourly mean wind speed at observation level & $u_{\text {obs }}(27)$ \\
\hline
\end{tabular}

Atmospheric temperature (T) and relative humidity (HUM) were measured at a height of $1.50 \mathrm{~m}$ for this meteorological station, which is the reference level $z_{r}$ to be entered in the *.txw file (see Section 3.2.1). The cloud cover is recorded in octants 1 to 8 . The values given are the hourly observations in a natural day. The octant number is translated in the meteo file by dividing the octant number by 8 resulting in values ranging from zero (octant value is 0 ) to 1 (octant value is 8 ). For octant value 9 the cloud cover is also set to 1 . The wind speed (WIND) was measured at a height of $10 \mathrm{~m}$, which is the observation level $z_{\mathrm{obs}}$ to be entered in the *.txw file (see Section 3.2.1). The socalled reference evaporation (ETref) is not used by TOXSWA at present.

\subsection{Description of output}

\subsubsection{The intermediate temperature file}

Output related to the temperature is written in a file with extension "tem". In this file, the temperature in water and in sediment and all simulated energy fluxes are reported for every time step. This file is used by TOXSWA as input for the substance calculation loop of the TOXSWA kernel.

An example of the *.tem file is given in Figure 7. The explanation of the header of the file is given in Table 3, in which the equations of Chapter 2 are indicated, used to calculate the mentioned output.

Table 3 Description of header of the intermediate temperature file, *.tem, with reference to the parameters and equations given in Chapter 2.

\begin{tabular}{|c|c|c|c|}
\hline $\begin{array}{l}\text { Parameter in } \\
\text { "tem" file }\end{array}$ & Unit & Description & $\begin{array}{c}\text { Parameter and } \\
\text { equation } \mathrm{nr}\end{array}$ \\
\hline Time & d & time & \\
\hline TemWat & $\mathrm{K}$ & water temperature & $T_{\mathrm{w}}(1)$ \\
\hline TemSed & $\mathrm{K}$ & sediment temperature & $T_{\text {sed }}(49)$ \\
\hline FleRadShoBot & W.m-2 & shortwave radiation absorbed by sediment & $K_{\mathrm{b}}(4)$ \\
\hline FleRadShoUpw & W.m-2 & reflected short wave radiation & $K_{\mathrm{u}}(16)$ \\
\hline FleRadLonDow & W.m-2 & incoming longwave radiation & $L_{d}(17)$ \\
\hline FleRadLonUpw & W.m-2 & reflected longwave radiation & $L_{u}(19)$ \\
\hline HeaFIxPrc & W.m-2 & exchange of heat through precipitation & $Q_{\mathrm{pr}}(28)$ \\
\hline HeaFlxExt & W.m-2 & other heat sources and sinks & $\Sigma S(32)$ \\
\hline
\end{tabular}




\begin{tabular}{|c|c|c|c|c|c|c|c|c|c|c|c|c|c|c|c|}
\hline $\begin{array}{ll}* & \text { Time } \\
* & \text { (d) } \\
* & \end{array}$ & $\begin{array}{r}\text { Date } \\
\text { (date) }\end{array}$ & $\begin{array}{r}\text { TemWat } \\
\text { (K) }\end{array}$ & $\begin{array}{c}\text { DepwatAvgRep } \\
(\mathrm{m})\end{array}$ & $\begin{array}{r}\text { FleRadShoDow } \\
\text { (W.m-2) }\end{array}$ & $\begin{array}{r}\text { FleRadShoBot } \\
\text { (W.m-2) }\end{array}$ & $\begin{array}{r}\text { FleRadShoUpw } \\
(\text { (W.m-2) }\end{array}$ & $\begin{array}{r}\text { FleRadLonDow } \\
(\mathrm{W} \cdot \mathrm{m}-2)\end{array}$ & $\begin{array}{l}\text { WleRadLonUpw } \\
\text { (w.m-2) }\end{array}$ & W SensHeaF & $\begin{array}{r}\text { a XAirwat } \\
\text { (W.m-2) }\end{array}$ & VapHeaF & $\begin{array}{r}\text { aFl xAirWat } \\
\text { (W.m-2) }\end{array}$ & $\begin{array}{l}\text { t) SensHeaFlxwatsed } \\
\text { (W.m-2) }\end{array}$ & 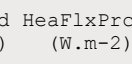 & $\begin{array}{l}\text { HearlxExt } \\
\text { (W.m-2) }\end{array}$ \\
\hline 0.042 & 01-Jan-1986-01h00 & 277.1500 & 0.3200 & 0.0000 & 0.0000 & 0.0000 & 243.7742 & 336.5217 & & 187.6567 & & 133.0164 & 0.0000 & 0.0000 & 0.0000 \\
\hline 0.083 & 01 -Jan-1986-02h00 & 277.1500 & 0.3200 & 0.0000 & 0.0000 & 0.0000 & 253.6462 & 332.1091 & & 188.3067 & & 136.9107 & 0.0000 & 0.0000 & 0.0000 \\
\hline 0.125 & 01-Jan-1986-03h00 & 277.1500 & 0.3200 & 0.0000 & 0.0000 & 0.0000 & 254.8506 & 332.1452 & & 202.0482 & & 156.5580 & 0.0000 & 0.0000 & 0.0000 \\
\hline 0.167 & $01-J a n-1986-04 \mathrm{~h} 00$ & 277.1500 & 0.3200 & 0.0000 & 0.0000 & 0.0000 & 262.9353 & 332.3878 & & 201.9878 & & 158.1557 & 0.0000 & 0.0000 & 0.0000 \\
\hline 0.208 & 01 -Jan-1986-05h00 & 277.1500 & 0.3200 & 0.0000 & 0.0000 & 0.0000 & 262.2798 & 332.3681 & & 181.5729 & & 139.4251 & 0.0000 & 0.0000 & 0.0000 \\
\hline 0.250 & 01-Jan-1986-06h00 & 277.1500 & 0.3200 & 0.0000 & 0.0000 & 0.0000 & 265.3400 & 332.4599 & & 194.5056 & & 149.8978 & 0.0000 & 0.0000 & 0.0000 \\
\hline 0.292 & 01-Jan-1986-07hoo & 277.1500 & 0.3200 & 0.0000 & 0.0000 & 0.0000 & 267.3107 & 332.5190 & & 162.2294 & & 127.4807 & 0.0000 & 0.0000 & 0.0000 \\
\hline 0.333 & 01-Jan-1986-08ho0 & 277.1500 & 0.3200 & 0.0000 & 0.0000 & 0.0000 & 267.9854 & $\begin{array}{l}332.5393 \\
332\end{array}$ & & 201.7878 & & 162.1161 & 0.0000 & 0.0000 & 0.0000 \\
\hline $\begin{array}{l}0.375 \\
0.417\end{array}$ & $\begin{array}{l}\text { 1-Jan-1986-09hoo } \\
\text { o1-Jan-1986-10hoo }\end{array}$ & $\begin{array}{l}277.1500 \\
277.1500\end{array}$ & $\begin{array}{l}0.3200 \\
0.3200\end{array}$ & $\begin{array}{r}2.7778 \\
22.2222\end{array}$ & $\begin{array}{l}0.0000 \\
0.4471\end{array}$ & $\begin{array}{r}2.7778 \\
17.7465\end{array}$ & $\begin{array}{l}268.6150 \\
269.2965\end{array}$ & $\begin{array}{l}332.5582 \\
332.5786\end{array}$ & & 201.6871 & & $\begin{array}{l}158.2921 \\
157.4858\end{array}$ & 0.0000 & 0.0000 & 0.0000 \\
\hline $\begin{array}{l}0.417 \\
0.458\end{array}$ & 01 -Jan-1986-11h00 & 277.1500 & $\begin{array}{l}0.3200 \\
0.3200\end{array}$ & $\begin{array}{l}22.2222 \\
38.8889\end{array}$ & $\begin{array}{l}0.4471 \\
3.5756\end{array}$ & $\begin{array}{r}1 . .465 \\
3.0974\end{array}$ & $\begin{array}{l}269.2965 \\
270.6116\end{array}$ & 332.6181 & & $\begin{array}{l}196.1948 \\
190.5794\end{array}$ & & $\begin{array}{l}151.4858 \\
152.7695\end{array}$ & 0.0000 & 0.0000 & 0.0000 \\
\hline 0.500 & 01 -Jan-1986-12hoo & 277.1500 & 0.3200 & 72.2222 & 6.6573 & 5.5826 & 273.2540 & $\begin{array}{l}332.6181 \\
332.6973\end{array}$ & & $\begin{array}{l}19.5 / 94 \\
199.1612\end{array}$ & & 158.6250 & 0.0000 & 0.0000 & 0.0000 \\
\hline 0.542 & $01-J a n-1986-13 \mathrm{~h} 00$ & 277.1500 & 0.3200 & 61.1111 & 5.6604 & 4.4510 & 275.7088 & 332.7710 & & $\begin{array}{l}199.1612 \\
171.3659\end{array}$ & & $\begin{array}{l}158.6250 \\
132.4644\end{array}$ & 0.0000 & 0.0000 & 0.0000 \\
\hline 0.583 & 01 -Jan-1986-14h00 & 277.1500 & 0.3200 & 44.4444 & 4.1207 & 3.1968 & 276.6261 & 332.7985 & & 127.7682 & & 103.3616 & 0.0000 & 0.0000 & 0.0000 \\
\hline 0.625 & $01-J a n-1986-15 h 00$ & 277.1500 & 0.3200 & 27.7778 & 2.5759 & 1.9926 & 279.6252 & 332.8885 & & 135.9115 & & 106.4241 & 0.0000 & 0.0000 & 0.0000 \\
\hline 0.667 & 01-Jan-1986-16h00 & 277.1500 & 0.3200 & 5.5556 & 0.5156 & 0.3939 & 280.1451 & 332.9041 & & 133.3988 & & 104.9924 & 0.0000 & 0.0000 & 0.0000 \\
\hline 0.708 & $01-J a n-1986-17 h 00$ & 277.1500 & 0.3200 & 0.0000 & 0.0000 & 0.0000 & 280.8755 & 332.9260 & & 128.6104 & & 104.0817 & 0.0000 & 0.0000 & 0.0000 \\
\hline 0.750 & 01-Jan-1986-18hoo & 277.1500 & 0.3200 & 0.0000 & 0.0000 & 0.0000 & 282.2346 & 332.9668 & & 138.8061 & & 111.2800 & 0.0000 & 0.0000 & 0.0000 \\
\hline 0.792 & $01-J a n-1986-19 h 00$ & 277.1500 & 0.3200 & 0.0000 & 0.0000 & 0.0000 & 282.2346 & 332.9668 & & 153.7240 & & 123.3756 & 0.0000 & 0.0000 & 0.0000 \\
\hline 0.833 & 01-Jan-1986-20hoo & 277.1500 & 0.3200 & 0.0000 & 0.0000 & 0.0000 & 282.7595 & 332.9825 & & 150.5864 & & 121.5440 & 0.0000 & 0.0000 & 0.0000 \\
\hline 0.875 & $01-J a n-1986-21$ hoo & 277.1500 & 0.3200 & 0.0000 & 0.0000 & 0.0000 & 283.2854 & 332.9983 & & 164.8891 & & 133.7846 & 0.0000 & 0.0000 & 0.0000 \\
\hline 0.917 & $01-J a n-1986-22 \mathrm{~h} 00$ & 277.1500 & 0.3200 & 0.0000 & 0.0000 & 0.0000 & 283.2854 & 332.9983 & & 164.7233 & & 133.7846 & 0.0000 & 0.0000 & 0.0000 \\
\hline 0.958 & $01-J a n-1986-23 h 00$ & 277.1500 & 0.3200 & 0.0000 & 0.0000 & 0.0000 & 281.9207 & 332.9573 & & 171.0848 & & 140.6778 & 0.0000 & 0.0000 & 0.0000 \\
\hline 1.000 & 02-Jan-1986 & 277.1500 & 0.3200 & 0.0000 & 0.0000 & 0.0000 & 281.0816 & 332.9322 & & 174.1484 & & 145.4619 & 0.0000 & 0.0000 & 0.0000 \\
\hline 1.042 & 02-Jan-1986-01hoo & 277.1500 & 0.3200 & 0.0000 & 0.0000 & 0.0000 & 280.8755 & 332.9260 & & 177.2596 & & 144.6990 & -4.6493 & 0.0000 & 0.0000 \\
\hline
\end{tabular}

Figure 7 Example of intermediate *.tem file, with hourly values of temperature and terms of the energy balance, as calculated by TOXSWA. 


\subsection{Example calculation}

An example of the simulation of water temperature using hourly meteorological data is presented in Figure 8 and Figure 9 . The system modelled is a pond of $32 \mathrm{~cm}$ deep. Meteorological data of the weather station De Bilt in the Netherlands were used. The sections of the TOXSWA input file that are relevant for the simulation of water temperature are given in Annex 8.

In the figures it is shown that at a seasonal scale the water temperature follows the air temperature in time. Looking at the diurnal variation it can be seen that the water temperature may lag somewhat behind (see Figure 9). The maximum values of the water temperature are lower than the maximum values of the air temperature, and the minimum values of the water temperature are higher than the minimum values of the air temperature. The difference between the water temperature and the air temperature can be large sometimes, e.g. at day 121 . Note that in periods that the calculated water temperature is below $4^{\circ} \mathrm{C}$, the temperature was set to $4^{\circ} \mathrm{C}$ (see Section 2.2 .8 ).

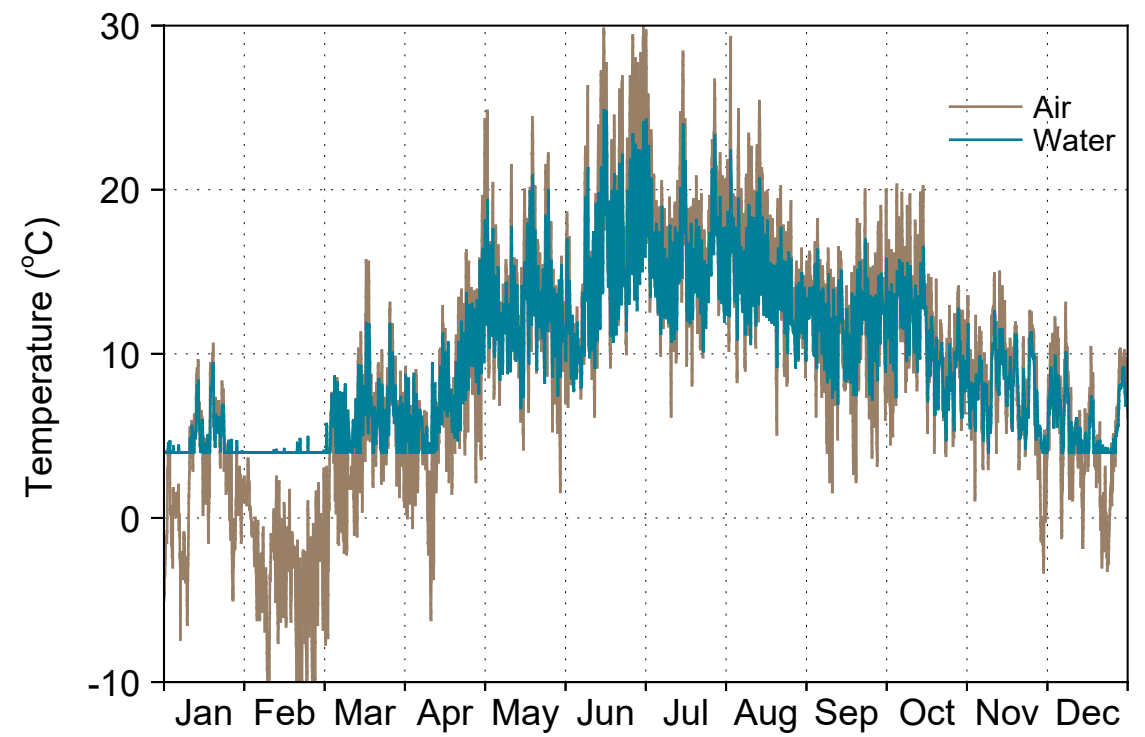

Figure $8 \quad$ Temperature of air and of water in 1986 in a $32 \mathrm{~cm}$ deep pond. Water temperature is calculated with TOXSWA using hourly meteorological data from De Bilt.

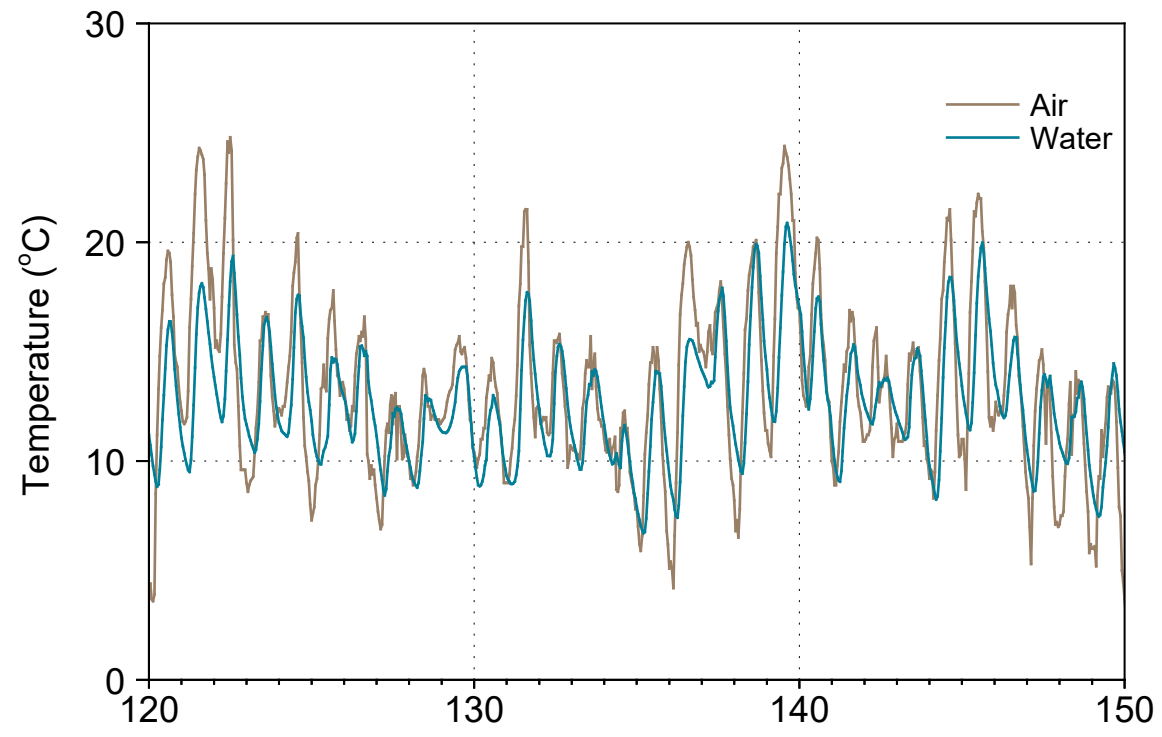

Figure 9 Temperature of air and of water from 1 May to 30 May 1986 in a $32 \mathrm{~cm}$ deep pond. The water temperature was calculated with TOXSWA using hourly meteorological data from De Bilt. 


\section{$4 \quad$ Verification of temperature concept in the TOXSWA model}

\subsection{Introduction}

To verify the implementation of the temperature concept in TOXSWA, simulation results achieved with the newest version of TOXSWA were compared with results of the temperature model implemented in a spreadsheet (Jacobs et al., 2010). Also, the robustness of TOXSWA was tested at extremely high temperatures. There is no need to test robustness at extremely low temperatures because decrease of the water temperatures below $4^{\circ} \mathrm{C}$ is prevented in TOXSWA. The implementation of the concept to account for the contribution of external energy via drainage as documented in this report was also tested.

This chapter describes three separate tests that were applied to check the calculation of the water temperature:

Test 1: Implementation of the temperature of water calculated from hourly meteorological data was tested against an implementation of the SIM3 model in a spreadsheet described by Jacobs et al. (2010). The implementation was considered correct when the calculated temperatures were the same.

Test 2: Robustness at high water temperature was tested by means of calculations that use hourly meteorological data expected to cause high temperatures. The model was considered robust when the calculated temperatures were plausible and did not show irregular responses or results.

Test 3: A comparison was made between a TOXSWA result for the contribution of external energy via drainage water against an equation for calculation of water temperature due to entry of drainage water. The implementation was considered correct when the calculated temperatures were the same.

\subsection{Test 1: Comparison of water temperature calculated by TOXSWA and through SIM3 simulation of Jacobs et al.}

\subsubsection{Setup of the test}

To compare water temperatures calculated by TOXSWA with water temperatures calculated by the spreadsheet version of the SIM3 model of Jacobs et al. (2010) calculations were done with both models. Simulations were performed for the period 1 January to 31 December 1986 . The aerodynamic roughness $\left(z_{0}\right)$ was set to $0.03 \mathrm{~m}$. The parameterisation of the $32 \mathrm{~cm}$ deep pond described in Section 3.4 was used for the test (see also Jacobs et al., 2010).

\subsubsection{Results and discussion}

Figure 10 shows the water temperature in May 1986 simulated by TOXSWA and by the SIM3 spreadsheet model of Jacobs et al. (2010). The red curve of the TOXSWA simulation is the same as the blue curve of the TOXSWA simulation shown in Figure 8. The temperatures calculated by the two model versions are the same during the whole year of 1986, except for the periods during which the water temperature calculated by SIM3 drops below $4^{\circ} \mathrm{C}$ (not shown). Whereas the spreadsheet model allows temperatures below $4{ }^{\circ} \mathrm{C}$, TOXSWA limits temperatures to $4{ }^{\circ} \mathrm{C}$ or higher. This result indicates that the concept for water temperature calculated from hourly meteorological data was implemented correctly in TOXSWA. 


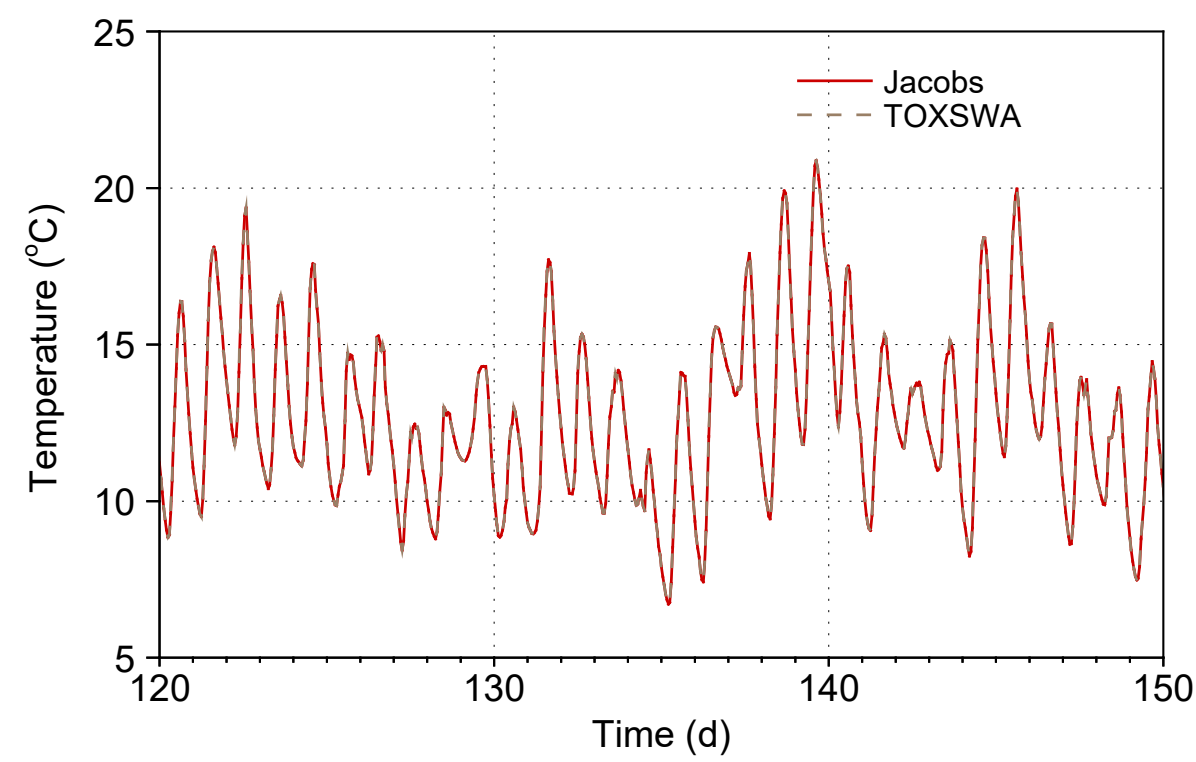

Figure 10 Water temperature from 1 May to 30 May 1986 (day 120 to 150) in a $32 \mathrm{~cm}$ deep pond, calculated by TOXSWA and by the SIM3 spreadsheet of Jacobs et al. (2010) using hourly meteorological data from De Bilt.

\subsection{Test 2: Robustness of the TOXSWA model for high water temperatures}

\subsubsection{Setup of the test}

To test the robustness of TOXSWA at high water temperatures, input was set to create conditions that result in high water temperatures; the latitude was set to the equator (latitude $=0$ ) and a low water depth of $10 \mathrm{~cm}$ was used. The meteorological forcing were set to cause high water temperatures during a daylight period of 12 hours (see Annex 9). The extreme conditions are high values for air temperature $\left(50{ }^{\circ} \mathrm{C}\right)$, solar radiation $\left(833 \mathrm{~W} / \mathrm{m}^{2}\right)$ and air moisture content $(90 \%)$, combined with low values for wind velocity $(0.5 \mathrm{~m} / \mathrm{s})$ and a clear sky. All values were taken constant during the entire daylight period between 6 and 18 hours, thus ignoring diurnal variations. The parameterisation of the pond described in Section 3.4 was used for the test, except for the water depth. Starting with an initial water temperature of $25^{\circ} \mathrm{C}$ a period of 10 days was simulated.

\subsubsection{Results and discussion}

The results of the test are shown in Figure 11 . Within the first day the temperature increases to $55^{\circ} \mathrm{C}$. From then on a regular pattern of decrease to $38^{\circ} \mathrm{C}$ in the night an increase to $55 / 56^{\circ} \mathrm{C}$ in daytime can be seen. Further increases and even stronger variations of the water temperature due to the input of shortwave radiation are prevented by compensating heat fluxes and outgoing longwave radiation. There is only a slight increase of the extreme values over the 10 day period. TOXSWA does not take into account decreases in the water level because of evaporation. This effect would be significant for this shallow system would probably result in a further increase of temperature because of the reduced depth. The pattern shown in the graph does not indicate irregular behaviour of the model. Hence the robustness of the model is not contradicted by the outcome of the test. 


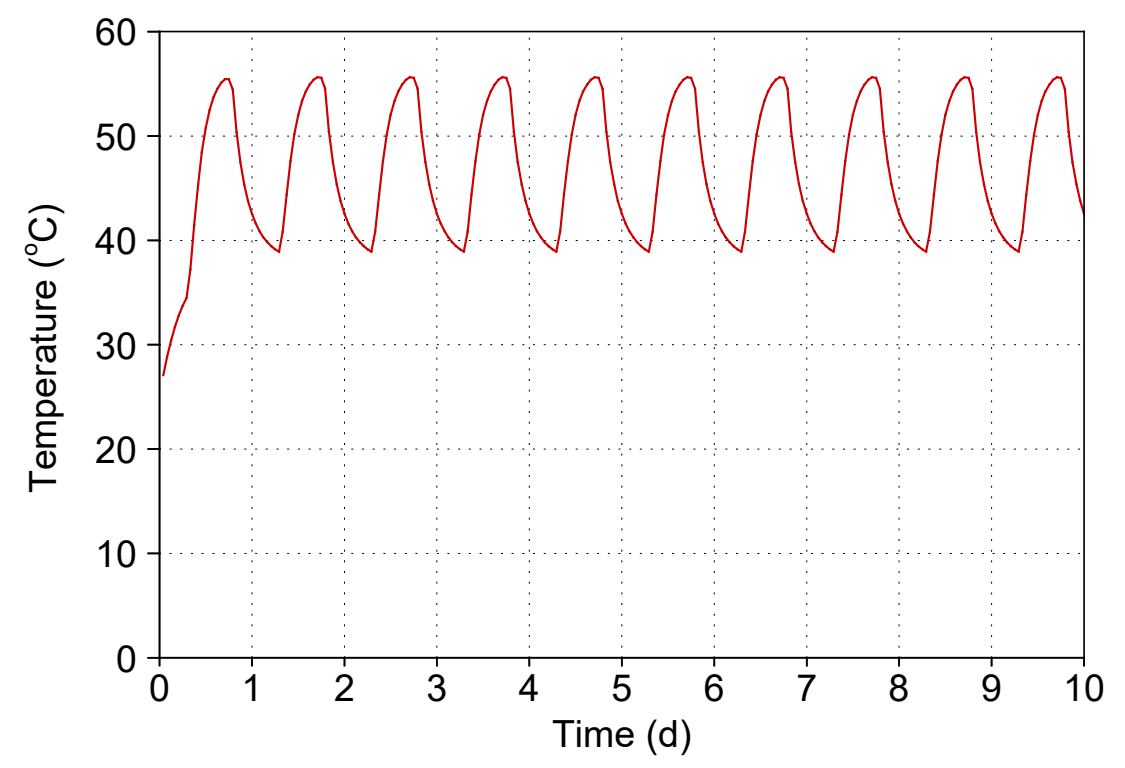

Figure 11 Temperature of water up to 10 days in a $10 \mathrm{~cm}$ deep pond situated at the equator with an initial water temperature of $25^{\circ} \mathrm{C}$, applying conditions favouring heating the water layer, calculated by TOXSWA.

\subsection{Test 3: Contribution of external energy from drainage}

\subsubsection{Setup of the test}

To test the implementation of the contribution of drainage to the energy budget, a simulation with TOXSWA was set up and compared to a numerical solution programmed in MS Excel ${ }^{\circledR}$. The TOXSWA code was temporarily changed in order to study the effect of the contribution of drainage to the energy balance in isolation, completely ignoring the influence of meteorological conditions. Hence the calculated temperature was determined only by the initial temperature and by the contribution from drainage. This version of the model was tested against a numerical solution derived from (47) combined with Eq. (51). All energy budget terms except the term for the external contribution were set to zero, resulting in:

$$
T_{w}^{i}=T_{w}^{i-1}+\frac{\Delta t}{h^{i}} \frac{B q_{d r}^{i}}{w^{i}}\left(T_{d r}^{i}-T_{w}^{i-1}\right)
$$

The test was performed assuming the ditch with a length of $350 \mathrm{~m}$, an initial average water depth of $0.206 \mathrm{~m}$ (giving a representative depth of $0.174 \mathrm{~m}$ for the temperature calculation) and a width at the water surface of $2.52 \mathrm{~m}$ as simulated by Tiktak et al. (2012). For the other input parameters used we refer to Tiktak et al. (2012). Because the drain flow was constant during the simulation the water depth and width of the water surface did not change during the simulation period.

A period of 4 days with constant drainage flow consisting of $0.002 \mathrm{~m}^{3} \mathrm{~m}^{-2} \mathrm{~d}^{-1}$ micropore flow and $0.01 \mathrm{~m}^{3} \mathrm{~m}^{-2} \mathrm{~d}^{-1}$ macropore flow was simulated by PEARL. These flows are in the range of the highest flows simulated by PEARL in the period 1986 - 2006, and are typical for the months February - March and November - December. The sum of the two flows, $0.012 \mathrm{~m}^{3} \mathrm{~m}^{-2} \mathrm{~d}^{-1}$, is equivalent to $0.476 \mathrm{~m}^{3} \mathrm{~d}^{-1}$ of water per $\mathrm{m}^{2}$ of the water surface $\left(B . q_{\mathrm{dr}} / w\right)$. Division by the representative water depth indicates that the water volume of the ditch is replaced 2.7 times per day. The temperatures of drain water were set stepwise in two blocks. At days 1 and 2 the temperatures of micropore water and of macropore water were set to $25^{\circ} \mathrm{C}$ and to $20^{\circ} \mathrm{C}$, respectively. At days 3 and 4 they were set to $10^{\circ} \mathrm{C}$ and to $5^{\circ} \mathrm{C}$. With the constant micropore and macropore flows this resulted in calculated temperatures of drain water of $20.8^{\circ} \mathrm{C}$ on days 1 and 2 , and of $5.8^{\circ} \mathrm{C}$ on days 3 and 4 . 
The calculation with Eq. (53) was also done in MS Excel ${ }^{\circledR}$, using a representative water depth $(h)$ of $0.174 \mathrm{~m}$, and width of the water surface $(w) 2.52 \mathrm{~m}$. For both calculations a time step of $3600 \mathrm{~s}$ was used.

\subsubsection{Results and discussion}

Figure 12 shows the temperature of water calculated by TOXSWA and calculated with Eq. (53) via MS Excel $^{\circledR}$. The temperature of drain water is shown as well. It can be seen that the temperature of the ditch water gradually increases to reach the temperature of the drain water $\left(20.8^{\circ} \mathrm{C}\right)$ entering the ditch. At Day 2 the temperature of drainage water changed to $5.8^{\circ} \mathrm{C}$. The temperature of ditch water then gradually decreased to that temperature. The temperatures calculated by TOXSWA are the same as those calculated by Eq. (53). Hence this test confirms that the concept for the contribution of external heat of drainage water was correctly implemented in the TOXSWA code.

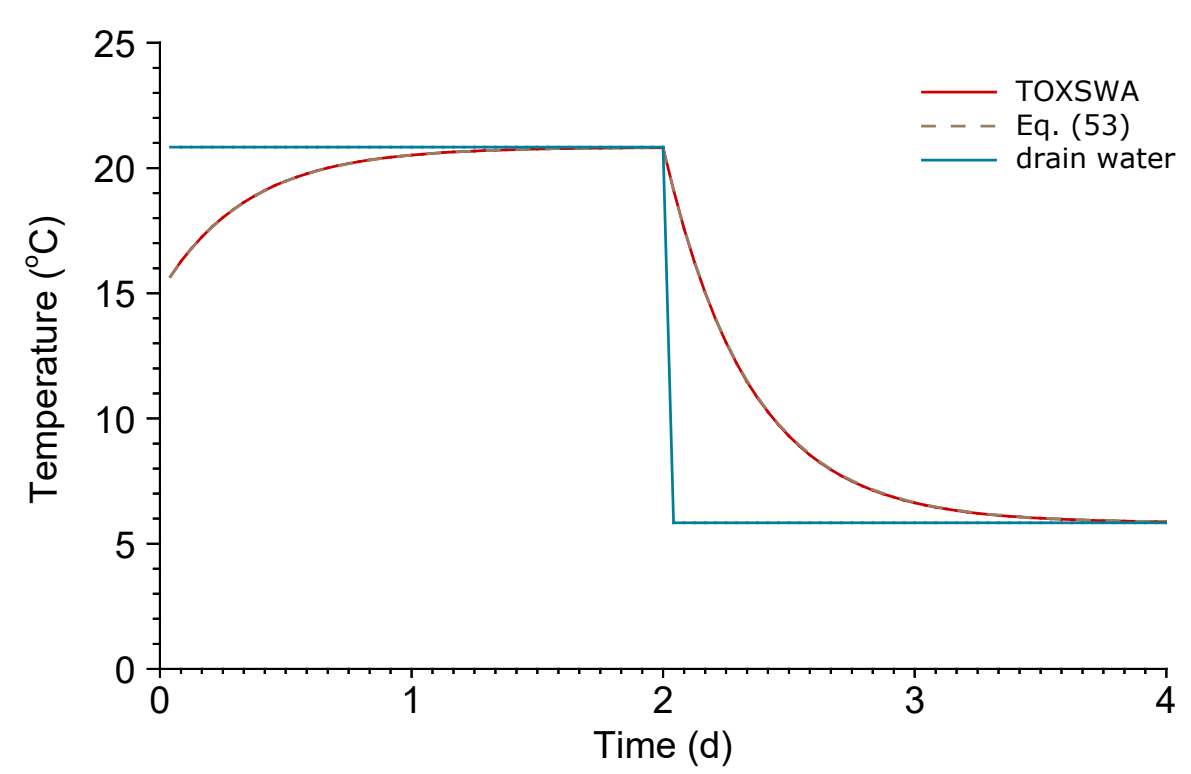

Figure 12 Simulated water temperature taking into account the contribution of drainage to the energy budget of the water as only energy budget term. Simulations were performed for a period of 4 days, using TOXSWA (red curve) and Eq. (53) implemented in MS Excelß(beige curve), respectively. The initial water temperature was set to $15^{\circ} \mathrm{C}$. The temperature of drain water assumed in the test is shown as well (blue curve).

\subsection{Conclusions}

The conclusions of the tests with TOXSWA kernel 3.4 described in sections 4.2 to 4.4 are:

- The concept of water temperature calculated from hourly meteorological data is implemented correctly in TOXSWA.

- The calculation using meteorological conditions that lead to extremely high water temperatures is robust.

- The concept of contribution of external heat of drainage water to the calculation of the water temperature is implemented correctly in TOXSWA. 


\section{Impact of improvement on calculated exposure concentrations}

\subsection{Introduction}

In TOXSWA version 3.4, water temperatures are calculated from hourly meteorological data, instead of from monthly averaged air temperatures. The water temperatures are used to calculate the rates of the transformation in water and in sediment, volatilization from the water layer and diffusion between the water and the sediment and in sediment.

In this chapter, an assessment of the impact of the potential improvements in water temperature calculations on the aforementioned processes is described. Simulations were performed using the parameterisation of the $32 \mathrm{~cm}$ deep pond described in Section 3.4, for May 1986 after a spray drift entry at May $1^{\text {st }}$. The substance properties of the example substance Im of Tiktak et al. (2014) were used. The substance and management sections of the txw input file of TOXSWA used as a basis for the simulations are shown in Annex 10. The process parameters tested were changed as indicated in Sections 5.2 to 5.4 , respectively.

The mean monthly air temperatures currently used in TOXSWA were calculated on the basis of the daily minimum and maximum air temperatures (FOCUS, 2001;Tiktak et al., 2012). In this way, the mean obtained for May 1986 is $15.8^{\circ} \mathrm{C}$. However, the average of all hourly air temperatures is lower, $13.3^{\circ} \mathrm{C}$. Therefore, three sets of simulations were performed for each of the three processes considered:

- hourly: water temperature calculated from hourly meteorological data, i.e., using the new functionality

- monthly-daily air: water temperature based on the monthly mean of daily minimum and maximum air temperatures $\left(15.8{ }^{\circ} \mathrm{C}\right)$, and

- monthly-hourly air: water temperature based on the monthly mean of hourly air temperatures $\left(13.3^{\circ} \mathrm{C}\right)$.

Note that the TOXSWA 3.4 kernel was extended with the functionality to correct the diffusion coefficient for the temperature of water (see Annex 2), whereas in previous versions the diffusion coefficient was constant (Adriaanse, 1996). Therefore in the simulation done for diffusion, a fourth simulation is done:

\section{- constant diffusion coefficient.}

Simulations were carried out using the three different options for temperature simulation described above. To better identify effects on transformation and volatilisation rates, excluding effects on the diffusion coefficient, the latter was set to a constant default value in the transformation and volatilisation related runs.

\subsection{Transformation in water}

\subsubsection{Setup of the test}

The transformation rate in water is a function of the temperature as described by the Arrhenius equation (see Appendix 1 in Beltman et al., 2006). The transformation rate increases with increasing temperature. To create a rapidly degrading substance for this test the DegT50 was set to $10 \mathrm{~d}$, and vapour pressure and solubility were set to values causing negligible volatilization of the substance. 


\subsubsection{Results and discussion}

Figure 13 shows the concentration in water calculated with the three different methods. The red curve representing the concentration based on hourly temperatures shows a somewhat irregular decline due to the fluctuating temperature. The beige and blue curves, respectively, show a smooth exponential decrease due to the constant temperature during the whole month. The concentrations based on hourly temperatures and monthly-hourly air temperatures are higher than those based on the monthly-daily air temperature. At the end of the month the concentration calculated from hourly temperatures is $0.077 \mu \mathrm{g} / \mathrm{L}$, whereas the concentration based on monthly-daily air temperature is $0.062 \mu \mathrm{g} / \mathrm{L}$. Hence using the hourly method gives higher concentrations than using the monthly-daily air method. A second application after 30 days would result in a $0.015 \mu \mathrm{g} / \mathrm{L}$ higher peak concentration $(=4 \%)$. The concentration at the end of the month using monthly-hourly air average temperatures was $0.081 \mu \mathrm{g} / \mathrm{L}$. Hence using the hourly temperatures results in a somewhat lower concentration than using the monthly-hourly air temperatures.

In these simulations, using hourly temperatures results in higher concentrations than the method currently used (monthly-daily air temperatures). However, the difference between using hourly values and the current method (monthly-daily air) can mainly be attributed to the averaging method i.e. taking the average of the daily maximum and minimum temperatures versus the average of all hourly air temperatures.

These simulations do not represent all possible situations. In months with higher temperatures the effect on calculated concentrations might be the opposite. The simulated month may not be representative regarding variability of the weather and of the water temperature. Hence, only one of the impacts of the improvement has been identified.

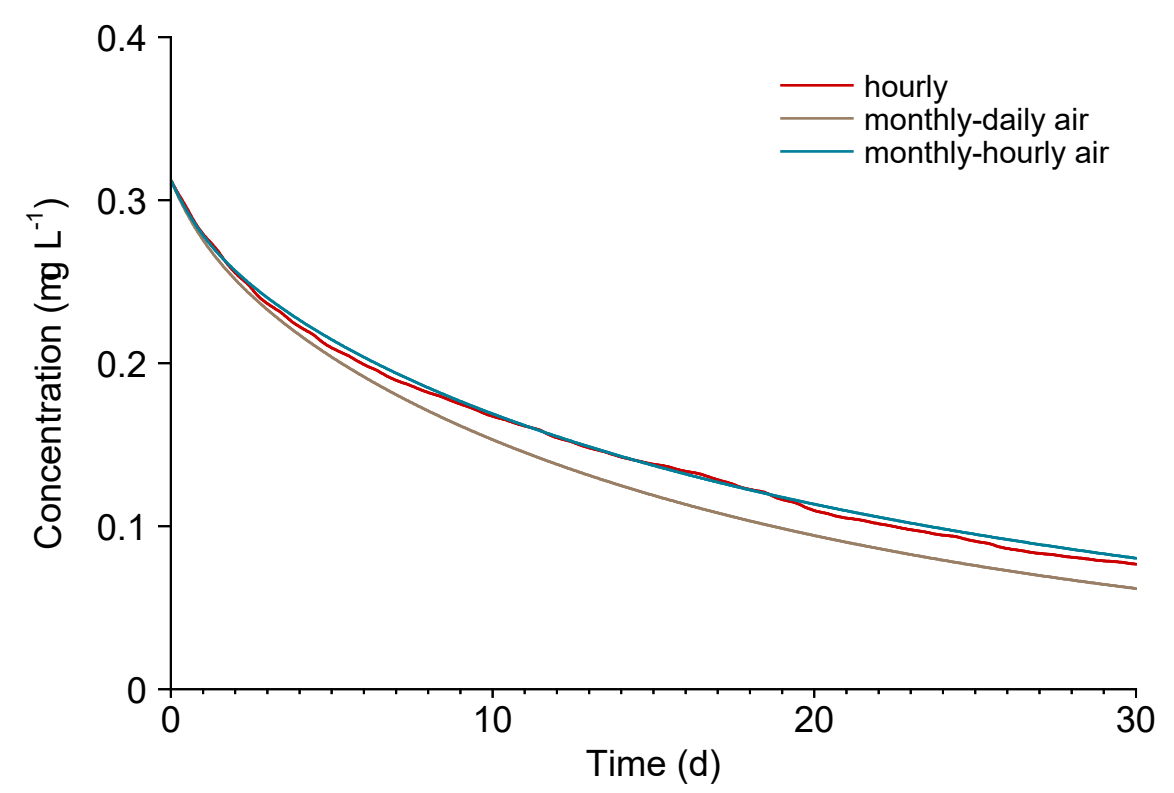

Figure 13 Effect of transformation rate: concentration in water in a $32 \mathrm{~cm}$ deep pond calculated by TOXSWA, with application on May $1^{\text {st }}$. The transformation DegT50 is $10 \mathrm{~d}^{-1}$. The concentrations were calculated using hourly water temperatures based upon hourly meteorological data (red curve), the monthly-daily air temperature, $15.8^{\circ} \mathrm{C}$, (beige curve) and from monthly-hourly air temperature, $13.3^{\circ} \mathrm{C}$ (blue curve). 


\subsection{Volatilization from the water layer}

\subsubsection{Setup of the test}

The volatilization rate in water is a function of the water temperature because the saturated vapour pressure and solubility of the substance both depend on temperature via their molar enthalpies (see Appendix 1 in Beltman et al., 2006). Generally, the volatilization rate increases with increasing temperature. To create a relatively volatile substance for this test the saturated vapour pressure was set to $5.10^{-4} \mathrm{~Pa}$ and the solubility to $1 \mathrm{mg} / \mathrm{L}$. The degradation rate constant DegT50 was set to $1000 \mathrm{~d}$, thus representing minimal degradation in the aqueous layer and the sediment.

\subsubsection{Results and discussion}

Figure 14 shows the concentration in water calculated with the three different methods to compute water temperature. Like in the previous case, the red curve, representing the concentration based on hourly temperatures, shows a somewhat irregular decline due to the fluctuating temperature. The beige and blue curves, respectively, show a smooth exponential decrease due to the constant temperature during the whole month. The concentrations based on hourly temperatures and monthlyhourly air temperatures are higher than those based on the monthly-daily air temperature. At the end of the month the concentration calculated from hourly temperatures is $0.121 \mu \mathrm{g} / \mathrm{L}$, whereas the concentration calculated using monthly-daily air temperatures is $0.110 \mu \mathrm{g} / \mathrm{L}$. Hence using the hourly temperatures gives higher concentrations than using the monthly-daily air temperatures. A second application after 30 days would result in a $0.011 \mu \mathrm{g} / \mathrm{L}$ higher peak concentration $(=3 \%)$. The concentration calculated using monthly-hourly air temperatures was $0.123 \mu \mathrm{g} / \mathrm{L}$. Hence using the hourly temperatures results in a somewhat lower concentration than using the monthly-hourly air temperatures.

In these simulations, using hourly temperatures results in higher concentrations than the method currently used (monthly-daily air temperatures). However, the difference can mainly be attributed to to the averaging method i.e. taking the average of the daily maximum and minimum temperatures versus the average of all hourly air temperatures.

These simulations do not represent all possible situations. In months with higher temperatures the effect on calculated concentrations might be the opposite. The simulated month may not be representative regarding variability of the weather and of the water temperature. Hence, only one of the impacts of the improvement has been identified. 


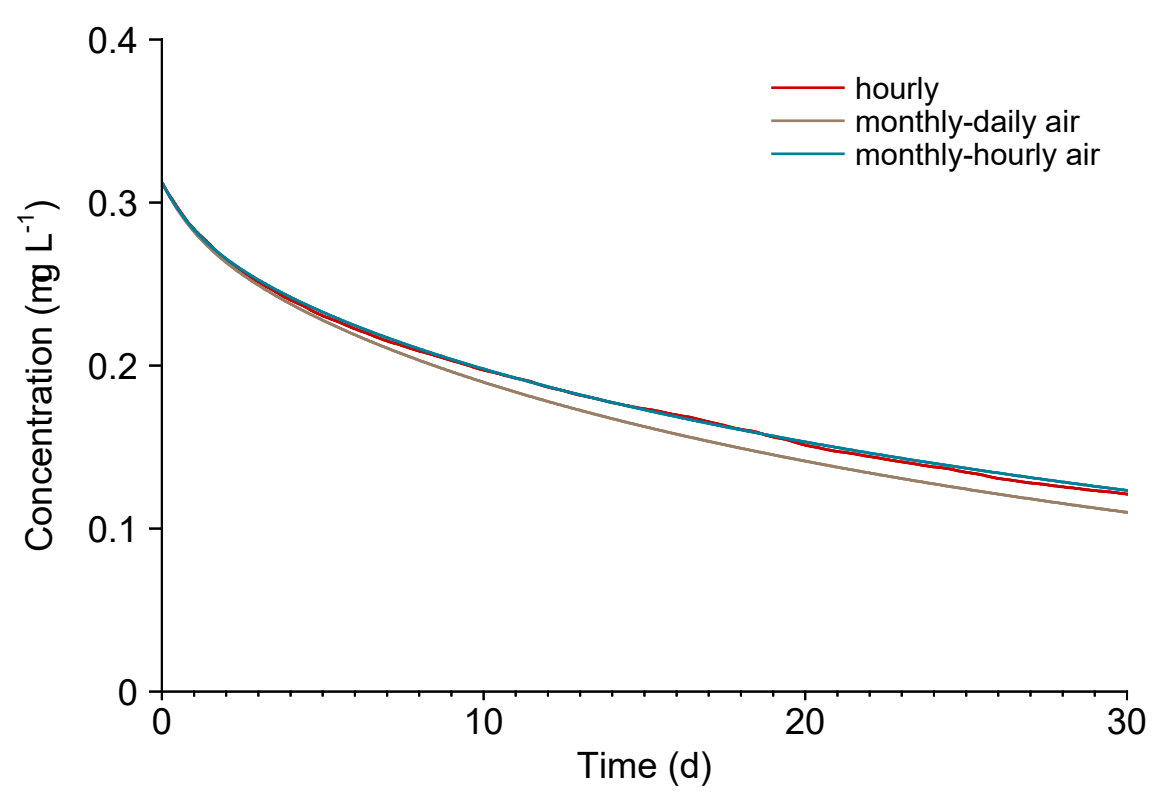

Figure 14 Effect of volatilization rate: concentration in water in a $32 \mathrm{~cm}$ deep pond calculated by TOXSWA, with application on May $1^{\text {st }}$. The saturated vapour pressure was $5.10^{-4} \mathrm{~Pa}$ and the solubility was $1 \mathrm{mg} / \mathrm{L}$. The concentrations were calculated using hourly water temperatures based upon hourly meteorological data (red curve), the monthly-daily air temperature, $15.8^{\circ} \mathrm{C}$, (beige curve) and from monthly-hourly air temperature, $13.3^{\circ} \mathrm{C}$ (blue curve).

\subsection{Diffusion between water and sediment}

\subsubsection{Setup of the test}

The diffusion coefficient in water is a function of the temperature (see Annex 2). The diffusion coefficient becomes larger with increasing temperature.

For the diffusion coefficient a default value of $4 \cdot 3 \cdot 10^{-5} \mathrm{~m}^{2} / \mathrm{d}$ at $20{ }^{\circ} \mathrm{C}$ was used for all tests. Because diffusion to and from sediment depends strongly on the sediment sorption coefficient, simulations were done with the $K_{\mathrm{om}}$ of $107 \mathrm{~L} / \mathrm{kg}$ of the example substance and with a high $K_{\mathrm{om}}$ of $100000 \mathrm{~L} / \mathrm{kg}$, respectively. For the simulations with $K_{\mathrm{om}}$ of $100000 \mathrm{~L} / \mathrm{kg}$ a more detailed sediment segmentation was used (see Beltman et al., 2014).

\subsubsection{Results and discussion}

Figure 15 shows the concentration in water calculated for the four different methods described in Section 5.1, in the case of the substance with a $K_{\mathrm{om}}$ of $107 \mathrm{~L} / \mathrm{kg}$. The concentrations based on hourly temperatures and monthly-hourly air temperatures are slightly higher than those based on the monthly-daily air temperature. The concentrations of all three methods are higher than the concentrations calculated with the constant diffusion coefficient (i.e. not depending on water temperature).

Using hourly temperatures results in higher concentrations than the method currently used, i.e. a constant diffusion coefficient. The differences in calculated concentrations for the three temperature dependent calculations are small for this substance.

Figure 16 shows the concentration in water calculated using the four different methods for the substance with $K_{\mathrm{om}}$ of $100000 \mathrm{~L} / \mathrm{kg}$. The concentrations calculated with the four methods hardly differ from each other. Apparently, the differences that may occur due to different diffusion behaviour were superseded by the effect of sorption for this strongly sorbing substance. 
The monthly average temperature used in the example is $15.8^{\circ} \mathrm{C}$, which is lower than the reference temperature for the diffusion coefficient of $20^{\circ} \mathrm{C}$ and the effective diffusion coefficient is lower than 4.3.10 $10^{-5} \mathrm{~m}^{2} \mathrm{~d}^{-1}$. As a result, there is less diffusion to sediment. For periods in which the monthly average temperature is higher than the reference temperature the effective diffusion into sediment will be higher, resulting in lower concentrations in water.

Using hourly water temperatures in combination with a temperature-dependent diffusion coefficient results in water concentrations that can be both higher or lower than calculated with the method currently used (monthly-daily air temperatures and constant diffusion coefficient), depending on the water temperature being higher or lower than $20^{\circ} \mathrm{C}$, the reference temperature of the diffusion coefficient.

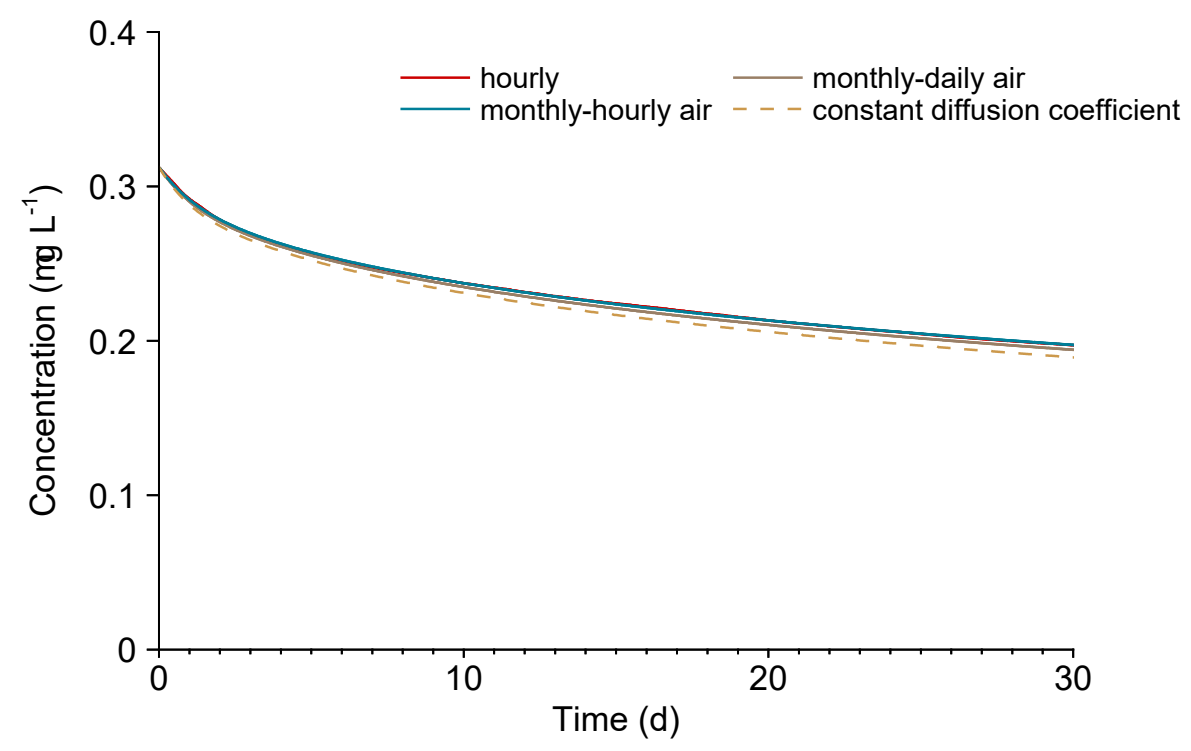

Figure 15 Effect of diffusion coefficient: concentration in water in a $32 \mathrm{~cm}$ deep pond calculated by TOXSWA, with application on May $1^{\text {st }}$. The default value of $4.3 .10^{-5} \mathrm{~m}^{2} / d$ is used. Simulations were done with the $107 \mathrm{~L} / \mathrm{kg}$ of the example substance. The concentrations were calculated using hourly water temperatures based upon hourly meteorological data (red curve), the monthly-daily air temperature, $15.8{ }^{\circ} \mathrm{C}$, (beige curve), the monthly-hourly air temperature, $13.3^{\circ} \mathrm{C}$ (blue curve), and with constant diffusion coefficient (orange dashed curve). 


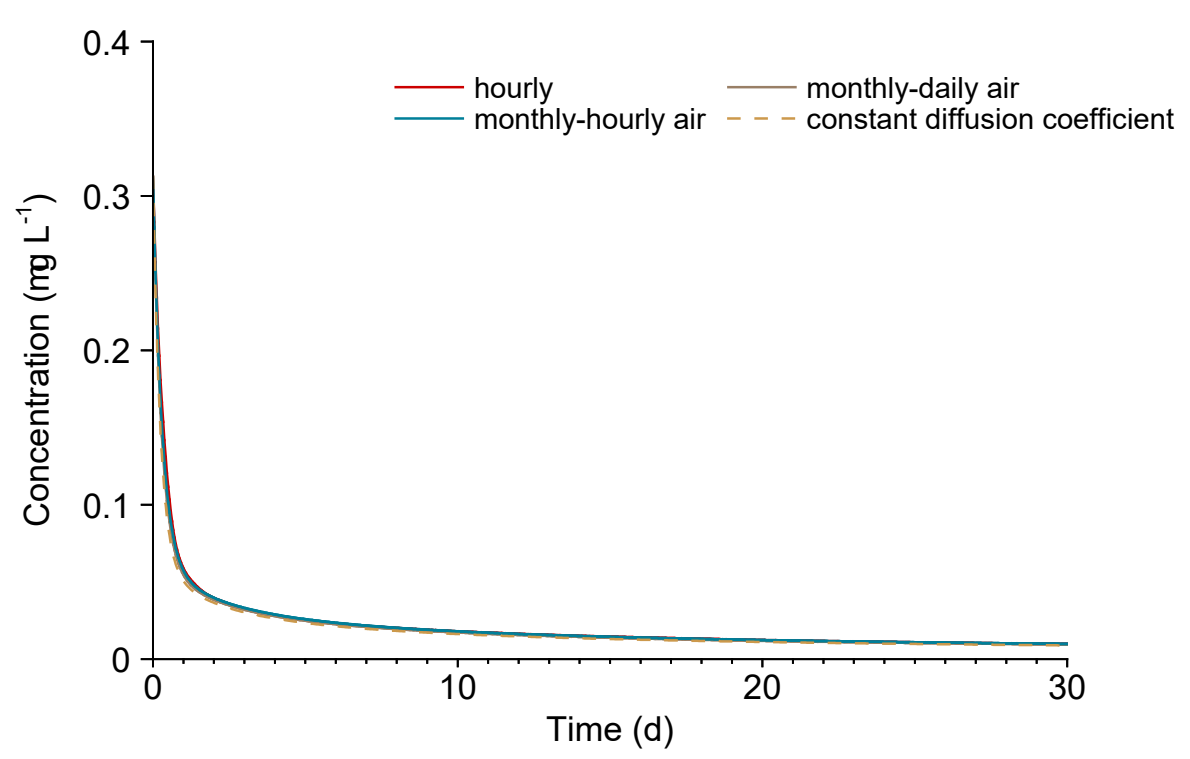

Figure 16 Effect of diffusion coefficient: concentration in water in a $32 \mathrm{~cm}$ deep pond calculated by TOXSWA, with application on May $1^{\text {st }}$. The default value of $4.3 .10^{-5} \mathrm{~m}^{2} / \mathrm{d}$ is used. Simulations were done with a high $K_{\text {om }}$ of $100000 \mathrm{~L} / \mathrm{kg}$. The concentrations were calculated using hourly water temperatures based upon hourly meteorological data (red curve), the monthly-daily air temperature, $15.8^{\circ} \mathrm{C}$, (beige curve, the monthly-hourly air temperature, $13.3^{\circ} \mathrm{C}$ (blue curve), and with constant diffusion coefficient (orange dashed curve).

\subsection{Conclusions}

Transformation and volatilization

In these simulations, using hourly temperatures results in higher concentrations than the method currently used (monthly-daily air temperatures). The difference can mainly be attributed to the averaging method i.e. taking the average of the daily maximum and minimum temperatures versus the average of all hourly air temperatures. For warmer periods of the year or periods with more variation the impact on calculated concentrations might be the opposite or differ otherwise.

\section{Diffusion}

Using a water temperature calculated from hourly meteorological data, in combination with the use of a temperature-dependent diffusion coefficient, results in concentrations that can be both higher or lower than the concentrations calculated using a constant diffusion coefficient. The result depends on water temperatures being higher or lower than $20^{\circ} \mathrm{C}$, the reference temperature of the diffusion coefficient.

In general, using the new water temperature concept instead of the current concept of using monthly averaged water temperatures results in relatively small changes in calculated exposure concentrations in water for the cases considered here. 


\section{$6 \quad$ Conclusions and recommendations}

The TOXSWA model has been extended with the functionality to simulate water temperature using hourly meteorological data to drive the water energy budget, to provide a more physically-based alternative to simply using monthly averaged air temperatures. The new functionality is based on a 1D-bulk approach, which assumes a well-mixed water layer. Contributions to the energy budget from shortwave radiation, longwave radiation, sensible and latent heat exchange between air and water, precipitation, potential heat exchange between water and sediment and external sources, such as incoming drainage water are taken into account.

The temperature of the sediment is assumed to be equal to the water temperature. This is a reasonable assumption for the top millimetres of the sediment which are in direct contact with the water layer and often have a high porosity. As plant protection products entering waterbodies reside predominantly in the top $\mathrm{cm}$ of the sediment the effect of temperature on transformation and on diffusion is considered to be described in a defensible manner in the TOXSWA model. Heat fluxes in soil below sediment could be described by a numerical model for the sediment and soil layers, using the temperature at a certain soil depth simulated by a model that simulates soil temperature as lower boundary.

Tests with TOXSWA confirmed that the concepts for simulation of water temperature derived from hourly meteorological data and the use of water temperatures of drain water have been implemented correctly in the calculations. Also, the calculation of temperature under meteorological conditions and for characteristics of the water body leading to extremely high water temperatures appears to be robust.

The effect of using the new water temperature concept instead of the current approach of using monthly averaged air temperatures was tested for the processes that are affected by temperature, i.e. transformation, volatilization and diffusion.

The new concept results in slightly higher calculated concentrations in water, due to a slightly lower transformation and volatilization rates for some simulated cases of the month May. The difference can mainly be attributed to the way in which the monthly temperatures were calculated, i.e. taking the average of the maximum and minimum daily or hourly air temperatures in the month. For warmer or colder periods or periods with more variation the impact on calculated concentrations might be the opposite or differ otherwise.

For diffusion the effect of applying a temperature-dependent diffusion coefficient (incorporated in version 3.4) instead of a temperature-independent diffusion coefficient (up to version 3.3) is larger than the effect of using hourly water temperatures computed from hourly meteorological data. The temperature dependency of the diffusion coefficient can result in both higher or lower calculated concentrations, depending on whether the temperature used is higher or lower than the reference temperature of the diffusion coefficient.

If monthly average water temperatures are used by TOXSWA for exposure calculations, we recommend that monthly average water temperatures are calculated from hourly air temperatures instead of the daily minimum and maximum air temperature values, because the exposure concentration based upon the first averaging method represent reality better than the second averaging method. 


\section{References}

Adriaanse, P.I., S.J.H. Crum, J.A. Elbers, H.T.L. Massop, W.H.J. Beltman, 2015. Sediment properties in five Dutch watercourses : indicative measurements for the registration procedure of plant protection products in The Netherlands. Alterra Wageningen UR (University and Research centre). Alterra report 2574 .

Adriaanse, P.I., W.H.J. Beltman, F. van den Berg, 2014. Metabolite formation in water and in sediment in the TOXSWA model. Theory and procedure for the upstream catchment of FOCUS streams. Wageningen, Alterra Wageningen UR (University and Research centre). Alterra report 2587.

Adriaanse, P.I., W.H.J. Beltman, 2009. Transient water flow in the TOXSWA model (FOCUS versions): concepts and mathematical description. Report 101, Wettelijke Onderzoekstaken Natuur \& Milieu, Wageningen, The Netherlands.

Adriaanse, 1996. Fate of pesticides in field ditches: the TOXSWA simulation model. Wageningen, SC-DLO Report 90. 241 p.

Beltman, W.H.J., M.M.S. ter Horst, P.I. Adriaanse, A. de Jong, J.W. Deneer, 2014. FOCUS_TOXSWA manual 4.4.2 : User's Guide version 4. Wageningen, WOt technical report 14, 130p.

Beltman, W.H.J., M.M.S. ter Horst, P.I. Adriaanse, A. de Jong, 2006. Manual of FOCUS_TOXSWA Version 2.2.1. Wageningen, Alterra-rapport 586, $198 \mathrm{p}$.

Drake, J.M.K., 1972. Evaporative cooling of a body of water. Water Resour. Res., 8, 1087-1091.

De Bruin, H.A.R. and H.R.A. Wessels, 1988. A model for the formation and melting of ice on surface waters. J. Appl. Meteor., 27, 164-173.

De Lange, H.J., 2000. The attenuation of ultraviolet and visible radiation in Dutch inland waters. Aquatic Ecol., 34, 215-226.

FOCUS, 2001. FOCUS Surface Water Scenarios in the EU Evaluation Process under 91/414/EEC. Report of the FOCUS Working Group on Surface Water Scenarios, EC Document Reference SANCO/4802/2001-rev2.245 pp.

Henderson-Sellers, B., 1984. A new formula for latent heat of vaporization of water as a function of temperature. Quart. J. R. Met. SOC., 110, 1186-1190.

Jacobs, C.M.J., P.I. Adriaanse and J. Deneer, 2010. Modelling water temperature in TOXSWA. Wageningen, Alterra report 2099.

Jacobs, C.M.J., H.W. ter Maat, J.A. Elbers and L.C.P.M. Stuyt, 2009. Conditionering van de Watertemperatuur in Buitenvijvers voor de Aquacultuur. Wageningen, Alterra, Alterra-Report, (Dutch text).

List, R.J. (Ed.), 1966. Smithsonian Meteorological Tables, 6th ed. (Table 92), p. 343. Smithsonian Institution, Washington, D.C.

Monteith, J.L. and M.H. Unsworth, 1990. Principles of environmental physics. Edward Arnold, Londen.

Paaijmans, K.P., B.G. Heusinkveld, A.F.G. Jacobs, 2008. A simplified model to predict diurnal water temperature dynamics in a shallow tropical pool. Int. J. Biometeorol., 52, 797-803. 
Paulson, C.A. and J.J. Simpson, 1977. Irradiance measurements in the upper ocean. J. Phys. Oceanogr., 7, 952-956.

Scheffer, M., 2004. Ecology of shallow lakes (3rd edition). Kluwer Academic Publishers, Dordrecht, $357 \mathrm{pp}$.

Tiktak, A., P.I. Adriaanse, J.J.T.I. Boesten, C. van Griethuysen, M.M.S. ter Horst, J.B.H.J. Linders, A.M.A. van der Linden, J.C. van der Zanden, 2012. Scenarios for exposure of aquatic organisms to plant protection product in the Netherlands. Part 1: Field crops and downward spraying. RIVM Report 607407002/2012, Bilthoven, 129 p.

Van den Berg, F., A. Tiktak, J.J.T.I. Boesten, A.M.A. van der Linden, 2016. PEARL model for pesticide behaviour and emissions in soil-plant systems. Wageningen : Statutory Research Tasks Unit for Nature \& the Environment, (WOt-technical report 61), 134 p.

Westein, E., M.J.W. Jansen, P.I. Adriaanse \& W.H.J. Beltman, 1998. Sensitivity analysis of the TOXSWA model simulating fate of pesticides in surface waters. Wageningen, SC-DLO, Report 154, 119 pp. 


\section{Annex 1 Description of parameters in the temperature module}

Table A1 Parameter symbols, units and descriptions, as well as the equation they are first used in, parameter type (fixed or calculated by TOXSWA) and value when fixed, and given in input or output file, which file and parameter name in input or output file. Input files are the *.txw and *.meth files, and output files are the *.tem and *.out files.

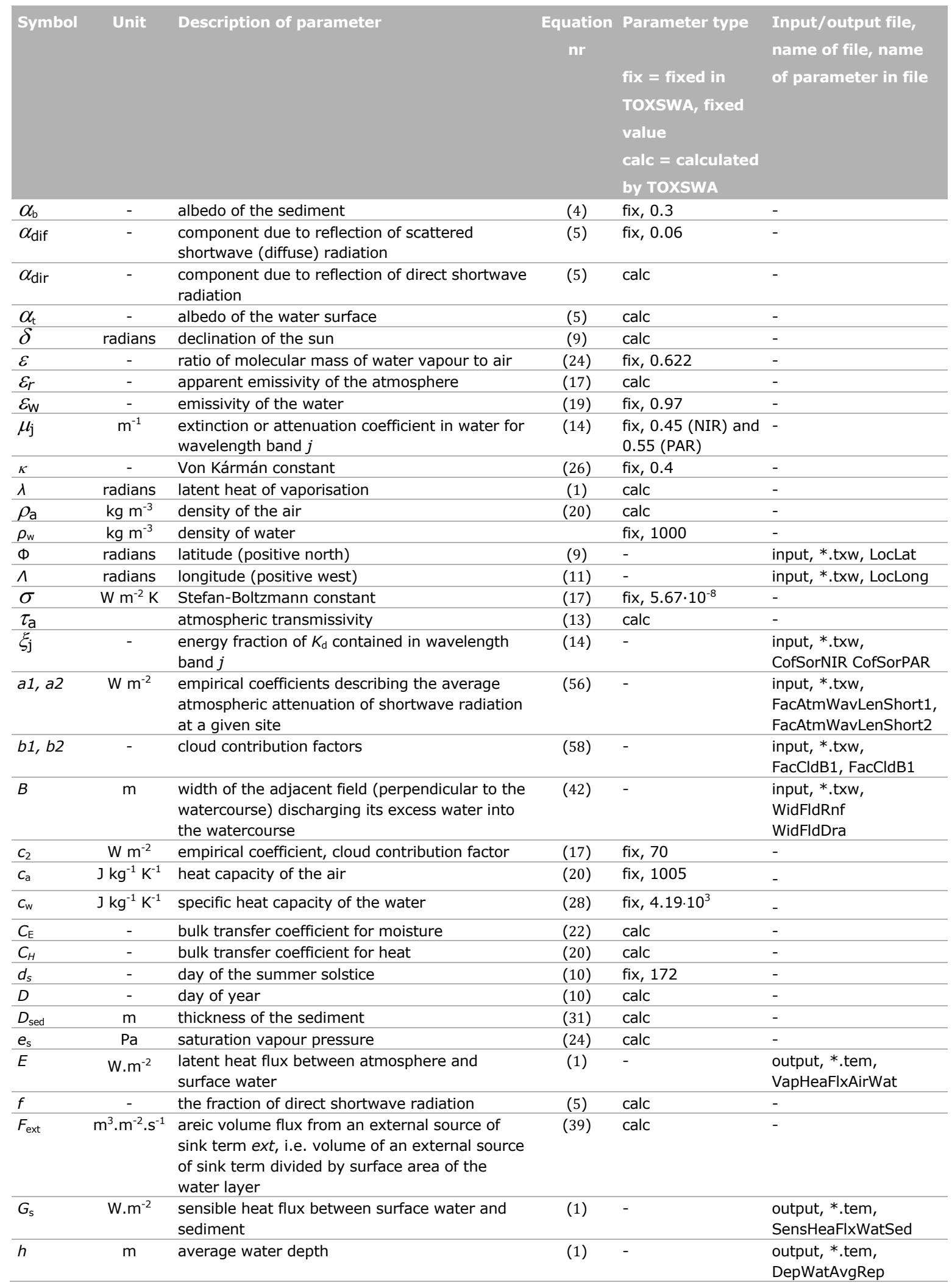




\begin{tabular}{|c|c|c|c|c|c|}
\hline Symbol & Unit & Description of parameter & $\begin{array}{l}\text { Equation } \\
\mathrm{nr}\end{array}$ & $\begin{array}{l}\text { Parameter type } \\
\text { fix = fixed in } \\
\text { ToxsWA, fixed } \\
\text { value } \\
\text { calc = calculated } \\
\text { by ToxsWA }\end{array}$ & $\begin{array}{l}\text { Input/output file, } \\
\text { name of file, name } \\
\text { of parameter in file }\end{array}$ \\
\hline$H_{r}$ & - & relative humidity at the reference level & $(18)$ & - & input, *.meth, HUM \\
\hline$K^{\downarrow}$ & W. $\mathrm{m}^{-2}$ & $\begin{array}{l}\text { energy in the downward shortwave beam at the } \\
\text { bottom of the water layer or the distance from } \\
\text { the water surface }\end{array}$ & $(14)$ & calc & - \\
\hline$K_{\mathrm{b}}$ & W. $\mathrm{m}^{-2}$ & shortwave radiation absorbed by the sediment & $(1)$ & calc & $\begin{array}{l}\text { output, *.meth, } \\
\text { FleRadShoBot }\end{array}$ \\
\hline$K_{\text {bot }}$ & $W \cdot m^{-2}$ & $\begin{array}{l}\text { downward radiation reaching depth of the } \\
\text { sediment }\end{array}$ & $(14)$ & calc & - \\
\hline$K_{\mathrm{d}}$ & W. $\mathrm{m}^{-2}$ & incoming shortwave radiation & $(1)$ & - & $\begin{array}{l}\text { output, } * \text {.tem, } \\
\text { FleRadShoDow }\end{array}$ \\
\hline$K_{\mathrm{d}, \mathrm{obs}}$ & & observed incoming shortwave radiation & - & - & input, *.meth, RAD \\
\hline$k_{\text {sed }}$ & $\mathrm{W} \cdot \mathrm{m}^{-1} \cdot \mathrm{K}^{-1}$ & heat conduction coefficient of the sediment & $(31)$ & fix, 0.57 & - \\
\hline$K_{\mathrm{u}}$ & W. $\mathrm{m}^{-2}$ & reflected short wave radiation & $(1)$ & - & $\begin{array}{l}\text { output, } * \text {.tem, } \\
\text { FleRadShoUpw }\end{array}$ \\
\hline$L$ & $\mathrm{~m}$ & length of the water body & $(36)$ & - & input, *.txw, Len \\
\hline$L_{\mathrm{d}}$ & W. $\mathrm{m}^{-2}$ & incoming longwave radiation & $(1)$ & - & $\begin{array}{l}\text { output, *.tem, } \\
\text { FleRadLonDow }\end{array}$ \\
\hline$L_{\mathrm{u}}$ & W. $\mathrm{m}^{-2}$ & reflected longwave radiation & (1) & - & $\begin{array}{l}\text { output, } * \text {.tem, } \\
\text { FleRadLonUpw }\end{array}$ \\
\hline$H$ & W. $\mathrm{m}^{-2}$ & $\begin{array}{l}\text { sensible heat flux between atmosphere and } \\
\text { surface water }\end{array}$ & (1) & - & $\begin{array}{l}\text { output, *.tem, } \\
\text { SensHeaFlxAirWat }\end{array}$ \\
\hline$N$ & - & fraction of cloud cover & $(17)$ & - & input, *.meth, CLD \\
\hline$O_{x}$ & $\mathrm{~m}^{2}$ & horizontal surface area of the water layer & $(2)$ & calc & - \\
\hline$p_{\mathrm{a}}$ & $\mathrm{Pa}$ & atmospheric pressure at the surface & $(21)$ & - & input, *.meth, PA \\
\hline$P_{\mathrm{I}}$ & $\mathrm{m} \cdot \mathrm{s}^{-1}$ & precipitation rate & (28) & - & input, *.meth, RAIN \\
\hline$q_{\mathrm{s}}$ & $\mathrm{kg} \cdot \mathrm{kg}^{-1}$ & $\begin{array}{l}\text { saturation specific humidity at the given } \\
\text { temperature }\end{array}$ & $(22)$ & calc & - \\
\hline$q_{\text {ext }}$ & $\mathrm{m}^{3} \mathrm{~m}^{2} \mathrm{~s}^{-1}$ & $\begin{array}{l}\text { areic volume flux of external source of sink term } \\
\text { ext water of the adjacent field }\end{array}$ & $(42)$ & - & $\begin{array}{l}\text { input, lateral entries } \\
\text { file, model dependant }\end{array}$ \\
\hline$Q_{\text {down }}$ & $\mathrm{m}^{3} \cdot \mathrm{s}^{-1}$ & $\begin{array}{l}\text { discharge at the lower boundary of the water } \\
\text { body }\end{array}$ & $(36)$ & calc & - \\
\hline$Q_{p r}$ & W. $\mathrm{m}^{-2}$ & exchange of heat through precipitation & (1) & - & $\begin{array}{l}\text { output, } * \text {. tem, } \\
\text { HeaFIxPrc }\end{array}$ \\
\hline$Q_{\mathrm{x}=0}$ & $\mathrm{~m}^{3} \cdot \mathrm{s}^{-1}$ & $\begin{array}{l}\text { discharge of volumic rate of water at the upper } \\
\text { boundary of the watercourse (at } x=0)\end{array}$ & (36) & calc & - \\
\hline$r$ & - & refraction angle & $(7)$ & calc & - \\
\hline$R$ & $\mathrm{~J} . \mathrm{kg}^{-1} \cdot \mathrm{K}^{-1}$ & specific gas constant for dry air & $(21)$ & fix, 287 & - \\
\hline$s$ & $\mathrm{~Pa} . \mathrm{K}^{-1}$ & $\begin{array}{l}\text { rate of increase of the saturation vapour } \\
\text { pressure with temperature evaluated }\end{array}$ & (30) & calc & - \\
\hline$S$ & W. $\mathrm{m}^{-2}$ & external source and sink terms heat exchange & (32) & - & $\begin{array}{l}\text { output, *.tem, } \\
\text { HeaFIxExt }\end{array}$ \\
\hline$S_{\text {ext }}$ & W. $\mathrm{m}^{-2}$ & $\begin{array}{l}\text { exchange of heat with water with an external } \\
\text { source of sink (ext) entering or leaving the } \\
\text { waterlayer }\end{array}$ & $(32)$ & calc & - \\
\hline$t$ & s, d & time & - & - & - \\
\hline$t_{\mathrm{d}}$ & $\mathrm{h}$ & time of day in UTC & $(11)$ & calc & - \\
\hline$t_{\mathrm{h}}$ & radians & hour angle & $(9)$ & calc & - \\
\hline$T_{\text {ext }}$ & $\mathrm{K}$ & $\begin{array}{l}\text { temperature of water of an external source or } \\
\text { sink term ext }\end{array}$ & (33) & - & $\begin{array}{l}\text { input, lateral entries } \\
\text { file, model dependant }\end{array}$ \\
\hline$T_{\mathrm{p}}$ & $\mathrm{K}$ & temperature of the raindrops & (28) & calc & - \\
\hline$T_{\mathrm{r}}$ & $\mathrm{K}$ & air temperature at reference height & (17) & - & input, *.meth, $\mathrm{T}$ \\
\hline$T_{\text {sed }}$ & $\mathrm{K}$ & temperature of the sediment & $(31)$ & calc & - \\
\hline$T_{\mathrm{w}}$ & $\mathrm{K}$ & temperature of water in the water layer & $(1)$ & - & $\begin{array}{l}\text { output, tem/out, } \\
\text { TemWat }\end{array}$ \\
\hline$u_{\mathrm{obs}}$ & $\mathrm{m} \mathrm{s}^{-1}$ & observed wind speed at observation level & $(27)$ & - & input, *.meth, WIND \\
\hline$u_{r}$ & $\mathrm{~m} \mathrm{~s}^{-1}$ & wind speed at the reference level & $(20)$ & calc & - \\
\hline V & $\mathrm{m}^{3}$ & volume of water layer & $(2)$ & calc & - \\
\hline$w$ & $\mathrm{~m}$ & width of the water layer & $(35)$ & calc & - \\
\hline$z_{0}$ & $\mathrm{~m}$ & aerodynamic roughness & $(26)$ & fix, 0.03 & - \\
\hline$z_{\mathrm{h}}$ & $\mathrm{m}$ & roughness length for heat & $(26)$ & calc & - \\
\hline$z_{r}$ & $\mathrm{~m}$ & reference height & $(26)$ & - & input, *.txw, MetLvIRef \\
\hline$z_{\text {obs }}$ & $\mathrm{m}$ & observation height & $(27)$ & - & $\begin{array}{l}\text { input, } * . t x w \\
\text { MetLviobs }\end{array}$ \\
\hline$z$ & - & solar zenith angle & $(6)$ & calc & - \\
\hline
\end{tabular}




\section{Annex 2 Relation between diffusion coefficient in water and temperature}

\section{Introduction}

The diffusion coefficient in water depends on the temperature and the viscosity of water. The viscosity of water also depends on temperature.

In the TOXSWA kernel version 3.3 the diffusion coefficient in water has a constant value, not depending on the temperature of water. In the TOXSWA 3.3 version the diffusion in water is responsible for the exchange of substance between the water layer and the sediment and for vertical transport in the sediment. In the TOXSWA kernel version 3.4 the diffusion coefficient in water is also used to simulate volatilization of substance to the air with the concept described by Jacobs and Adriaanse (2012), implemented in TOXSWA.

\section{Concept}

The method used to simulate the effect of temperature on the diffusion coefficient of the substance in water is given in Appendix 4 of Van den Berg et al. (2016), and based on Tucker and Nelken (1982). The value of the diffusion coefficient $D_{\mathrm{w}}$ depends on the temperature, mainly because the viscosity of water depends on the temperature. The relation between the diffusion coefficient in water, $D_{w}$, and temperature is described by:

$D_{w}=\frac{T}{T_{r e f}} \frac{\eta_{w, r e f}}{\eta_{w}} D_{w, r e f}$

where:

$D_{\mathrm{w}} \quad=$ diffusion coefficient in water $\left(\mathrm{m}^{2} \mathrm{~s}^{-1}\right)$

$T \quad=$ temperature of water $(\mathrm{K})$

$T_{\text {ref }} \quad=$ reference temperature $(\mathrm{K})$

$\eta_{\mathrm{w}} \quad=$ dynamic viscosity of water $\left(\mathrm{Pa} \mathrm{s}^{-1}\right)$

$\eta_{\mathrm{w}, \text { ref }}=$ dynamic viscosity of water at reference temperature $\left(\mathrm{Pa} \mathrm{s}^{-1}\right)$

$D_{\mathrm{w}, \text { ref }}=$ diffusion coefficient in water at reference temperature $\left(\mathrm{m}^{2} \mathrm{~s}^{-1}\right)$

Viscosity coefficients for pure water were determined by a fit on the data (temperature in ${ }^{\circ} \mathrm{C}$ ) tabulated in the Handbook of chemistry and physics (ed. 1947).

$\eta_{w}=-0.1388 .10^{-10} T^{3}+1.3114 .10^{-9} T^{2}-5.986 .10^{-8} T+1.7887 .10^{-6}$

\section{Implementation in TOXSWA}

The Eqs. (54) and (55) have been implemented in TOXSWA version 3.4 ${ }^{4}$. For Eq. (55) the temperature in TOXSWA, which is in Kelvin, is converted to ${ }^{\circ} \mathrm{C}$ by subtracting $273.15 \mathrm{~K}$.

The impact of applying the effect of temperature on the diffusion coefficient in water is considerable. The diffusion from water into sediment (and vice versa) as driven by concentration differences between water and sediment (where sorption takes place) is the only process for transfer of substance between the water layer and the sediment. At $10^{\circ} \mathrm{C}$ the diffusion coefficient is a factor $2 / 3$ of the

\footnotetext{
4 Note that using the dynamic viscosity fitted for calculation of the diffusion coefficient in water differs from the approach of Leistra (linearization of temperature dependency of viscosity based on viscosity at 10 and at $20{ }^{\circ} \mathrm{C}$ ). The difference between the two approaches is negligible; in the range from 10 to $20^{\circ} \mathrm{C}$ it is less than $0.1 \%$, and from 10 to $30{ }^{\circ} \mathrm{C}$ it is $4 \%$. The rationale of using the fitted equation is that the dynamic viscosity will also be used to calculate the Schmidt number in the improved concept for volatilization in TOXSWA (Jacobs and Adriaanse, 2012).
} 
diffusion coefficient at $20^{\circ} \mathrm{C}$. Hence for scenarios situated in cold and temperate climate areas the transfer of substance to sediment can reduce substantially, whereas in climates with water temperatures above $20^{\circ} \mathrm{C}$ the transfer to sediment may increase.

The values of the diffusion coefficient in water at reference temperature $\left(D_{\mathrm{w}}\right)$ and the reference temperature $\left(T_{\text {ref }}\right)$ must be entered by the user. These values can be entered in the txw input file, in the compound section:

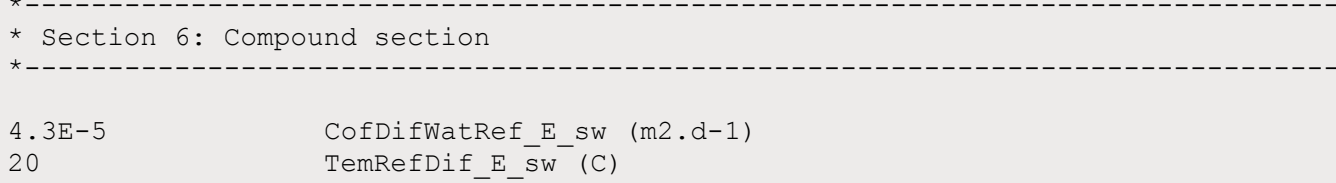

\section{Test of implementation}

To test if the concept for temperature dependency of diffusion was implemented correctly in TOXSWA simulation results of TOXSWA were compared with results of calculations with an analytical model for the sediment (based ${ }^{5}$ on Eq. 7.39 in Adriaanse (1996)). The concept was considered correctly implemented if TOXSWA and the analytical model yielded the same results as seen from graphs of concentration as a function of depth

The effect of temperature on diffusion was calculated for three constant temperatures, $5^{\circ} \mathrm{C}, 20^{\circ} \mathrm{C}$ and $35^{\circ} \mathrm{C}$. Note that $20^{\circ} \mathrm{C}$ should yield results equivalent to the situation before this change, as the $20^{\circ} \mathrm{C}$ diffusion coefficient of $4 \cdot 3 \cdot 10^{-5} \mathrm{~m}^{2} / \mathrm{d}$ has always been used in the past.

A pulse input was applied at $t=0$ as initial total concentration $c_{b}{ }^{*}$ of $10 \mathrm{~g} / \mathrm{m}^{3}$ in the segment from 0.03 to $0.032 \mathrm{~m}$ depth in the TOXSWA simulation. For the analytical solution the same mass (corresponding to $16 \mathrm{mg} / \mathrm{m}^{2}$ ) was applied at $0.03 \mathrm{~m}$ depth. The substance simulated was an inert substance that does not adsorb and is not transformed. The sediment is homogeneous and there is no seepage flow. Hence, the only process affecting the concentration distribution in sediment is diffusion. Table A2 shows the scenario and the substance properties as used for the test for TOXSWA and for the FORTRAN program used to calculate the analytical solution. The concentration profiles at $t=1$ day calculated by TOXSWA were compared with concentration profiles calculated by the analytical model.

5 Eq. 7.39 can be used for a semi-infinite system with $V>0$. For this test for an infinite system the mass "M" in the equation is replaced by "M/2". 
Table A2 Values of scenario and substance properties used in test of TOXSWA against an analytical solution.

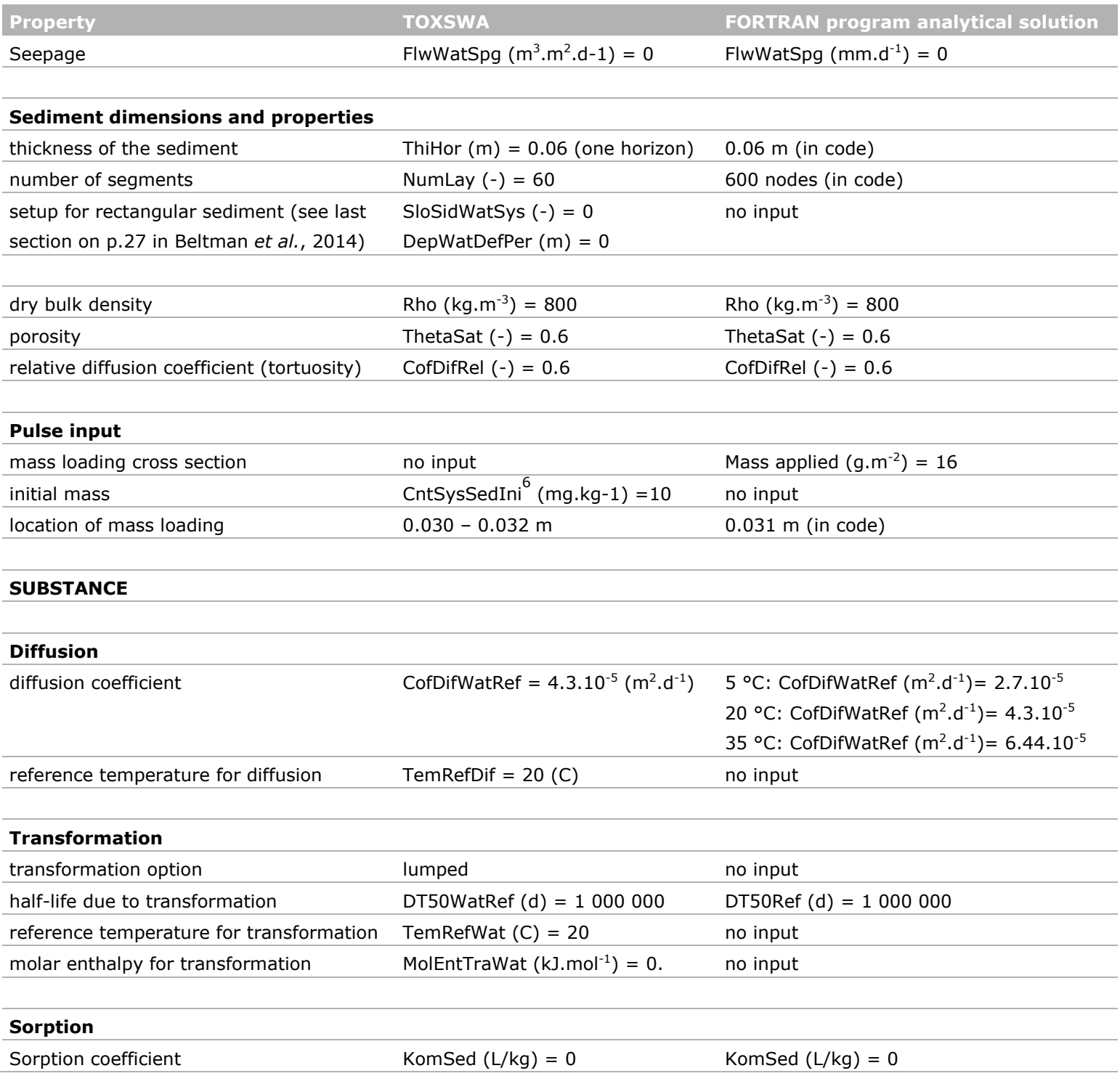

\footnotetext{
6 Note that CntSysSedIni input is in $\mathrm{g} \mathrm{kg}^{-1}$ dry weight of the sediment. Hence $10 \mathrm{mg} \cdot \mathrm{kg}^{-1}$ with bulk density of $800 \mathrm{~kg} \cdot \mathrm{m}^{-3}$ is $8000 \mathrm{mg} \cdot \mathrm{m}^{-3}$. This mass is entered in a segment of $2 \mathrm{~mm}$ thickness with volume of $0.002 \mathrm{~m}^{-3}$, hence $16 \mathrm{mg}$ substance was added to the sediment.
} 


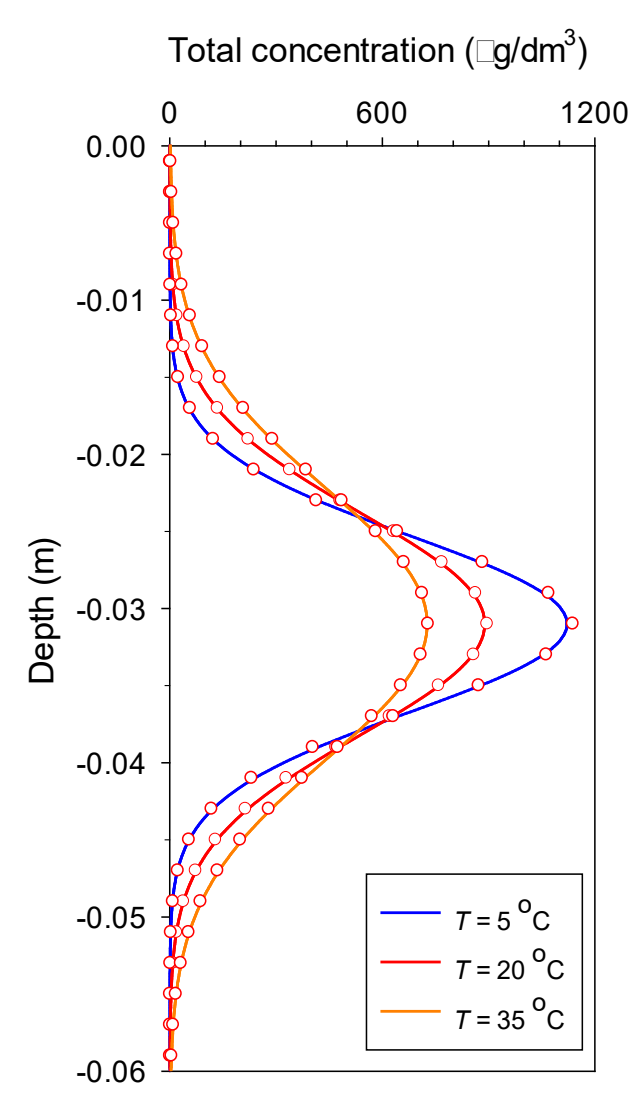

Figure A1 Total concentration of an inert substance in sediment at $t=1$ day after a pulse input of $16 \mathrm{mg} / \mathrm{m}^{-2}$ (in TOXSWA as $10 \mathrm{~g} / \mathrm{m}^{3}$ in segment from 0.030 to $0.032 \mathrm{~m}$ ) at 5,20 and $35{ }^{\circ} \mathrm{C}$. Contents given by solid lines were calculated with the analytical solution. Contents indicated by red circles were calculated by TOXSWA.

\section{Results and conclusion}

Figure A1 shows the concentration profiles in the sediment calculated by the TOXSWA model and by the analytical solution. The three curves show that with increasing temperature the spreading of the substance in the sediment profile increases. The concentrations calculated by TOXSWA correspond perfectly with the concentrations calculated by the analytical solution. Hence the effect of temperature on diffusion as modelled by Eqs. (54) and (55) is implemented correctly.

\section{References}

Jacobs, C.M.J. and P.I. Adriaanse, 2012. Pesticide volatilization from small surface waters. Rationale of a new parameterization for TOXSWA. Alterra Wageningen UR (University \& Research centre), Alterra report 2099.

Handbook of physics and chemistry, 1947. $30^{\text {th }}$ Revised Edition.

Van den Berg, F., Tiktak, A., Boesten, J.J.T.I., van der Linden, A.M.A., 2016. PEARL model for pesticide behaviour and emissions in soil-plant systems. Description of processes. Wageningen, Wot-technical report 161 .

Tucker, W.A. and L.H. Nelken, 1982. Diffusion coefficients in air and water. In: Handbook of chemical property estimation methods. Environmental behaviour of organic compounds. Chapter 17. W.J. Lyman, W.F. Reehl and D.H. Rosenblatt (Eds). McGraw-Hill Book Company, New York. 


\section{Annex 3 Radiation at the air-water interface}

Shortwave radiation is formally defined as the energy in the visible and near-infrared portion of the electromagnetic spectrum (400-1000 nm in wavelength). However, in meteorology the term is used to distinguish radiation in the visible and near-infrared portions of the electromagnetic spectrum (wavelength $400-4000 \mathrm{~nm}$ ), usually of solar origin, from that at longer wavelengths, the longwave radiation, usually of terrestrial origin. In this report, the latter convention will be followed. The distinction between shortwave and longwave radiation is possible in practice because the emission spectrum of radiators is a strong function of the absolute temperature. According to Wien's displacement law, the wavelength with the maximum radiative energy (peak in the spectrum) is inversely proportional to the absolute temperature. The solar radiation peaks at about $480 \mathrm{~nm}$ (at the sun's effective temperature of $\sim 6000 \mathrm{~K}$ ), while the terrestrial radiation peaks at about $9700 \mathrm{~nm}$ (assuming a temperature of $\sim 300 \mathrm{~K}$ ).

For the energy balance of water bodies, the total incoming shortwave radiation received at a horizontal surface at or near the Earth's surface is relevant. This quantity is also called global radiation, formally defined as the solar radiation received from a solid angle of $2 \pi$ steradians (one half of a globe) on a horizontal surface. It consists of the sum of direct solar radiation, the portion of the solar radiation that has not been scattered or absorbed, and diffuse radiation, the "downward scattered and reflected solar radiation coming from the whole hemisphere of the sky with the exception of the solid angle subtended by the sun's disk." The quantity $K_{\mathrm{d}}$ refers to the global radiation, but is called downward shortwave radiation to better distinguish it from the longwave radiation, in line with the meteorological practice and the upward shortwave radiation.

Global radiation is measured at the main Dutch meteorological stations and in a growing number of meteorological stations around the world. The measuring device is an upward facing pyranometer, which is able to measure the amount of solar energy contained in the wavelengths between -typically300 and $2800 \mathrm{~nm}$. If available, these observations can be used as the quantity $K_{d}$ in the TOXSWA temperature module. As an alternative, $K_{d}$ can be computed as described in Annex 4 .

A downward facing pyranometer would measure the reflected shortwave (or global) radiation, but such measurements are usually done only in the framework of field experiments. The ratio of upward (reflected) to incoming (downward) shortwave radiation is the albedo of a surface (also see Annex 5).

Longwave radiation is a term used in meteorology to distinguish radiation at wavelengths longer than about $4000 \mathrm{~nm}$, usually of terrestrial origin, from those at shorter wavelengths (shortwave radiation), usually of solar origin. Longwave radiation is sometimes called terrestrial radiation since it originates from thermal radiation emissions from the earth's surface and the atmosphere (see above). No distinction is made between direct and diffuse longwave radiation.

Longwave radiation can be measured using a pyrgeometer, which measures the amount of longwave energy contained in wavelengths between about 4500 and $100000 \mathrm{~nm}$. Upward facing pyrgeometers placed in close proximity to the Earth's surface measure the downward longwave radiation received from a solid angle of $2 \pi$ steradians, thus mainly originating from the sky. This downward longwave radiation is not commonly measured at standard meteorological sites and is computed in TOXSWA as $L_{d}$ (see Section 2.4.3). Downward facing pyrgeometers placed near the Earth's surface provide an estimate of the upward longwave radiation originating from the surface. This quantity is computed as $L_{u}$ (see Section 2.4.3).

\section{References}

American Meteorological Society, 2016. AMS Glossary of Meteorology. http://glossary.ametsoc.org/wiki/Main_Page. Accessed 2 November 2016. Search terms: shortwave radiation, solar radiation, global radiation, direct solar radiation, diffuse solar radiation, longwave radiation, terrestrial radiation.

Monteith, J.L. and M.H. Unsworth, 1990. Principles of environmental physics. Edward Arnold, London. 


\section{Annex 4 Calculation of shortwave radiation from solar elevation, atmospheric turbidity and cloud cover}

If the shortwave radiation is not available in the meteorological data or values are missing, the shortwave radiation $K_{\mathrm{d}}$ will be calculated. For this purpose, a parameterization was used to estimate the incoming shortwave radiation $K_{\mathrm{d}}$ from the set of the standard meteorological observations, solar elevation, an estimation of the atmospheric turbidity and cloud cover (Jacobs et al., 2010).

A well-known and widely used parameterisation to compute shortwave radiation under clear skies, $K_{d}^{0}$, from solar elevation is used (Holtslag and Van Ulden, 1983; De Rooy and Holtslag, 1999):

$$
K_{d}^{0}=a_{1} \sin \varphi+a_{2}
$$

where

$K_{\mathrm{d}}{ }^{0}=$ shortwave (solar) radiation under clear skies $\left[\mathrm{W} \mathrm{m}^{-2}\right]$

$a_{1}, a_{2}=$ empirical coefficients describing the average atmospheric attenuation of shortwave radiation at a given site $\left[\mathrm{W} \mathrm{m}^{-2}\right]$

For De Bilt (Netherlands), $a_{1}=1041 \mathrm{~W} \mathrm{~m}^{-2}$ and $a_{2}=-69 \mathrm{~W} \mathrm{~m}^{-2}$.

The solar elevation is obtained from:

$\sin \varphi=\sin \delta \sin \Phi+\cos t_{b} \cos \delta \cos \Phi$

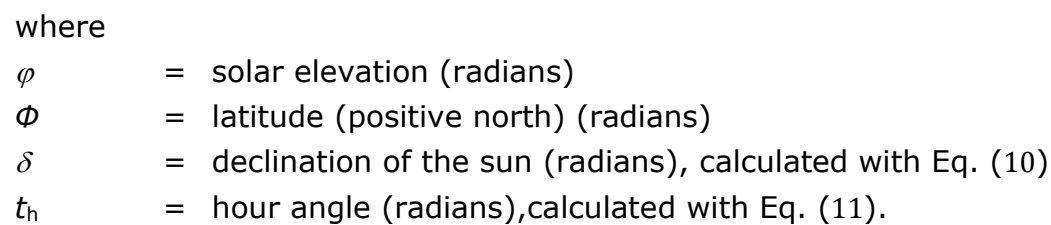

Under cloudy skies $K_{d}$ becomes

$K_{d}=K_{d}^{0}\left(1+b_{1} N^{b_{2}}\right)$

where

$N \quad=$ total cloud cover $(-)$

$b_{1}, b_{2}=$ cloud contribution factors, empirical coefficients (-)

Values for $b_{1}$ and $b_{2}$ derived from measurements in Western Europe are -0.75 and 3.4, respectively.

\section{References}

De Rooy, W.C. and A.A.M. Holtslag, 1999. Estimation of Surface Radiation and Energy Flux Densities from Single-Level Weather Data. J. Appl. Met., 38, 526-540.

Holtslag, A.A.M. and A.P. van Ulden, 1983. A simple scheme for daytime estimates of the surface fluxes from routine weather data. J. Climate Appl. Meteor., 22, 517-529.

Jacobs, C.M.J., P.I. Adriaanse and J. Deneer, 2010. Modelling water temperature in TOXSWA. Wageningen, Alterra report 2099. 


\section{Annex 5 Upward shortwave radiation at the water-air interface}

The concept for upward shortwave radiation at the water-air interface consists of the portion of incoming shortwave radiation reflected directly at the surface plus the portion leaving the water layer upon reflection at the sediment. To take into account the differences in the wavelength bands we apply a generalized form of Eqs. (9) and (10) in Section 3.2.1 of Jacobs et al. (2010).

The process of absorption is described using Lambert-Beer's extinction law. We apply this law in a bidirectional mode, with a downward beam and an upward beam. For the downward beam, the distribution of the radiation in the water column becomes (cf. Paulson and Simpson, 1977):

$$
K^{\downarrow}(d)=\left(1-\alpha_{t}\right) K_{d} \sum_{j=1}^{n} \xi_{j} \exp \left(-\mu_{j} d\right)
$$

where $K^{\downarrow}(d)$ [W $\left.\mathrm{m}^{-2}\right]$ is the energy in the downward beam as a function of the distance $d$ [m] from the water surface, $\alpha_{\mathrm{t}}[-]$ is the albedo of the water surface, $K_{\mathrm{d}}$ is the incoming shortwave radiation at the water surface, $\xi_{\mathrm{j}}[-]$ is the energy fraction of $K_{\mathrm{d}}$ contained in wavelength band $j[-]$ and $\mu_{\mathrm{j}}\left[\mathrm{m}^{-1}\right]$ the extinction or attenuation coefficient in that wavelength band. At the bottom of the water column, where $d=h$ :

$$
K^{\downarrow}(h)=\left(1-\alpha_{t}\right) K_{d} \sum_{j=1}^{n} \xi_{j} \exp \left(-\mu_{j} h\right) \equiv \sum_{j=1}^{n} K_{b o t, j}
$$

Thus, $K_{\mathrm{bot}, j}$ is the amount of radiation received at the bottom for each wavelength band. Given the lack of evidence regarding the reflection of shortwave radiation at the sediment, we assume the bottom albedo $\alpha_{\mathrm{b}}[-]$ to be equal for each wavelength band. Then, the upward beam is the total reflected radiation at depth $d$, denoted with $K^{\uparrow}(d)$ :

$$
K^{\uparrow}(d)=\alpha_{b} \sum_{j=1}^{n} K_{b o t, j} \exp \left(-\mu_{j}(h-d)\right)
$$

Since $d=0$ at the water surface, and ignoring refraction of the upward beam at the water surface:

$$
K_{u}=\alpha_{t} K_{d}+\alpha_{b} \sum_{j=1}^{n} K_{b o t, j} \exp \left(-\mu_{j} h\right)
$$

Eq. (10) in Section 3.2.1 of Jacobs et al. (2010) represents that total upward shortwave radiation $K_{\mathrm{u}}$ $\left[\mathrm{W} \mathrm{m}^{-2}\right]$ at the air-water interface. It includes both the amount of shortwave radiation directly reflected at the surface $\left(\alpha_{t} K_{d}\right)$ and the radiation that leaves the water again upon reflection at the sediment. For large water depths in particular, with $h \sim 1 \mathrm{~m}$ or more, the second term on the right hand side can become very small and may be neglected.

In TOXSWA, two wavelength bands are distinguished: Photosynthetic Active Radiation (PAR) and Near Infra-Red) NIR. Since NIR is almost completely absorbed in the first millimetre of the water column, only PAR will have an upward component related to reflection at the sediment. Then, computation of $K_{\mathrm{u}}$ can be simplified as follows:

$$
K^{\downarrow}(d)=\left(1-\alpha_{t}\right) K_{d} \xi_{P A R} \exp \left(-\mu_{P A R} d\right)
$$




\section{So that}

$K_{b o t, P A R}=K^{\downarrow}(h)=\left(1-\alpha_{t}\right) K_{d} \xi_{P A R} \exp \left(-\mu_{P A R} h\right)$

Upon which

$K_{u}=\alpha_{t} K_{d}+\alpha_{b} K_{b o t, P A R} \exp \left(-\mu_{P A R} h\right)$ 


\section{Annex 6 Parameters with fixed values in TOXSWA}

The parameters of the temperature and meteorological modules of TOXSWA that have a fixed value in the code are shown with their values in Table A3.

Table A3 Parameter symbols, units and descriptions, value and parameter name in TOXSWA's source code of parameters for which the value is a fixed value in the TOXSWA kernel.

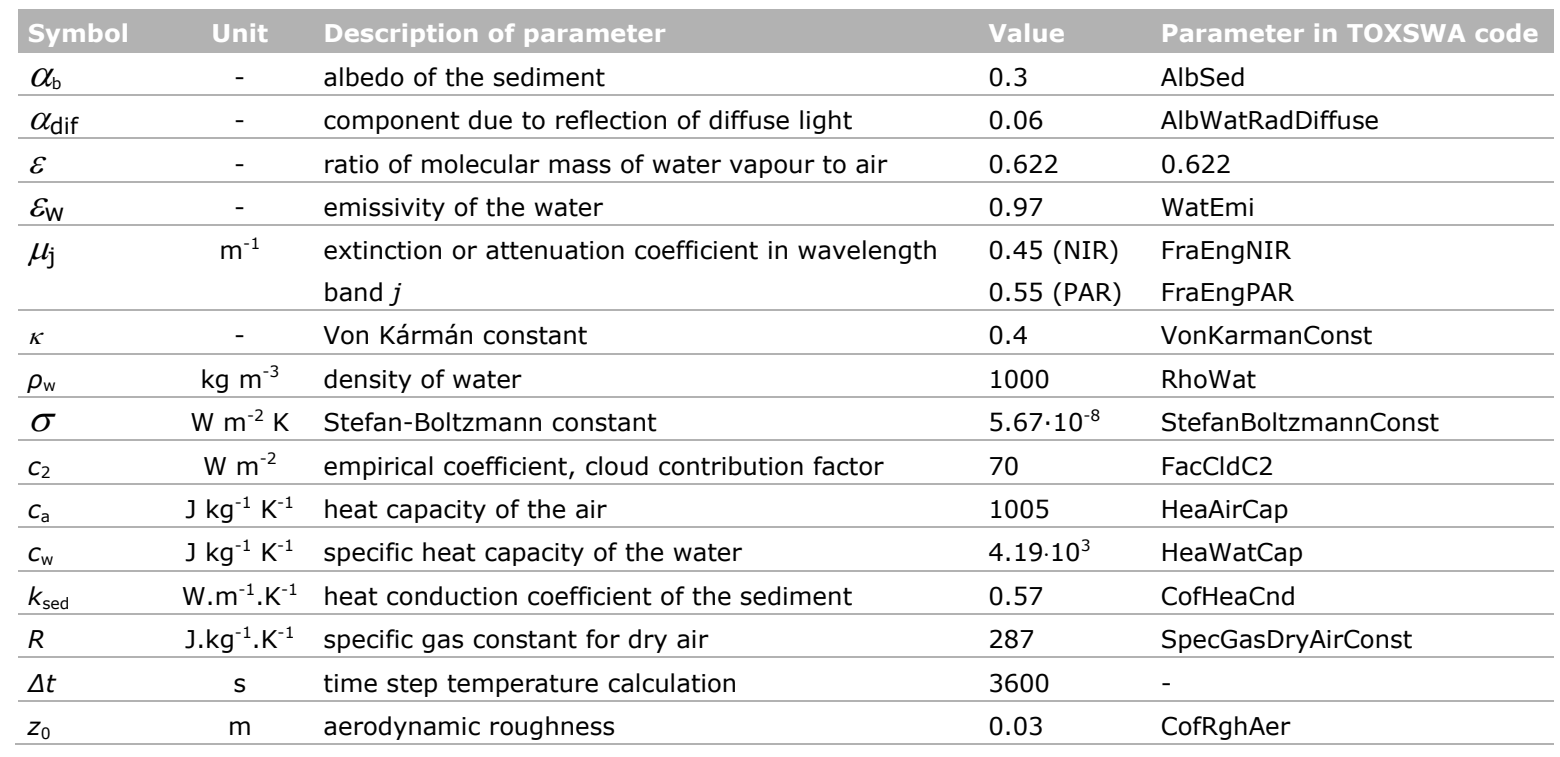




\section{Annex 7 Description of the PEARL *.e2t output file extended with temperatures of drain fluxes}

This annex describes the e2t file that is made by PEARL, extended with the temperatures of drainage water fluxes. This file is made for use with TOXSWA in the temperature module to be able to calculate hourly water temperatures. An example of the *.e2t file is shown on the next page.

The description of the columns is given by:

Time $\quad$ Time from start of calculation in days $(d)$

Date/Time Date and time

FlvLiqRun Runoff flux $\left(\mathrm{m}^{3} \cdot \mathrm{m}^{-2} \cdot \mathrm{d}^{-1}\right)$

FlvLiqDraMic Micropore drainage flux $\left(\mathrm{m}^{3} \cdot \mathrm{m}^{-2} \cdot \mathrm{d}^{-1}\right)$

TemLiqDraMic Temperature of micropore flux $\left({ }^{\circ} \mathrm{C}\right)$

FIvLiqDraByp Macropore drainage flux, bypass flow $\left(\mathrm{m}^{3} \cdot \mathrm{m}^{-2} \cdot \mathrm{d}^{-1}\right)$

TemLiqDraByp Temperature of macropore flux $\left({ }^{\circ} \mathrm{C}\right)$

ConLiqRun Substance concentration in runoff water $\left(\mathrm{g} \cdot \mathrm{m}^{-3}\right)$

ConLiqDraMic Substance concentration in micropore flow water $\left(\mathrm{g}_{\mathrm{m}} \mathrm{m}^{-3}\right)$

ConLiqDraByp Substance concentration in macropore flow water $\left(\mathrm{g}_{\mathrm{m}} \mathrm{m}^{-3}\right)$

When a drainage flux is zero the temperature is not determined. Therefore, the temperature of that flux is given with $-999.000^{\circ} \mathrm{C}$.

TOXSWA uses the total drainage flux and the flux-averaged temperature to calculate the contribution of external heat from drainage for the energy balance. Hence:

$$
q_{d r}=q_{d r, \text { micro }}+q_{d r, b y p}
$$

where

$q_{\mathrm{dr}} \quad=$ areic volume flux of drainage water of the adjacent field $\left(\mathrm{m}^{3} \mathrm{~m}^{2} \mathrm{~s}^{-1}\right)$

$q_{\mathrm{dr} \text {,micro }}=$ areic volume flux of drainage water from micropore flow of the adjacent field $\left(\mathrm{m}^{3} \mathrm{~m}^{2} \mathrm{~s}^{-1}\right)$

$q_{\mathrm{dr} \text {,byp }}=$ areic volume flux of drainage water from bypass flow of the adjacent field $\left(\mathrm{m}^{3} \mathrm{~m}^{2} \mathrm{~s}^{-1}\right)$

$$
T_{d r}=\frac{q_{d r, \text { micro }} T_{d r, \text { micro }}+q_{d r, \text { byp }} T_{d r, \text { byp }}}{q_{d r, \text { micro }}+q_{d r, \text { byp }}}
$$

where

$T_{\mathrm{dr}} \quad=$ temperature of drainage water of the adjacent field $\left({ }^{\circ} \mathrm{C}\right)$

$T_{\mathrm{dr} \text {, micro }}=$ temperature of drainage water from micropore flow of the adjacent field $\left({ }^{\circ} \mathrm{C}\right)$

$T_{\mathrm{dr} \text {, byp }}=$ temperature of drainage water from bypass flow of the adjacent field $\left({ }^{\circ} \mathrm{C}\right)$ 
* Results from the PEARL model (c) Alterra, PBL and RIVM

PEARL kernel version : 3.1 .2

SWAP kernel version : $\quad$ swap3232

* PEARL created on : 10-Feb-2011

* PEARL was called from : : DRAINBOW, version 1.1.1

* Working directory $\quad: \quad$ D: \USERDATA PEARLScenario

* Run ID $\quad$ : 1 03-05-2011

Number of substances:

Parent substance:

Metabolites substances:

NumApp 1
1
Date of application
Dosage
Soil Cover fraction
$0.0700 \quad 0.1720$

* Drain flux and concentration data for substance imida

* Legend to columns:

Time

FlvLiqRun

FlvLiqDraMic

$0.00 \mathrm{E}+00$

$0.00 \mathrm{E}+00$

$0.00 \mathrm{E}+00$

$0.00 \mathrm{E}+00$

$\begin{array}{ll}0.063 & 01-J a n-1986-01: 30 \\ 0.104 & 01-J a n-1986-02: 30\end{array}$

$0.146 \quad 01-J a n-1986-03: 30$

$\begin{array}{ll}0.188 & 01-J a n-1986-04: 30 \\ 0.229 & 01-J a n-1986-05: 30\end{array}$

$0.271 \quad 01-J a n-1986-06: 30$

$0.313 \quad 01-J a n-1986-07: 30$

$0.354 \quad 01-J a n-1986-08: 30$

$0.396 \quad 01-J a n-1986-09: 30$

$0.438 \quad 01-J a n-1986-10: 30$

$0.479 \quad 01-J a n-1986-11: 30$

$0.521 \quad 01-J a n-1986-12: 30$

$0.563 \quad 01-J a n-1986-13: 30$

$0.604 \quad 01-J a n-1986-14: 30$

$0.646 \quad 01-J a n-1986-15: 30$

$0.688 \quad 01-J a n-1986-16: 30$

0.729

$01-J a n-1986-17: 30$

.771

$01-J a n-1986-18: 30$

$0.00 \mathrm{E}+00$

$0.00 \mathrm{E}+00$

$0.00 \mathrm{E}+00$

$0.00 \mathrm{E}+00$
$0.00 \mathrm{E}+00$

$0.00 \mathrm{E}+00$
$0.00 \mathrm{E}+00$
$0.00 \mathrm{E}+00$

$0.00 \mathrm{E}+00$

$0.00 \mathrm{E}+00$

$0.00 \mathrm{E}+00$

$0.00 \mathrm{E}+00$

$0.00 \mathrm{E}+00$

$0.00 \mathrm{E}+00$

$0.00 \mathrm{E}+00$

$0.00 \mathrm{E}+00$

01-Jan-1986-20:30

$0.00 \mathrm{E}+00$

qDraMiC
0.002
0.002
0.002
0.002
0.002
0.002
0.002
0.002
0.002
0.002
0.002
0.002
0.002
0.002
0.002
0.002
0.002
0.002
0.002
0.002
0.002

TemLiqDraMic

25.0
25.0
25.0
25.0
25.0
25.0
25.0
25.0
25.0
25.0
25.0
25.0
25.0
25.0
25.0
25.0
25.0
25.0
25.0
25.0
25.0

$\begin{array}{rr}\text { LiqDraByp } & \text { TemLiqDraByp } \\ 0.01 & 20.0 \\ 0.01 & 20.0 \\ 0.01 & 20.0 \\ 0.01 & 20.0 \\ 0.01 & 20.0 \\ 0.01 & 20.0 \\ 0.01 & 20.0 \\ 0.01 & 20.0 \\ 0.01 & 20.0 \\ 0.01 & 20.0 \\ 0.01 & 20.0 \\ 0.01 & 20.0 \\ 0.01 & 20.0 \\ 0.01 & 20.0 \\ 0.01 & 20.0 \\ 0.01 & 20.0 \\ 0.01 & 20.0 \\ 0.01 & 20.0 \\ 0.01 & 20.0 \\ 0.01 & 20.0 \\ 0.01 & 20.0\end{array}$

ConLigRun

$0.00 \mathrm{E}+00$
$0.00 \mathrm{E}+00$
$0.00 \mathrm{E}+00$

$0.00 \mathrm{E}+00$

$0.00 \mathrm{E}+00$

$0.00 \mathrm{E}+00$

$0.00 \mathrm{E}+00$

$0.00 \mathrm{E}+00$

$0.00 \mathrm{E}+00$

$0.00 \mathrm{E}+00$
$0.00 \mathrm{E}+00$
$0.00 \mathrm{E}+00$

$0.00 \mathrm{E}+00$
$0.00 \mathrm{E}+00$
$0.00 \mathrm{E}+00$

$0.00 \mathrm{E}+00$

$0.00 \mathrm{E}+00$

$0.00 \mathrm{E}+00$

$0.00 \mathrm{E}+00$

$0.00 \mathrm{E}+00$

$0.00 \mathrm{E}+00$

$0.00 \mathrm{E}+00$

$0.00 \mathrm{E}+00$

$0.00 \mathrm{E}+00$

$0.00 \mathrm{E}+00$

$0.00 \mathrm{E}+00$

ConLiqDraMic ConLiqDraByp

$0.00 \mathrm{E}+00$

$0.00 \mathrm{E}+00$

$0.00 \mathrm{E}+00$

$\begin{array}{ll}0.00 \mathrm{E}+00 & 0.00 \mathrm{E}+00 \\ 0.00 \mathrm{E}+00 & 0.00 \mathrm{E}+00\end{array}$

$0.00 \mathrm{E}+00 \quad-0.00 \mathrm{E}+00$

$0.00 \mathrm{E}+00 \quad 0.00 \mathrm{E}+00$

$0.00 \mathrm{E}+00 \quad 0.00 \mathrm{E}+00$

$0.00 \mathrm{E}+00-0.00 \mathrm{E}+00$

$0.00 \mathrm{E}+00$

$0.00 \mathrm{E}+00$

$0.00 \mathrm{E}+00$

$0.00 \mathrm{E}+00$

$0.00 \mathrm{E}+00$
$0.00 \mathrm{E}+00$

$0.00 \mathrm{E}+00 \quad 0.00 \mathrm{E}+00$

$0.00 \mathrm{E}+00 \quad 0.00 \mathrm{E}+00$

$0.00 \mathrm{E}+00$

$0.00 \mathrm{E}+00-0.00 \mathrm{E}+00$

$0.00 \mathrm{E}+00 \quad 0.00 \mathrm{E}+00$ 


\section{Annex 8 TOXSWA input file for example simulation}

Sections 1, 2, 3 and 5 of the example simulation presented in Section 3.4.

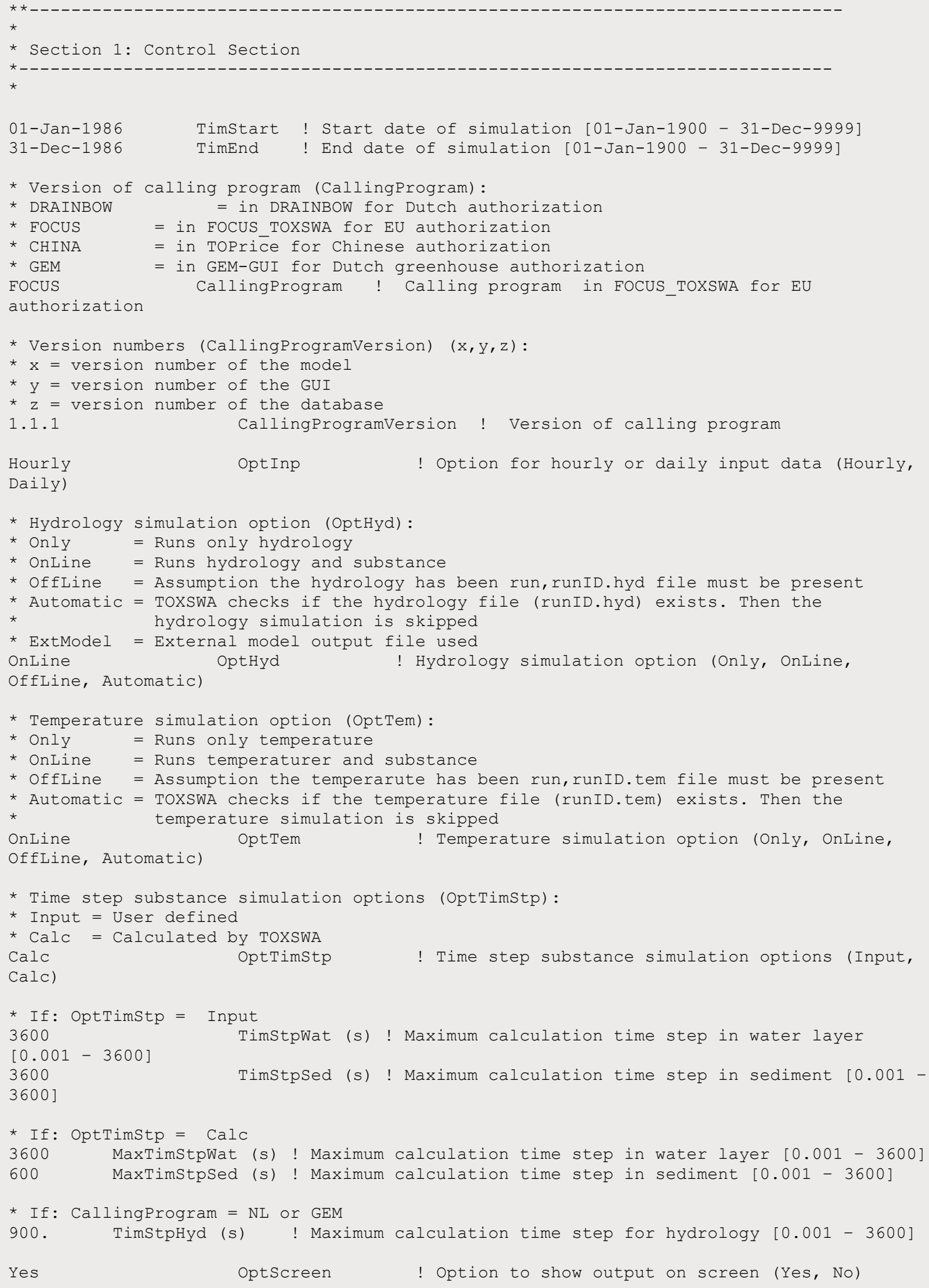




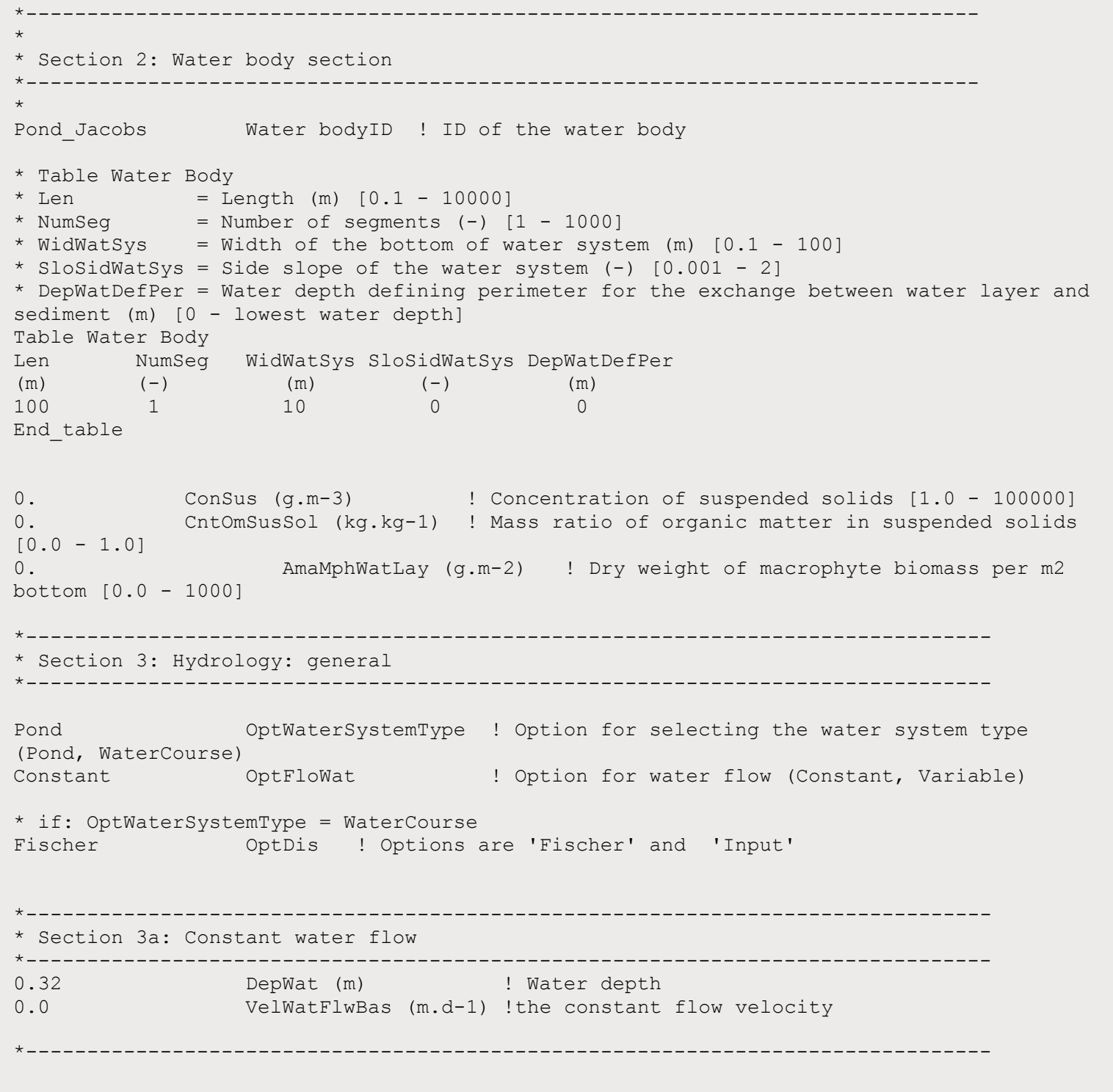




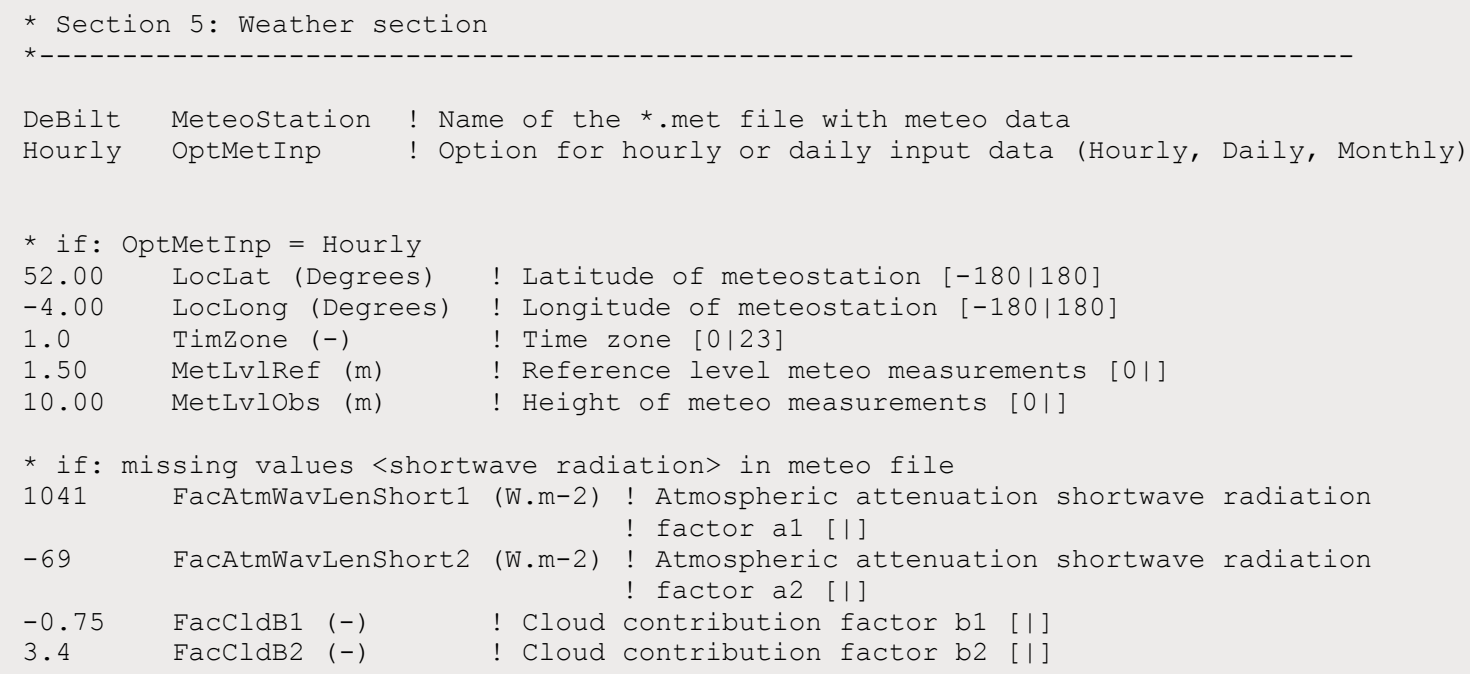




\section{Annex 9 Meteorological file used for robustness test of TOXSWA for high water temperatures}

This annex shows day 1 of the meteorological data file, *.meth, used for the robustness test described in Section 4.3. For a description of the columns in the file see Section 3.2.2.

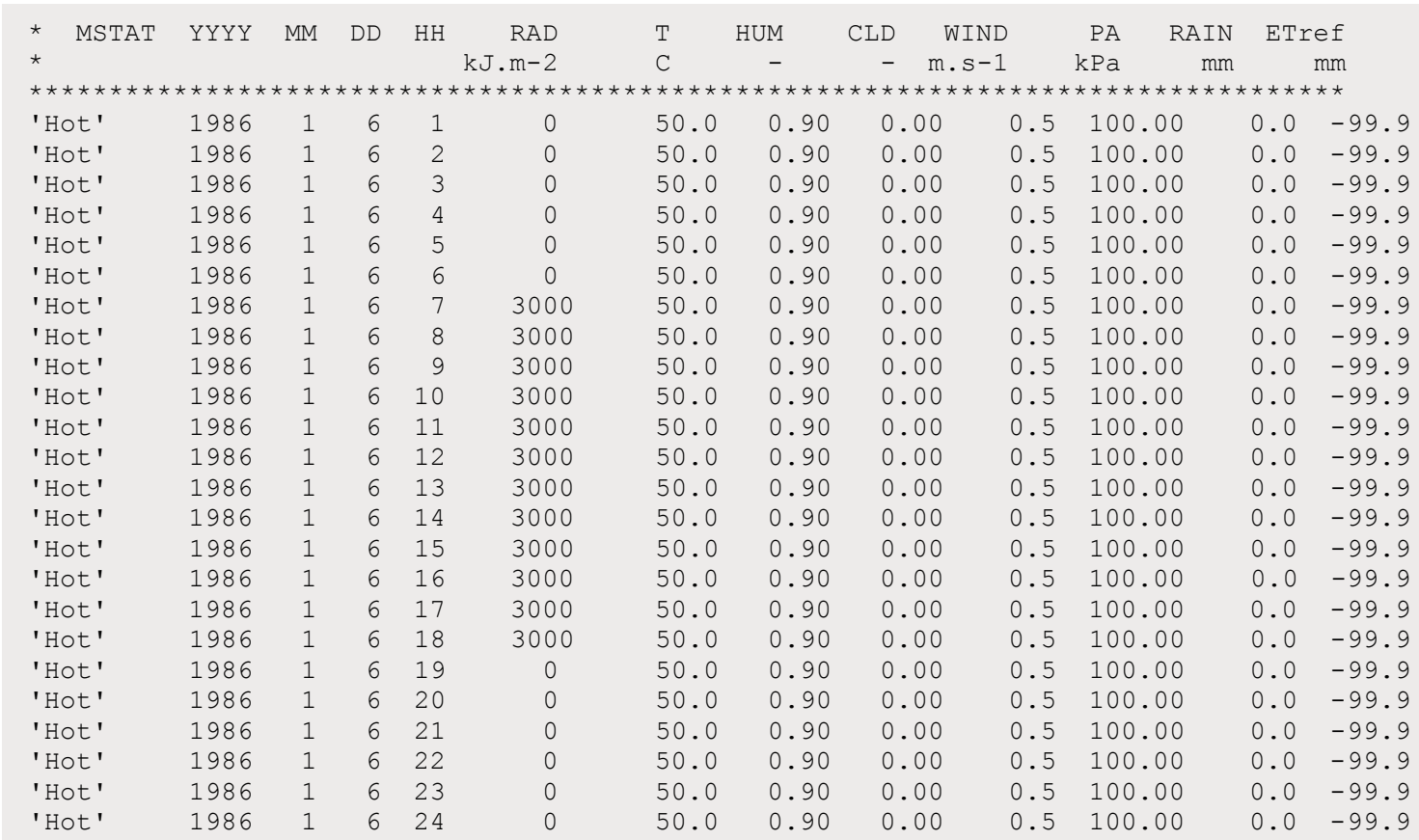




\section{Annex 10 Sections of *.txw file used for calculations assessing impact of calculated hourly water temperatures on exposure concentrations}

This annex shows the sections of the *.txw file to assess the impact of the calculated hourly water temperatures in TOXSWA version 3.4 on the exposure concentrations.

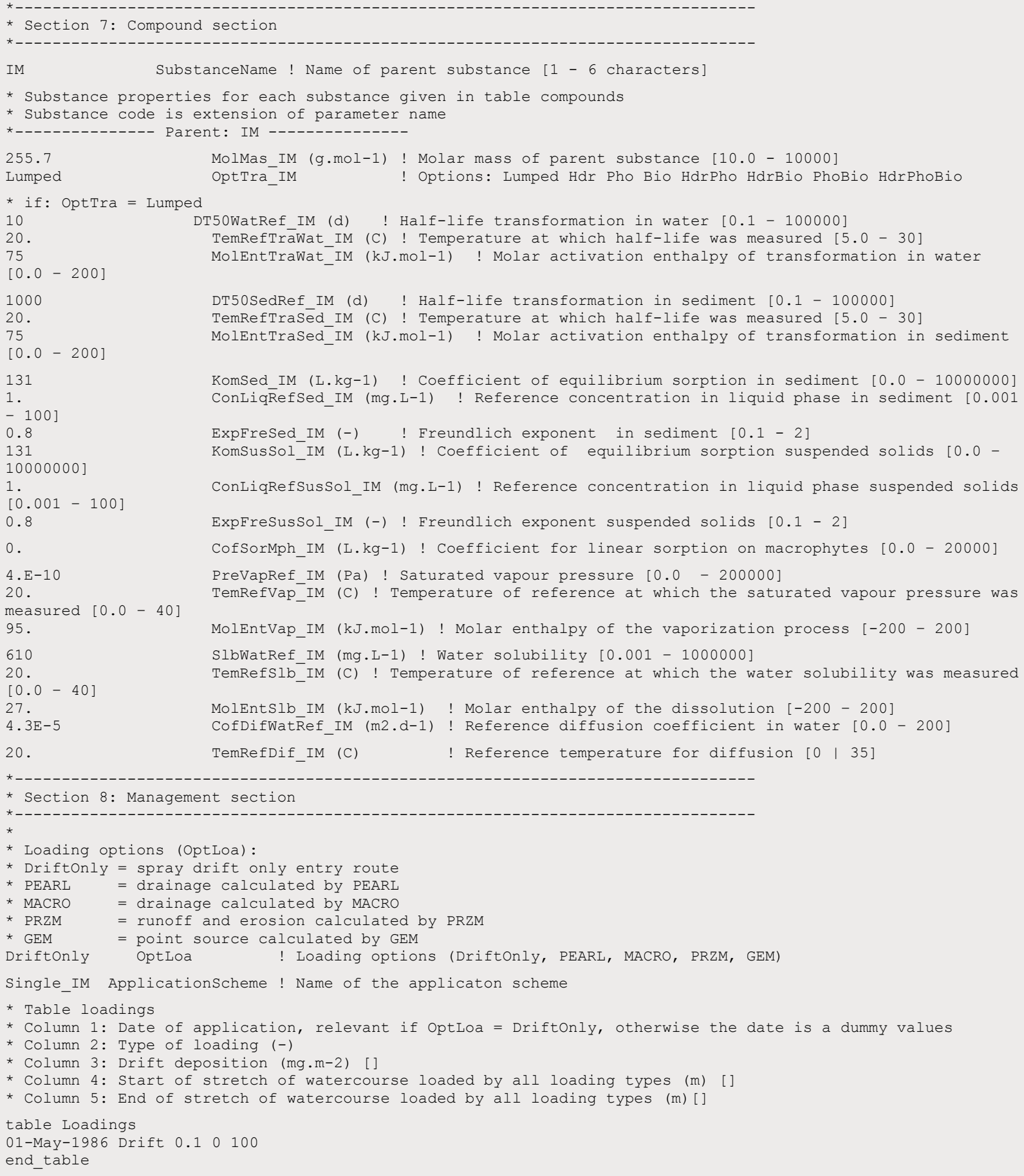


Wageningen Environmental Research P.O. Box 47

6700 AA Wageningen

The Netherlands

$\mathrm{T}+31(0) 317480700$

www.wur.nl/environmental-research

Wageningen Environmental Research

Report 2794

ISSN 1566-7197
The mission of Wageningen University and Research is "To explore the potential of nature to improve the quality of life". Under the banner Wageningen University \& Research, Wageningen University and the specialised research institutes of the Wageningen Research Foundation have joined forces in contributing to finding solutions to important questions in the domain of healthy food and living environment. With its roughly 30 branches, 5,000 employees and 10,000 students, Wageningen University \& Research is one of the leading organisations in its domain. The unique Wageningen approach lies in its integrated approach to issues and the collaboration between different disciplines.

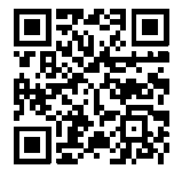




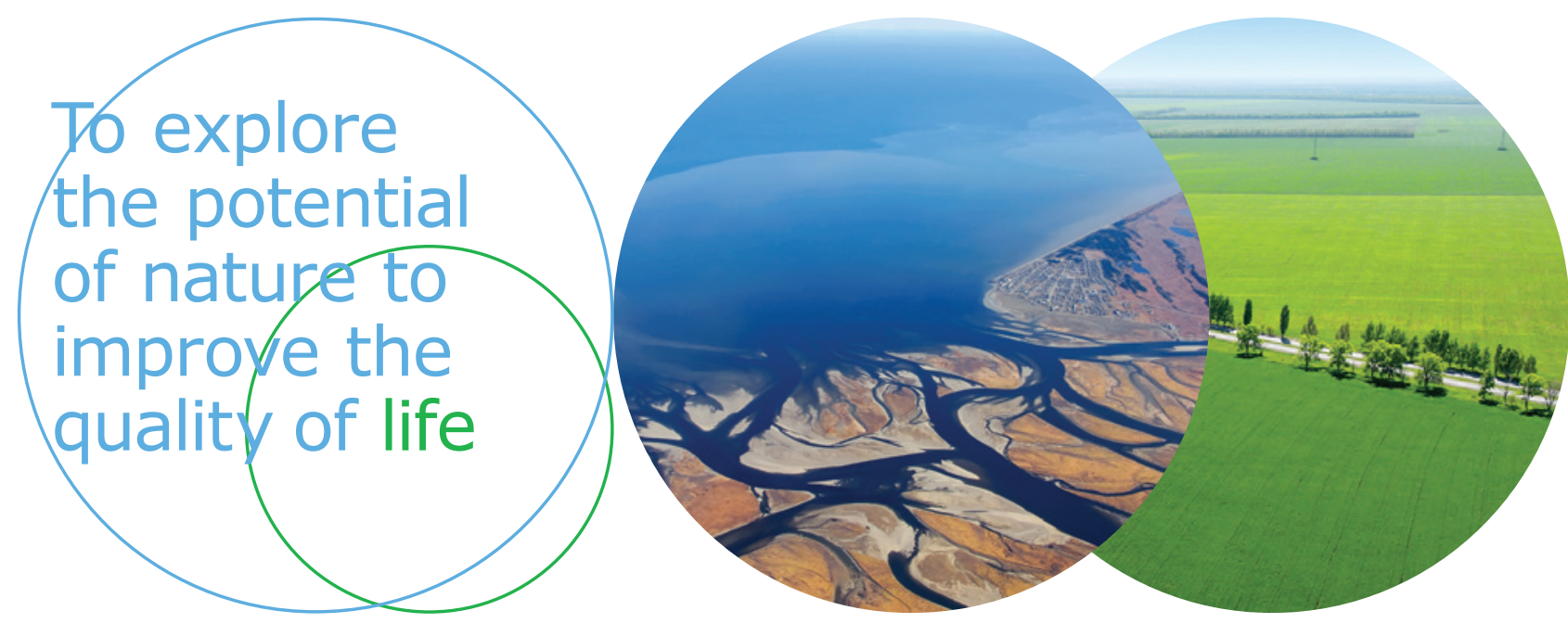

Wageningen Environmental Research P.O. Box 47

$6700 \mathrm{AB}$ Wageningen

The Netherlands

$\mathrm{T}+31(0) 317480700$

www.wur.eu/environmental-research

Report 2794

ISSN 1566-7197
The mission of Wageningen University and Research is "To explore the potential of nature to improve the quality of life". Under the banner Wageningen University \& Research, Wageningen University and the specialised research institutes of the Wageningen Research Foundation have joined forces in contributing to inding solutions to important questions in the domain of healthy food and living environment. With its roughly 30 branches, 5,000 employees and 10,000 students, Wageningen University \& Research is one of the leading organisations in its domain. The unique Wageningen approach lies in its integrated approach to issues and the collaboration between different disciplines. 